\title{
Techno-economic analysis of a biomass depot
}

J. Jacobson, P. Lamers, M. Roni, K. Cafferty, K. Kenney, B. Heath, J. Hansen, J. Tumuluru

October 2014

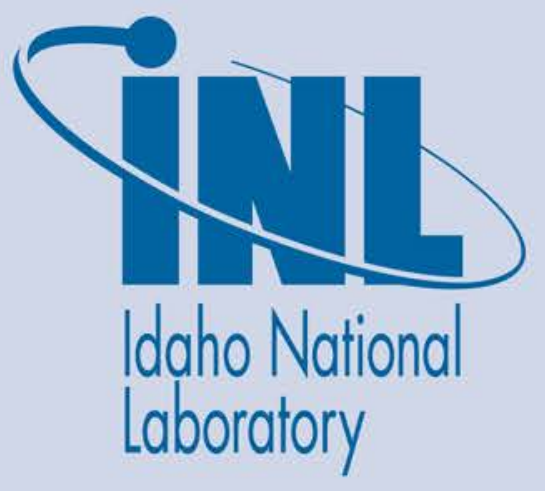

The INL is a U.S. Department of Energy National Laboratory operated by Battelle Energy Alliance 
INL/EXT-14-33225

\title{
Techno-economic analysis of a biomass depot
}

\author{
J. Jacobson, P. Lamers, M. Roni, K. Cafferty, K. Kenney, B. Heath, J. Hansen, \\ J. Tumuluru
}

October 2014

\begin{abstract}
Idaho National Laboratory
Idaho Falls, Idaho 83415
\end{abstract}

http://www.inl.gov

\author{
Prepared for the \\ U.S. Department of Energy \\ Assistant Secretary for ___, OR Office of \\ Under DOE Idaho Operations Office \\ Contract DE-AC07-05ID14517
}




\begin{tabular}{|l|l|}
\hline $\begin{array}{l}\text { ID\#: } 1.1 .1 .2 \\
\text { Type: Regular } \\
\text { WBS \#: 1.1.1.2 }\end{array}$ & $\begin{array}{l}\text { Completion Date: 09/30/2014 } \\
\text { Scheduled Completion: 09/30/2014 }\end{array}$ \\
\hline Milestone Title: & Techno-economic analysis of a biomass depot \\
\hline Authors: & $\begin{array}{l}\text { J. Jacobson, P. Lamers, M. Roni, K. Cafferty, K. Kenney, B. Heath, J. } \\
\text { Hansen, J. Tumuluru }\end{array}$ \\
\hline $\begin{array}{l}\text { Project Name: } \\
\text { Project Leader: }\end{array}$ & $\begin{array}{l}\text { Sustainable Feedstock Production-Logistics Interface } \\
\text { Richard Hess }\end{array}$ \\
\hline Key Words: & $\begin{array}{l}\text { Biomass Depot, Feedstock Logistics, Advanced Biomass Supply } \\
\text { System, Policy, Biofuel }\end{array}$ \\
\hline
\end{tabular}

INL/EXT-14-33225

\section{Milestone Objective}

Deliver a techno-economic analysis (TEA) that identifies critical cost factors that affect the overall feasibility of a biomass depot. The TEA will include a sensitivity analysis of depot design and operational variables affecting the cost feasibility of a biomass depot. 


\section{Executive Summary}

The U.S. Department of Energy (DOE) Bioenergy Technologies Office (BETO) promotes the production of an array of liquid fuels and fuel blendstocks from lignocellulosic biomass by funding fundamental and applied research that advances the state of technology in feedstock supply and logistics, conversion, deployment, and sustainability. As part of its involvement in this program, the Idaho National Laboratory (INL) investigates the technical, economic, and environmental performance of different feedstock supply systems linking feedstock production with downstream conversion processes.

Currently, the U.S. cellulosic biofuel industry relies on a conventional biomass supply system, hereinafter referred to as the conventional system, where feedstock is procured through contracts with local growers, harvested, locally stored, and delivered in low density format to the conversion facility. It is worth noting that the cellulosic biofuel industry is in its infancy, currently producing less than 1 million gallons of cellulosic ethanol per year and current practice may not represent that of a fully evolved industry. The conventional system has been demonstrated to work in a local supply context within high yield regions (e.g., the U.S. Corn Belt or southeast forest lands). However, scaling up the biorefinery industry will require increasing feedstock volumes at decreasing costs. BETO's goal is to meet a US\$80 dry ton ${ }^{-1}$ delivered feedstock cost at the throat of the conversion facility (including grower payment and logistics) in order to reach a US\$3 per gallon of gasoline equivalent (GGE) delivered fuel target by 2022. It is unclear, if a conventional system will allow for such goal to be met.

Previous INL analyses (Hess et al. 2009, Argo et al. 2013, Jacobson et al. 2014, Muth et al. 2014) have shown that the conventional system fails to meet BETO's supply cost target outside of highly productive regions and could encounter issues even in highly productive regions in some years due to inclement weather (e.g., drought, flood, heavy moisture during harvest, etc.). These supply uncertainties tend to classify the biomass industry as a high risk investment and limit the biorefinery concept from being broadly implemented. INL's advanced uniform design system, hereinafter referred to as the advanced system, introduces methods to reduce feedstock volume, price, and quality supply uncertainties. It is based on a network of distributed biomass preprocessing centers, so-called depots, which use one or several biomass types to generate uniform feedstock 'commodities'. These commodities are intermediates with consistent physical and chemical characteristics that meet conversion quality targets and at the same time leverage the spatial variability in supply volumes and costs by improving flowability, transportability (bulk density), and stability/storability (dry matter loss reduction).

This report presents a techno-economic analysis (TEA) of the depot concept and explores technical design options, operational/technical performance (feedstock moisture, flow rates, etc.), and economic feasibility. It focuses on the biochemical conversion pathway, using herbaceous residues as a feedstock to demonstrate different depot designs. The depot design can also be applied to the thermochemical conversion pathway with minor differences in material properties and small changes in unit operations (e.g., chippers replace coarse grinders). The biochemical conversion pathway using herbaceous residues and energy crops was chosen because these particular feedstocks face a limited market demand and their feedstock characteristics match-up well with biochemical conversion technologies. Also, logistical advancements are needed within the biochemical conversion supply chain to make herbaceous material cost effective while wood (pulpwood and logging residues) pelleting operations are well established in the heat and power industry. 
This report defines two distinct depot types. The minimum requirements for a depot to achieve the supply system benefits mentioned above, it must at least include particle size reduction, moisture mitigation, and densification. This is what we refer to as a 'Standard Depot'. Additional operations, e.g., leaching, chemical treatment, or washing, may be added in a 'Quality Depot' to specifically address feedstock quality requirements for improved downstream biorefinery operation. Within the Standard Depot design, we analyzed three configurations, each a step improvement over its counterpart: a Conventional Pelleting Process (CPP), a High-Moisture Pelleting Process (HMPP), and a HMPP plus Fractional Milling (HMPPFM). The Quality Depot design includes active quality management processes. Here, we analyzed the Ammonia Fiber Expansion (AFEX) process. This pretreatment technology serves as a representative design, in particular since we had data and information available.

The costs for the four different depot configurations are shown in Table E:1, and Figures E:1 and E:2. All depots have a capacity of 10 dry tons (DT) per hour or 80,000 DT per year. The model framework assumes 10 depots are required to fulfill a biorefinery demand of 800,000 DT per year. The specific equipment used within the depots is modular, as are the depots themselves. In summary, the additional preprocessing costs of a depot operation range between US\$27.91 to US\$69.77 per DT output material. Among the technologies investigated, the HMPP achieves significant cost reductions in comparison to the CPP and additional cost savings can be achieved in the HMPPFM where the material already meeting output size requirements after the first grind is separated out before milling (which further reduces energy costs).

It should be stressed that depots can take on many forms and sizes. Their configuration and location will largely depend on the end-use market (e.g., conversion technology), region, and feedstocks available. 
Table E:1. Total investment costs and costs per output (dry ton) for a depot sized at $\mathbf{8 0 , 0 0 0}$ dry ton (DT) annual capacity (equivalent to 10 DT per hour).

\begin{tabular}{rrrrr}
\hline Conventional & High & HMPP plus & Ammonia Fiber & Conventional \\
Pelleting Process & Moisture & Fractional & Expansion & Pelleting \\
$($ CPP) Herbaceous & Pelleting & Milling & (AFEX) & Process (CPP) \\
& Process & (HMPPFM) & Woody \\
& (HMPP) & & \\
& & \\
\end{tabular}

Total fixed capital costs and total capital investment (US\$)

\begin{tabular}{|c|c|c|c|c|c|}
\hline Grinder & [I] $810,400^{a}$ & [I] $324,000^{a, b}$ & [I] $791,200^{\mathrm{a}}$ & [I] $296,000^{\mathrm{a}}$ & \\
\hline $\begin{array}{l}\text { Chemical } \\
\text { pretreatment }\end{array}$ & & & & [II] 5,129,600 & \\
\hline Dryer & [II] $1,579,200$ & [IV] 64,000 & [IV] 64,000 ${ }^{c}$ & [III] 2,384,800 & [I] $1,579,200$ \\
\hline Hammer mill & [III] 515,200 & [II] $206,400^{d}$ & [II] 103,200 & [IV] 236,000 & [II] 515,200 \\
\hline Pellet mill & [IV] 630,400 & [III] 630,400 & [III] 630,400 & [V] $1,089,600$ & [III] 630,400 \\
\hline $\begin{array}{l}\text { Conveyor } \\
\text { equipment }\end{array}$ & 268,800 & 268,800 & 268,800 & 268,800 & 146,400 \\
\hline $\begin{array}{l}\text { Dust collection } \\
\text { equipment }\end{array}$ & 286,400 & 286,400 & 286,400 & 286,400 & 286,400 \\
\hline Surge bin & 96,800 & 96,800 & 96,800 & 96,800 & 96,800 \\
\hline $\begin{array}{l}\text { Miscellaneous } \\
\text { equipment }^{\mathrm{e}}\end{array}$ & 84,000 & 84,000 & 84,000 & 84,000 & 40,800 \\
\hline $\begin{array}{l}\text { Total fixed capital } \\
\text { costs (US\$) }\end{array}$ & $4,271,200$ & $1,960,800$ & $2,324,800$ & $9,872,000$ & $3,295,200$ \\
\hline $\begin{array}{l}\text { Total other direct } \\
\text { cost ( } 21 \% \text { of total } \\
\text { fixed capital cost) }\end{array}$ & 896,952 & 411,768 & 488,208 & $2,073,120$ & 691,992 \\
\hline $\begin{array}{l}\text { Total indirect cost } \\
\text { (15\% total fixed } \\
\text { capital cost) }\end{array}$ & 640,680 & 294,120 & 348,720 & $1,480,800$ & 494,280 \\
\hline $\begin{array}{l}\text { Total capital } \\
\text { investment (US\$) }\end{array}$ & $5,808,832$ & $2,666,688$ & $3,161,728$ & $13,425,920$ & $4,481,472$ \\
\hline
\end{tabular}

Total preprocessing costs per unit of output excluding grower payment (US\$/DT)

\begin{tabular}{lccccc}
\hline Ownership cost $^{\dagger}$ & 9.38 & 4.07 & 3.59 & 12.43 & 5.27 \\
\hline Operating cost $^{\mathrm{g}}$ & 52.82 & 25.73 & 24.32 & 57.34 & 44.09 \\
\hline Total (US\$/DT) & $\mathbf{6 2 . 2 0}$ & $\mathbf{2 9 . 8 0}$ & $\mathbf{2 7 . 9 1}$ & $\mathbf{6 9 . 7 7}$ & $\mathbf{4 9 . 3 6}$ \\
\hline
\end{tabular}

$[\mathrm{I}-\mathrm{V}]$ the roman letters indicate the process flow sequence

a The depot capacity is linked to the AFEX process whose machinery is set at 10 DT/hour (see Appendix for details). The CPP, HMPP, and HMPPFM designs have smaller individual machinery capacity, thus require several machines in order to gain a $10 \mathrm{DT} / \mathrm{hour}$ capacity.

b Reduction in cost due to: 1) Increased machine capacity reducing the number of equipment necessary to process material consequently lowering capital costs [Note that the capacity of the first stage grind for CPP, HMPP, and HMPPMF are 2 DT/hour, 5 DT/hour, and 8 DT/hour respectively]; 2) the addition of fractional milling in HMPPFM while increases machine capacity also requires additional equipment for separation, modeled as a trommel screen, reduces the capital cost compared to CPP but increases compared to HMPP.

c Cost reduction achieved by the transition from a rotary dryer in CPP to a cross flow pellet dryer in HMPP and HMPPFM.

d Cost reduction achieved by increasing the machine capacity caused by increasing the screen size of stage-one grinder in HMPP and HMPPFM.

e Miscellaneous equipment includes: Twine Remover, Moisture Meter, Electro Magnet, Baler Rejecter.

f Ownership costs include Interest and Depreciation (I\&D) and Insurance, Housing and Taxes (IH\&T).

g Operating costs cover Repairs and Maintenance (R\&M), Fuel, and Labor. 


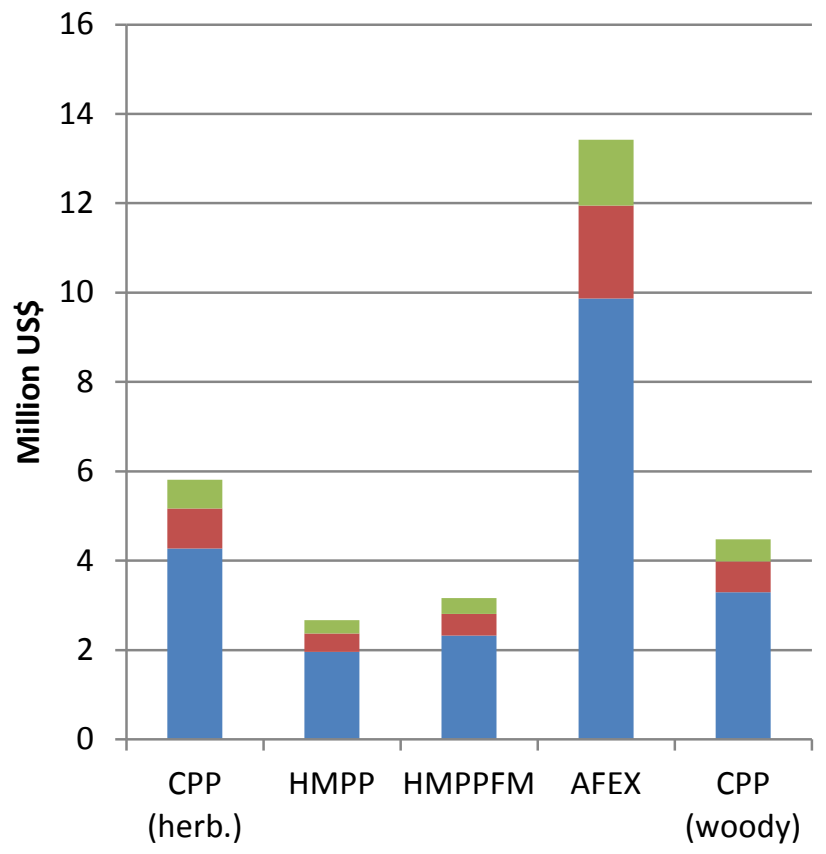

Total Indirect cost (15\% total fixed capital cost)

Total Other Direct Cost $(21 \%$ of total fixed capital cost)

Total fixed capital Cost (US\$)

Figure E:1. Comparison of total investment costs per configuration.

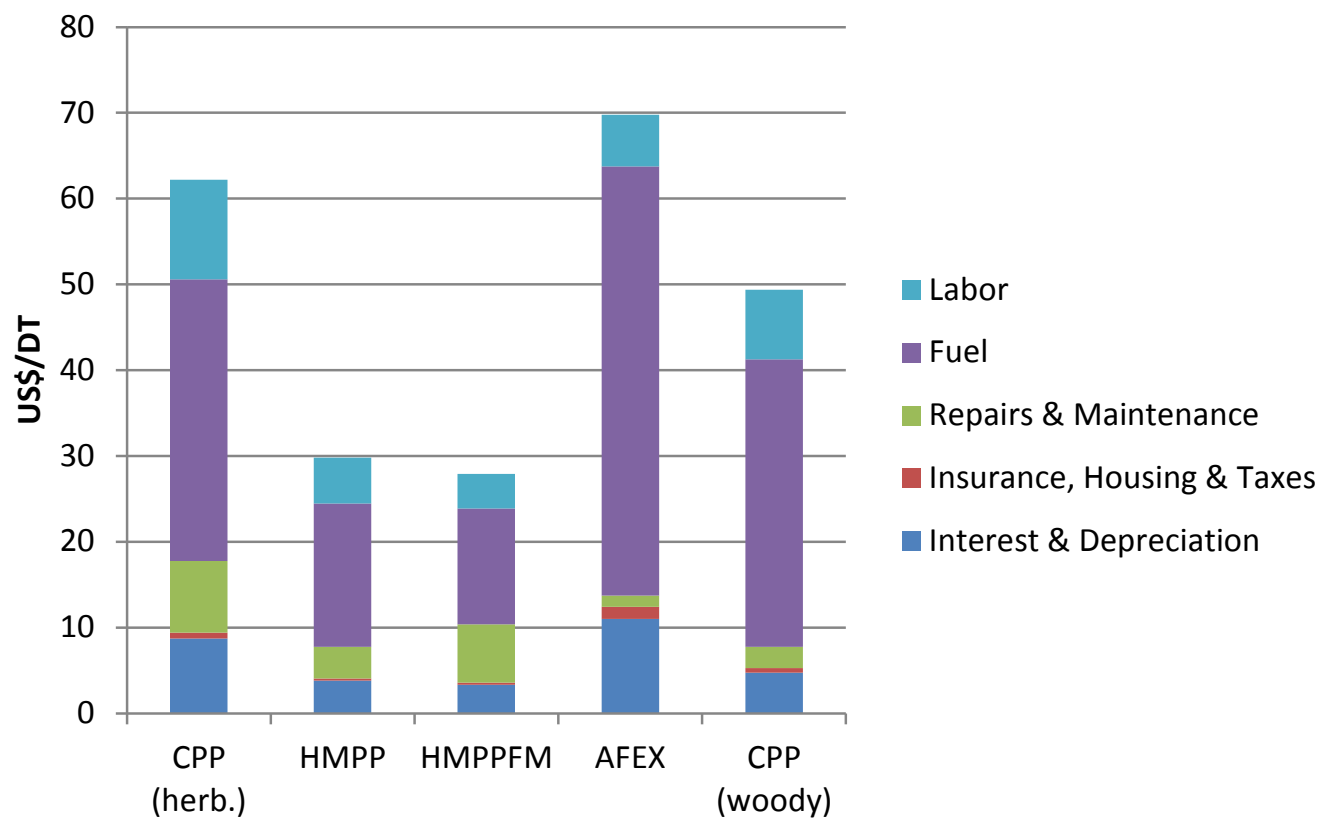

Figure E:2. Cost comparison per output unit (DT) and configuration.

CPP (herb.): Conventional Pelleting Process for herbaceous biomass, corn stover in this case HMPP: High Moisture Pelleting Process

HMPPFM: HMPP plus Fractional Milling

AFEX: Ammonia Fiber Expansion

CPP (woody): CPP for woody biomass, pulpwood in this case

Note: These costs only cover the preprocessing costs associated with a depot. The overall supply chain cost-benefits of a depot concept vs. a conventional feedstock system are not included in this graph. 
Depots add (preprocessing) costs to feedstock supply chains. The advanced system, building on a network of depots, however, addresses many of the feedstock-supply risks associated with the conventional system, and creates wider system benefits; most of which translate into cost benefits across the entire biofuel supply chain (Lamers et al. 2014). This report only quantifies four major cost benefits of a depot based supply system: supply risk reductions (leading to lower interest rates on loans), economies of scale, conversion efficiency improvements, and reduced equipment and operational costs at the biorefinery. Table E: 2 summarizes these benefits and compares them to depot costs per GGE produced. As can be seen from Table E:2, the cost of the depot is more than offset by the savings that depots enable across the entire biofuel supply system

Table E:2. Comparison of the additional preprocessing costs for a depot based supply system and its biorefinery investment and operation cost-benefits (based on 2011\$/GEE).

\begin{tabular}{|c|c|c|c|}
\hline & $\begin{array}{l}\text { Biochemical } \\
\text { (2011\$/GGE) }\end{array}$ & $\begin{array}{r}\text { Thermochemical } \\
(2011 \$ / G G E)\end{array}$ & $\begin{array}{r}\text { AFEX pretreatment } \\
(2011 \$ / G G E)\end{array}$ \\
\hline Depot costs & $+\$ 0.06$ to $+\$ 0.14$ & Up to $+\$ 0.11$ & Up to $+\$ 0.32$ \\
\hline \multicolumn{4}{|l|}{ Biorefinery benefits } \\
\hline $\begin{array}{l}\text { Supply risk (interest rate) } \\
\text { reduction by }-2 \% \text { to }-5 \%\end{array}$ & $-\$ 0.05$ to $-\$ 0.18$ & $-\$ 0.05$ to $-\$ 0.18$ & $-\$ 0.05$ to $-\$ 0.18$ \\
\hline $\begin{array}{r}\text { Economies of scale } \\
\text { (for biorefinery capital } \\
\text { equipment ) }\end{array}$ & $-\$ 0.07$ to $-\$ 0.23$ & $-\$ 0.06$ to $-\$ 0.60$ & $-\$ 0.07$ to $-\$ 0.23$ \\
\hline $\begin{array}{r}\text { Conversion efficiency } \\
\text { improvements }\end{array}$ & (lack of data) & $-\$ 0.14$ to $-\$ 0.51$ & (lack of data) \\
\hline $\begin{array}{l}\text { Reduced storage and } \\
\text { handling equipment }\end{array}$ & Up to $-\$ 0.20$ & Up to $-\$ 0.20$ & Up to $-\$ 0.20$ \\
\hline $\begin{array}{r}\text { Reduced preprocessing } \\
\text { equipment }\end{array}$ & Up to $-\$ 0.48$ & Up to $-\$ 0.29$ & Up to $-\$ 0.48$ \\
\hline $\begin{array}{r}\text { Reduced pretreatment } \\
\text { equipment }\end{array}$ & (not applicable) & (not applicable) & Up to $-\$ 0.45$ \\
\hline TOTAL & $-\$ 0.75$ to $-\$ 0.96$ & $-\$ 0.63$ to $-\$ 1.67$ & $-\$ 0.94$ to $-\$ 1.22$ \\
\hline
\end{tabular}

Note: not all benefits associated with the depot concept have been quantified and included in this table.

Depot systems, when matched with the appropriate mode of transportation, could help reduce temporal and spatial biomass variability and allow access to greater quantities of sustainable biomass within a cost target by decoupling the biorefinery from feedstock location. Additionally, processed granulated feedstock is higher in bulk density and has better flow characteristics which improves transport to and within the biorefinery (via rail, ship, conveyor belts, etc.). This extends the sourcing radius for the biorefinery well beyond the 50-mile radius of a conventional bale supply and mitigates risks associated with feedstock intermissions (e.g., due to adverse weather, pests, and resulting competition for the remaining feedstock within close range). The biorefinery should thus be less vulnerable to feedstock volume, quality, and price volatility (affecting its profitability) and may not need to contract directly with feedstock producers. Reducing profitability risks could also help leverage the reluctance from the investment community to invest in larger facilities, enabling production economies of scale. The variability of feedstock 
supply to biorefineries is recognized as an investment risk by financial institutions. Reducing the variability of feedstock supply will reduce associated project risks which will be reflected in the annual percentage rate (APR) for financing biorefineries. Also, depots will reduce the handling infrastructure (for raw biomass in various formats) at the biorefinery, improve in-feed operations and thus reduce investment and operating costs. This should further reduce investment risks. 


\section{Acknowledgements}

We are grateful to the following people/institutions that provided helpful comments, data, and other forms of support for this analysis.

DOE: Alison Goss Eng, Mark Elless, Sam Tagore, Steven Thomas

MBI: Farsaneh Teymouri, Bryan Bals

BCS: Daniel Adams, Max Broad

ORNL: Erin Webb, Shahab Sokhansanj, Matthew Langholtz, Laurence Eaton

NREL: Christopher Scarlata, Eric Tan

INL: Erin Searcy, Richard Hess 


\section{Table of Contents}

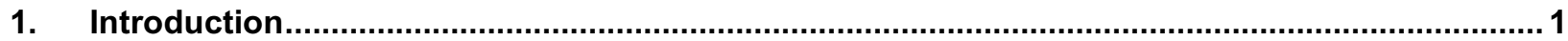

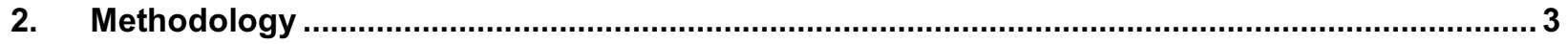

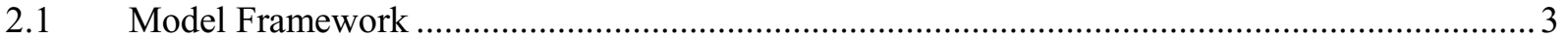

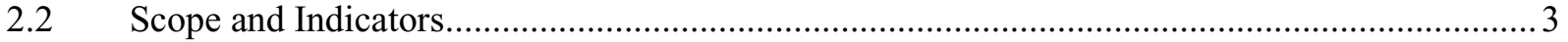

3. The Role of Depot-Based Feedstock Supply Systems in achieving BETO Volume and Cost

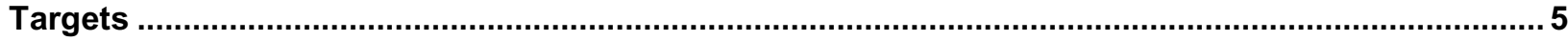

3.1 Reducing Temporal and Spatial Biomass Variability ......................................................... 5

3.2 Enabling Biorefinery Economies of Scale .................................................................... 6

3.3 System Benefits of Consistent Physical and Chemical Properties ........................................... 7

3.3.1 Managing Moisture: Reducing Energy Intensity, Improving Storability, Preventing Dry Matter Loss 8

3.3.2 Managing Sugar Carbohydrate Content..........................................................................................10

3.3.3 Blending/Least-Cost Formulation (see Appendix for details) …......................................................11

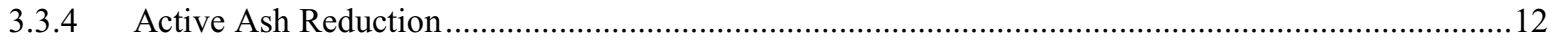

3.3.5 Consistent Physical Properties: Reducing Feeding and Handling Costs ...........................................14

3.4 Integrated Landscape Management ............................................................................... 14

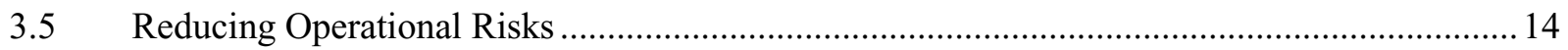

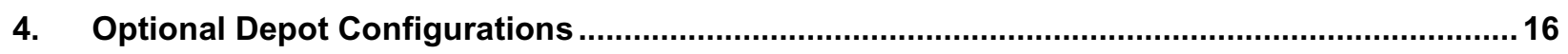

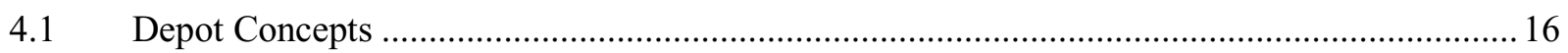

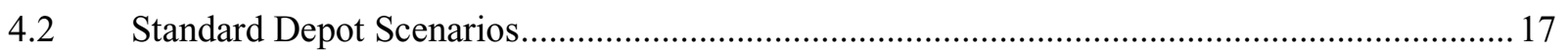

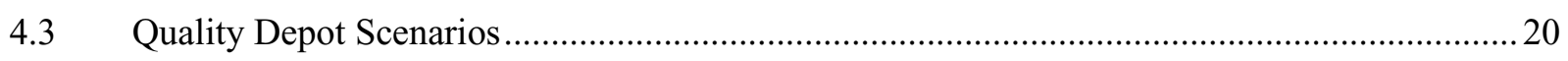

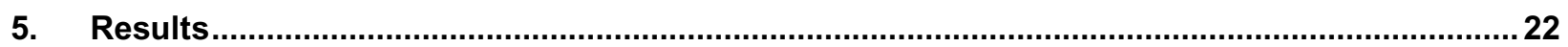

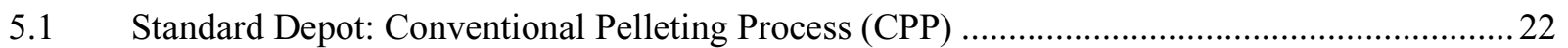

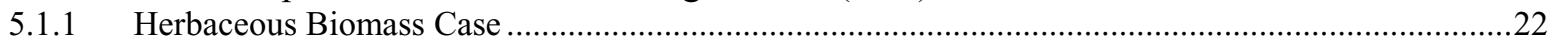

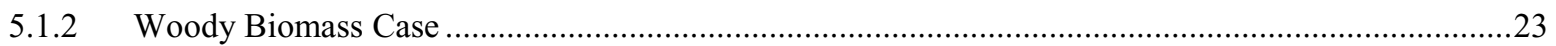

5.2 Standard Depot: High-Moisture Pelleting Process (HMPP) …............................................25

5.3 Standard Depot: High-Moisture Pelleting Process plus Fractional Milling (HMPPFM) ..........27

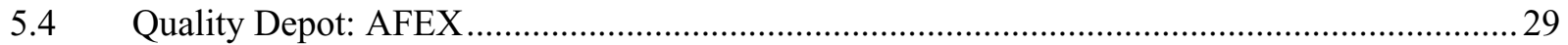

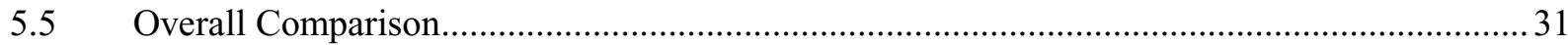

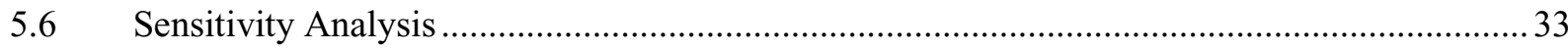

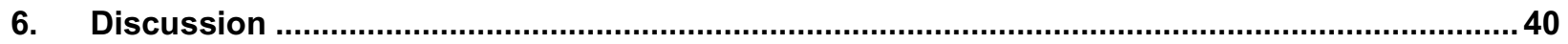

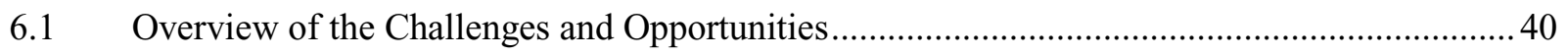

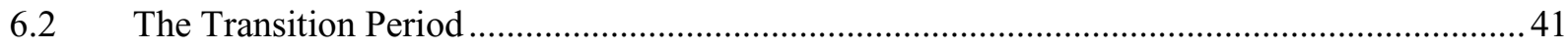

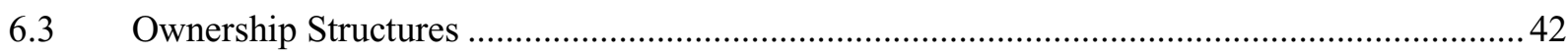

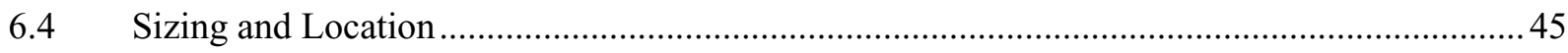

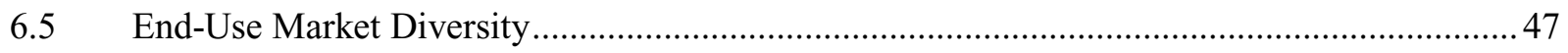

6.6 Cost-Benefit Comparison of a Conventional and an Advanced Feedstock Supply System based

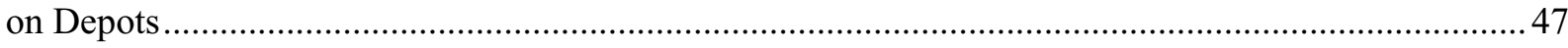

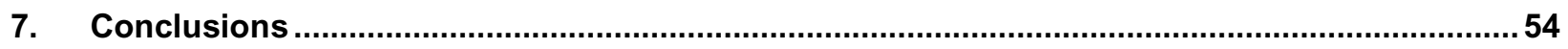

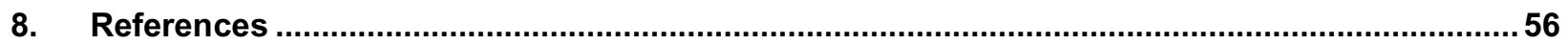




\section{List of Figures}

Figure E:1. Comparison of total investment costs per configuration....................................................

Figure E:2. Cost comparison per output unit (DT) and configuration..............................................

Figure 2:1. The BLM model structure (Cafferty et al. 2013) ................................................................ 3

Figure 3:1. Biomass resource assessments for three years exemplifying spatial and temporal variability (INL visualization of BT2-data)

Figure 3:2. Minimum ethanol/fuel selling price (MESP/MFSP) as a function of plant size (Argo et al. 2013). Note: The US\$3 GGE goal translates into a MFSP of US\$1.97. .............................. 6

Figure 3:3. Example of the spatial and temporal variability of corn stover characteristics such as $\%$ ash content, \% glucan content, and \% xylan (Data: INL Biomass R\&D Library)........................ 8

Figure 3:4. Grinding costs are a function of grinding energy needed for corn stover of various moisture contents. Current biochemical conversion pathway assumption is $20 \%$ moisture content (Kenney et al., 2013). *Note: BC stands for current biochemical conversion design case...... 9

Figure 3:5. The impact of dry matter loss on bale ash content and final conversion efficiency based on a $35 \%$ initial moisture and 10\% ash (INL 2013). *Note: Storage of six bale high stacks covered with tarp at field side or a similar 'unimproved' storage site.

Figure 3:6. MFSP in relation to initial sugar carbohydrate content. Current biochemical conversion pathway assumption is 59\% (Kenney et al. 2013). *Note: BC stands for current biochemical conversion design case.

Figure 3:7. Comparison of individual and blended feedstock costs. A blend of $60 \%$ corn stover, $35 \%$ switchgrass, and 5\% municipal solid waste is needed to hit the US\$80 feedstock cost target for a volume of 880,000 DT. The two blended lines are weighted average cost curves of amount of each feedstock with associated delivered feedstock cost. Note: the dotted lines indicate the cost and volume lines for both feedstock blends at a total delivered volume of 880,000 DT (i.e., 800,000 DT plus a $10 \%$ buffer).

Figure 3:8. Ash removal, disposal, and feedstock replacement costs to the biorefinery depending on ash content. Current biochemical conversion pathway assumption is $5 \%$. Underlying data for biomass types from Kenney et al. 2013. Ash costs include replacement and disposal ( US\$2.25/ton/\%ash above 5\%). Additional costs not included would be wear in processing equipment, pretreatment, etc. *Note: BC stands for current biochemical conversion design

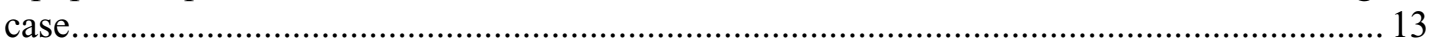

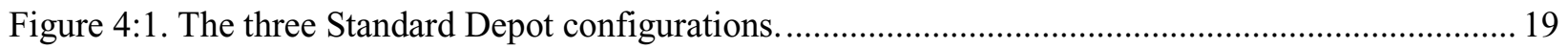

Figure 4:2. Ammonia Fiber Expansion (AFEX) process flow diagram (Source: MBI) ......................... 21

Figure 5:1. Comparison of total investment costs per configuration.................................................. 32

Figure 5:2. Cost comparison per dry ton (DT) output and configuration. .......................................... 32

Figure 5:3. Minimum selling price of AFEX product to gain a 12\% return on investment for different

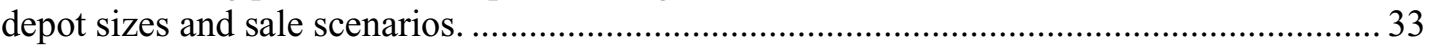

Figure 5:4. The impact of electricity price, energy consumption of different equipment used at CPP (herbaceous case) on depot fixed and operations cost.

Figure 5:5. The impact of electricity price, energy consumption of different equipment used at CPP (woody case) on depot fixed and operations cost. ............................................................... 35

Figure 5:6. The impact of electricity price, energy consumption of different equipment used at HMPP on

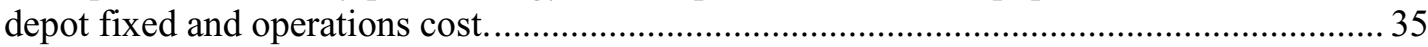

Figure 5:7. The impact of electricity price, energy consumption of different equipment used at HMPPFM

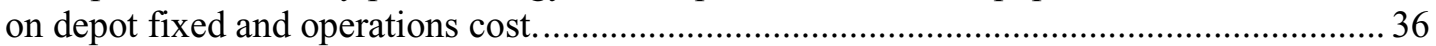

Figure 5:8. The impact of electricity price, energy consumption of different equipment used at AFEX on

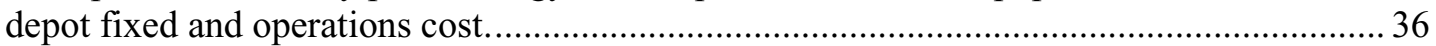

Figure 5:9. Impact of depot size on fixed and operations cost at different depot scenarios. .................... 37

Figure 5:10. Impact of all sensitivity parameters on depot fixed and operations cost for CPP, herbaceous

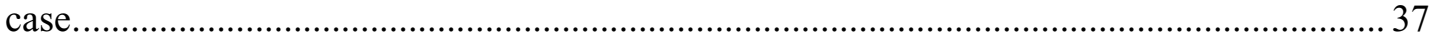

Figure 5:11. Impact of all sensitivity parameters on depot fixed and operations cost for CPP, woody case.38 Figure 5:12. Impact of all sensitivity parameters on depot fixed and operations cost for HMPP. ............. 38 
Figure 5:13. Impact of all sensitivity parameters on depot fixed and operations cost for HMPPFM........ 39

Figure 5:14. Impact of all sensitivity parameters on depot fixed and operations cost for AFEX .............. 39

Figure 6:1. Change of unit capital cost of pellet production plant with capacity (Sultana et al. 2010)..... 45

Figure 6:2. Annual total interest for biorefinery investments of 800,000 DT annual capacity facilities across varying interest rates and their respective impact on the production costs per GGE. . 48

\section{List of Tables}

Table 4:1. Comparison of depot concepts and their main characteristics.............................................. 17

Table 5:1. CPP total capital investment costs (herbaceous case) ............................................................2 22

Table 5:2. CPP operating and fixed costs (US\$/DT) (herbaceous case) ............................................... 23

Table 5:3. CPP total capital investment costs (woody case) ...................................................................24

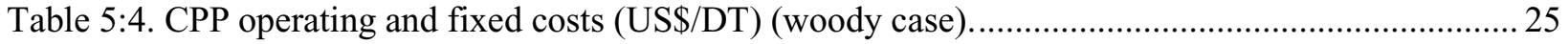

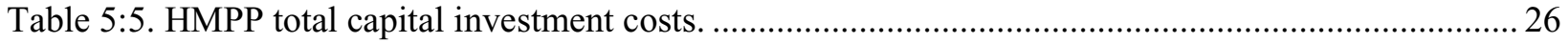

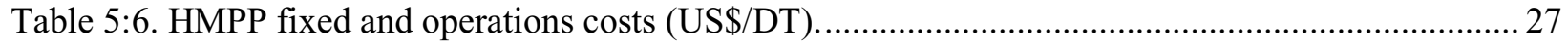

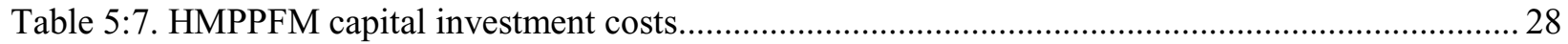

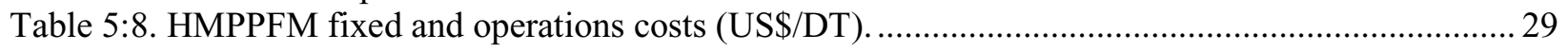

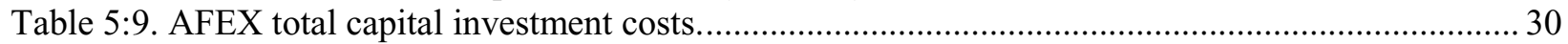

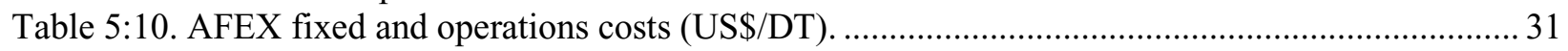

Table 5:11. Parameter ranges and variations for a triangular distribution-based sensitivity analysis. ....... 34

Table 6:1. Overview of potential challenges and opportunities linked to the implementation of the depot

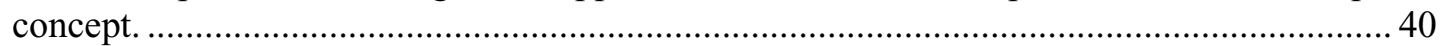

Table 6:2. Depot transition periods by elements of characteristics..................................................... 42

Table 6:3. Impact of interest rate reductions between calculated impacts per GGE for interest rates in the range of $8-30 \%$ for a 10 year loan for $40 \%$ of the total capital investment for a biochemical or thermochemical conversion facility of 800,000 DT annual capacity. ................................ 49

Table 6:4. Additional cost reductions per unit produced (in 2011\$/GGE) for biorefineries relying on an advanced feedstock supply system over 2 Million DT per year capacity compared to a 800,000 DT per year biorefinery baseline with a conventional feedstock supply system. .... 49

Table 6:5. Mixed alcohol yields (in gal/DT) as a function of preprocessing levels for different feedstock qualities and the respective impact per unit produced (in 2011\$/GGE). ...............................50

Table 6:6. Preprocessing costs at the biorefinery in a conventional supply system and savings achieved by

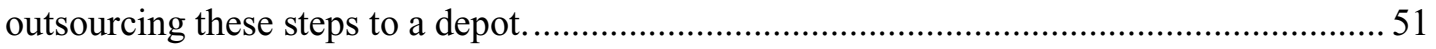

Table 6:7. Storage sizes, type, and cost comparison....................................................................... 51

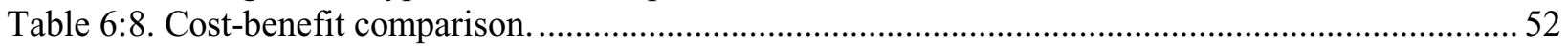

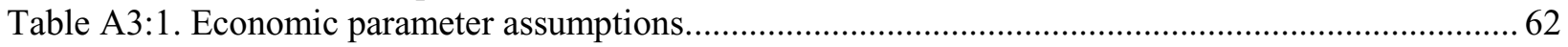

Table A3:2. Average feedstock characteristics and process parameter assumptions. ............................ 63 


\section{List of Acronyms}

AAEA Agricultural \& Applied Economics Association

AFEX Ammonia Fiber Expansion

APR Annual Percentage Rate

ASABE America Society of Agricultural and Biological Engineers

BETO Bioenergy Technologies Office

BT2 Billion Ton Study Update

CPP Conventional Pelleting Process

DT Dry Ton (U.S. short ton)

DOE U.S. Department of Energy

GGE Gallon of Gasoline Equivalent

HMPP High-Moisture Pelleting Process

HMPPFM HMPP with Fractional Milling

I\&D Interest and Depreciation (costs)

IH\&T Insurance Housing and Taxes (costs)

INL Idaho National Laboratory

MBI Michigan Biotechnology Institute

MC Moisture Content

MFSP Minimum Fuel Selling Price

ORNL Oak Ridge National Laboratory

PDU Process Demonstration Unit (at INL)

R\&M Repairs and Maintenance (costs)

SOT State of Technology

TEA Techno-Economic Analysis

WWT Waste Water Treatment 


\section{Introduction}

Motivation and Background: Currently, the U.S. cellulosic biofuel industry relies on a conventional biomass supply system, hereinafter referred to as the conventional system, where corn stover, pulpwood, energy crops or other herbaceous and woody residues are procured through contracts with local growers, harvested, stored locally, and delivered in bale or low density bulk format to the conversion facility. The conventional system has been demonstrated to work in a local supply context within high yield regions (e.g., the U.S. Corn Belt or southeast forests); however, scaling up the biorefinery industry will require increasing biomass volumes at decreasing costs. The U.S. Department of Energy's (DOE) Bioenergy Technologies Office (BETO) has a goal of US\$80 dry $\operatorname{ton}^{-1}$ (DT) logistics cost target to the throat of the conversion facility (including grower payment and logistics) to reach a final ethanol target of US\$3 per gallon of gasoline equivalent (GGE) by 2022 (DOE 2013).

Different analyses (Hess et al. 2009, Argo et al. 2013, Jacobson et al. 2014, Muth et al. 2014) have shown that the conventional system option may not be able to reach this target beyond highly productive regions and will even struggle in some years within these areas due to incremental weather during production and harvest seasons or extreme events such as flood or draught. These supply uncertainties will tend to classify the biomass industry as a high risk investment and limit the biorefinery concept from being broadly implemented (Lamers et al. 2014). Financial institutions translate high risk ventures into higher interest rates, which have a profound impact on the overall costs to a biorefinery over its operational life span. Jacobson and Cafferty 2013 calculated a US $\$ 350$ million reduction in interest paid over a 20 year lifespan for a US $\$ 500$ million dollar facility, should the investment loan rate drop from $10 \%$ to $5 \%$. This translates roughly into US $\$ 0.25 /$ gal of fuel produced.

The advanced systems developed by Hess et al. 2009, Searcy et al. 2011 provide a method to reduce feedstock volume, price, and quality supply uncertainties. It is based on a network of distributed biomass preprocessing centers Eranki et al. 2011, so-called depots, which use one or several biomass types to generate uniform feedstock 'commodities'. These commodities are intermediates with consistent physical and chemical characteristics that meet conversion quality targets and at the same time leverage the spatial variability in supply volumes and costs by improving flowability, transportability (bulk density), and stability/storability (dry matter loss reduction).

Research objective and questions: This report's objective is to present and evaluate the technical and economic feasibility of the depot concept, in addressing the following questions:

- What are the main technical and cost configuration options of a depot?

- What are the operational details (e.g., regarding material flow) of a depot?

- What are the economic impacts of these different depot concepts?

- How may the transition from a conventional system to an advanced system occur?

Outline and connection to other work: Section 2 of the TEA starts by providing details on the materials and methods applied in this study. Section 3 outlines the key benefits of depot based supply networks for achieving the price and volume targets. Section 4 presents different depot design options and their respective scenarios. Section 5 presents the results of the different depot designs. Section 6 outlines the barriers and opportunities linked to the depot concept and 
addresses wider depot design choices not part of this analysis. Section 7 closes with a conclusion and outlook for future research.

This study is directly related to project work undertaken by Oak Ridge National Laboratory (ORNL) that is studying optimal depot locations based on biomass availability (i.e., linked to the U.S. Billion Ton Update data) and logistics network. The INL study investigates the depot internal aspects and provides feedback to ORNL based on changes in feedstock characteristics (i.e., changes in moisture content, flowability, bulk density, etc.), which affect the optimization runs for both a depot and biorefinery location.

This study also directly supports the annual State of Technology (SOT) reports that capture the cost and volume improvements annually based on engineering and design improvements of the feedstock logistic supply systems. The goal of the SOT reports are to present the strategies to meet the 2022 BETO cost target of delivering large volumes of feedstocks to a conversion facility at $\$ 80 /$ dry ton $^{-1}$ including grower payment. Depot designs are an important concept that is included in the SOT reports. 


\section{Methodology}

\subsection{Model Framework}

The Biomass Logistics Model (BLM) framework (see Cafferty et al. 2013 for a detailed description) was used to conduct the economic analysis of each depot design. The BLM is part of a versatile analysis toolset developed by INL to estimate delivered feedstock cost, energy consumption and greenhouse gas (GHG) emissions for the entire biomass supply system designs from harvest and collection to delivery to the throat of the conversion facility. This analysis was focused only on the depot aspect of the supply system and did not account for the other operations. The BLM simulates a broad set of parameters and allows the user to investigate important sensitivities and uncertainties of equipment lineups, efficiencies and flow rates that are currently a primary source of feedstock risk for the biorefinery industry. The BLM model structure is shown in Figure 2:1.

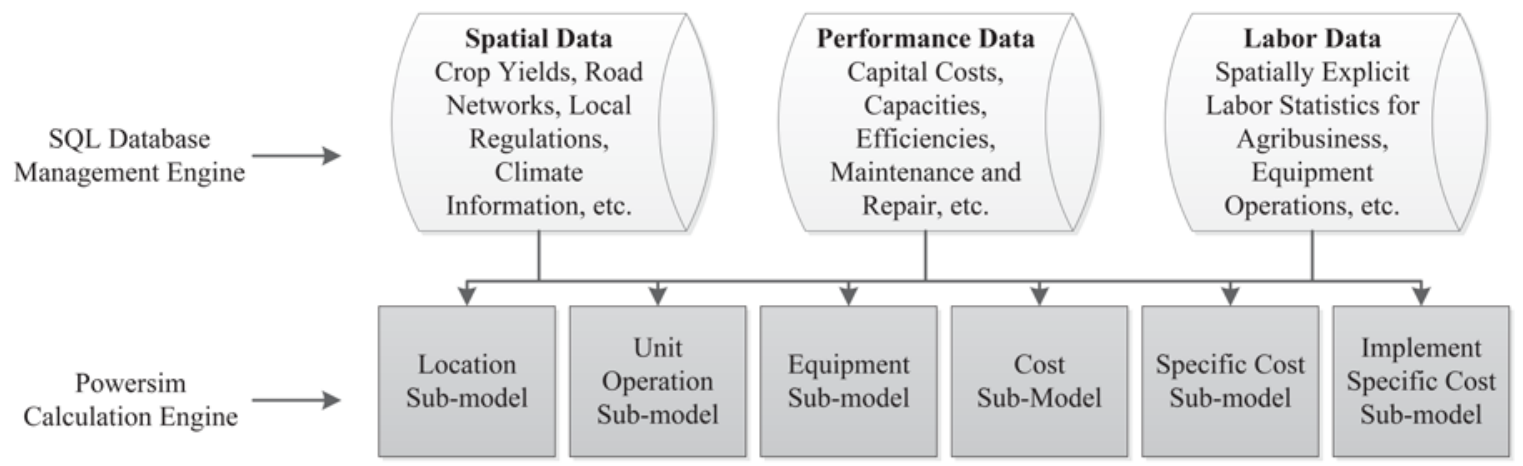

Figure 2:1. The BLM model structure (Cafferty et al. 2013).

The BLM incorporates information from a collection of databases that provide 1) engineering performance data for hundreds of equipment systems, 2) spatially explicit labor cost datasets, and 3) local tax and regulation data. The BLM is designed to work with various thermochemical and biochemical conversion platforms and accommodates numerous biomass varieties (i.e., herbaceous residues, short- rotation woody and herbaceous energy crops, woody residues, algae, etc.), resulting in a robust and flexible systems model. The BLM simulates the flow of biomass through the entire supply chain, tracking changes in feedstock characteristics (i.e., moisture content, dry matter, ash content, and dry bulk density) as influenced by the various operations in the supply chain. By accounting for all of the equipment that comes into contact with biomass from the point of harvest to the throat of the conversion facility and the change in characteristics, the BLM enables highly detailed economic cost, energy consumption and environmental impact analyses. As a result of these highly detailed analyses, areas for improvement (i.e., equipment efficiencies, operational parameters, environmental conditions, etc.) can be identified through sensitivity analyses that can be used to enhance the design and performance of these systems. Finally, the BLM can be coupled to additional models as it is part of a greater modeling toolset used to assess sustainability, environmental impacts (GHG emissions), and feedstock quality specifications.

\subsection{Scope and Indicators}

The scope of the TEA covers the operations of a depot 'within the gate'. It does not include the assessment of varying feedstock prices (due to different grower payments or transportation 
systems, etc.). The primary indicators of the TEA are economic feasibility and output cost in dry tons (DT). Secondary indicators include energy use, preprocessing times, throughput rates, and moisture levels.

The primary process focus of this TEA is biochemical conversion using herbaceous residues as a feedstock. The underlying feedstock selected for this TEA was primarily corn stover but blended materials (e.g., with woody biomass) can also move through a depot and are discussed in the document. Herbaceous residues and energy crops currently face a limited market demand and their feedstock characteristics match up well with biochemical conversion technologies. Depots, if designed properly, can support more than ethanol markets, such as biopower, animal feed, and bioplastics, which should help facilitate additional and constant demand. Furthermore, logistical advancements are needed within the biochemical conversion supply chain to make herbaceous material cost efficient. Also, herbaceous residues are not widely used in the heat and power market due to combustion issues (e.g., slacking and fouling). Woody biomass is expected to also have a role in biochemical conversion (via blending) but more so in thermochemical conversion processes. At the same time, wood (pulpwood and residues) pelleting operations have already proven to be economical and the evolution of a depot concept could benefit significantly from current operations in the wood sector. Any new operations in a depot operation defined under the herbaceous design would transfer into a woody depot system after the initial grinding operations. 


\section{The Role of Depot-Based Feedstock Supply Systems in achieving BETO Volume and Cost Targets}

\subsection{Reducing Temporal and Spatial Biomass Variability}

Biomass is highly variable both spatially and temporally (Kenney et al. 2013) which can have big implications when considering a national scale feedstock supply system for biofuels. A comparison of U.S. resource assessments for 2012, 2017, and 2022 (DOE 2011) shows large variability in quantity, location, and type of feedstock (Figure 3:1). This variability adds complexity to the feedstock delivery and supply.

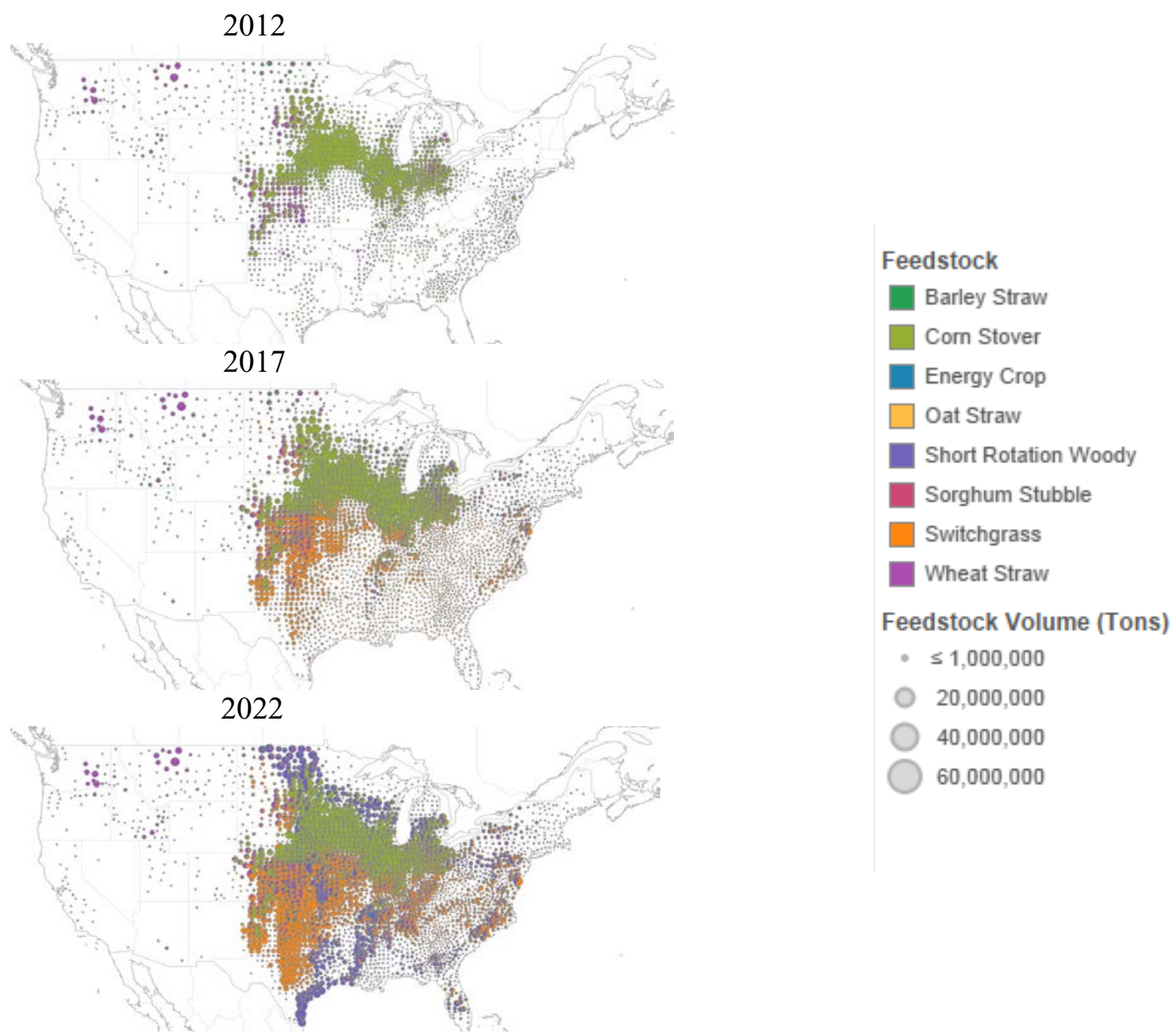

Figure 3:1. Biomass resource assessments for three years exemplifying spatial and temporal variability (INL visualization of Billion Ton 2012 Update data).

Excluding spatial and temporal variability risks, Jacobson et al. 2014 concluded that going from conventional to an advanced feedstock supply system based on a network of depots may not prove to be economically advantageous within the logistics supply system. Rather, advanced 
system systems typically have higher average logistics costs than conventional system systems due to increased preprocessing costs and increased transportation costs with multiple transportation steps for the advanced system (Argo et al. 2013). However, the advanced system addresses many of the conventional system feedstock-supply risks and creates wider system benefits, most of which translate into cost benefits across the entire biofuel supply chain which includes the conversion facilities and farmer costs (Lamers et al. 2014). So while the advanced supply system appears to be more expensive when looking strictly at the logistic costs, an analysis of the entire biofuel supply system including the biorefinery capital and operating costs could reveal that overall system costs are lower in the advanced system. A comprehensive discussion of the cost advantages of the advanced supply system is provided in Section 6.6.

\subsection{Enabling Biorefinery Economies of Scale}

The size of a biorefinery has been an area of debate and will have a significant influence on the supply system costs (Argo et al. 2013, Muth et al. 2014). Aden et al. 2002 showed that biorefinery size of at least 2,000 DT/day capacity is required to reach a competitive minimum fuel selling price (MFSP). More recent studies indicate that in order to achieve conversion process economics, facilities of 5,500 to $11,000 \mathrm{DT} /$ day are required (Carolan et al. 2007, Argo et al. 2013, Muth et al. 2014). However, the truck frequency for biorefinery capacities at 5,500 DT/day in the conventional system is one truck every three minutes; which represents a key system limitation in terms of overall truck traffic, constriction due to loading and unloading times. Larger facilities are predicted to more than offset the MFSP increase associated with more expensive preprocessed feedstock (Argo et al. 2013; Figure 3:2). Moreover, biorefineries with capacities in excess of $11,000 \mathrm{DT} /$ day are only possible with advanced system due to transportation limitations (Argo et al. 2013). With the conventional system, logistic costs increase as either biorefinery capacity or feedstock collection radius increase. With the advanced supply systems the collection radius does increase costs but not as significantly as with a conventional supply system.

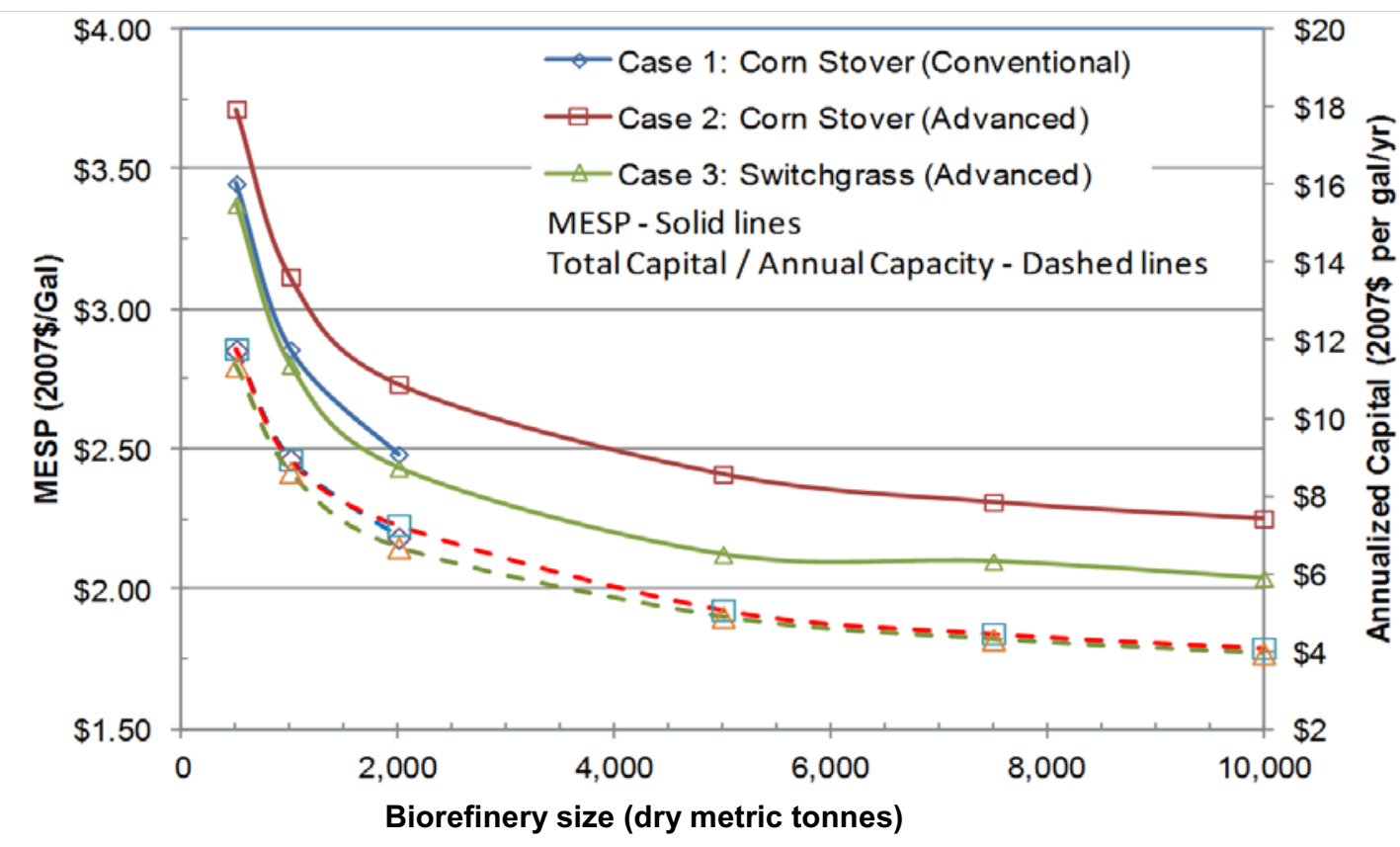

Figure 3:2. Minimum ethanol/fuel selling price (MESP/MFSP) as a function of plant size (Argo et al. 2013). 
Note: The US\$3 GGE goal translates into a MFSP of US\$1.97.

\subsection{System Benefits of Consistent Physical and Chemical Properties}

Typical harvested biomass varies in quality (e.g., ash, xylan, and glucan), as illustrated for U.S. Midwestern corn stover in Figure 3:3.
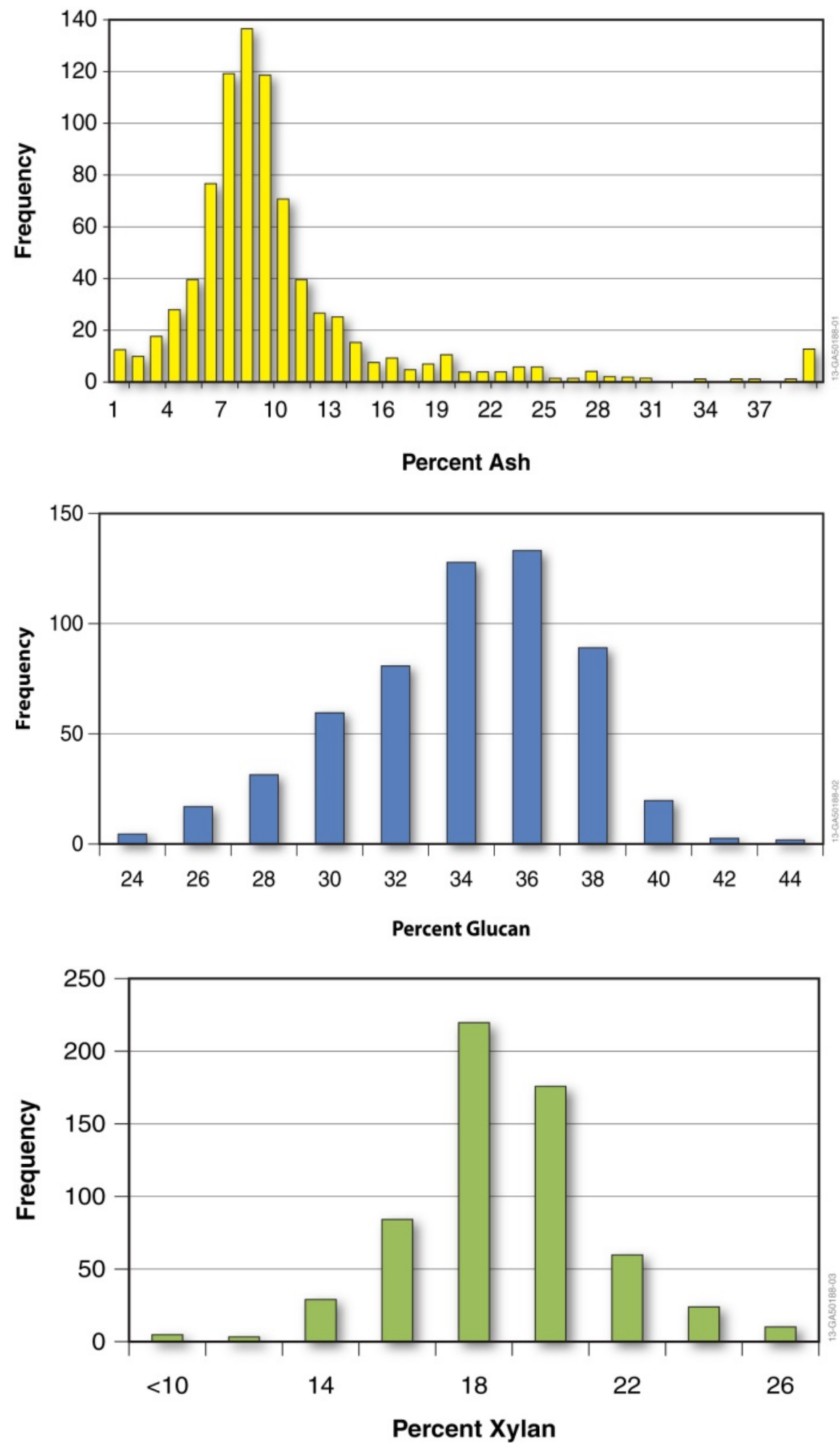
Figure 3:3. Example of the spatial and temporal variability of corn stover characteristics such as $\%$ ash content, \% glucan content, and \% xylan (Data: INL Biomass R\&D Library).

Figure 3.3 shows that ash content (wt $\%$ ) typically varies from 3 to $15 \%$ but can range all the way to nearly $40 \%$. The conversion specifications for a biochemical conversion request around $5 \%$ ash. This distribution shows that most material is above the target values. It is a similar situation for glucan and zylan. The distributions show significant variation which will cause the conversion process to experience varying conversion efficiencies all.

Feedstock quality directly influences conversion capability and ultimately influences total production costs (e.g., the MFSP). Addressing quality issues early in the supply chain creates downstream benefits. Standardization of chemical characteristics, in particular ash, moisture, and carbohydrate content, increases pretreatment and conversion efficiencies and reduces waste streams. Quality targets can have a large impact on whether or not a particular feedstock is cost effective. Approaches to address quality variability include blending/formulation, leaching, and other preprocessing options that are possible options within a depot.

\subsubsection{Managing Moisture: Reducing Energy Intensity, Improving Storability, Preventing Dry Matter Loss}

Limiting chemical feedstock variations includes the ability to actively manage moisture along the supply system, a key aspect of current grain commodity systems. Biomass moisture is subject to a variety of components including harvest timing, and weather at time of harvest. Figure 3:4 below shows the moisture content of corn stover from the same field for two different years. In 2009, the harvest season was plagued with significant rain while in 2010 the harvest season was reasonably dry. The difference in moisture content was considerable due to the conditions at the time of harvest and collection. The conventional supply system does not have any methods for actively addressing moisture in the supply system. Moisture content variations impact transportation costs, grinding energy, drying energy and storage dry matter loss (DML) in terms of rotting, which increases fire hazard and impacts feedstock quality and quantity due to required feedstock substitution. Preprocessing at the depot can reduce moisture, stabilize feedstock, and facilitate commodity scale storage and distribution. 


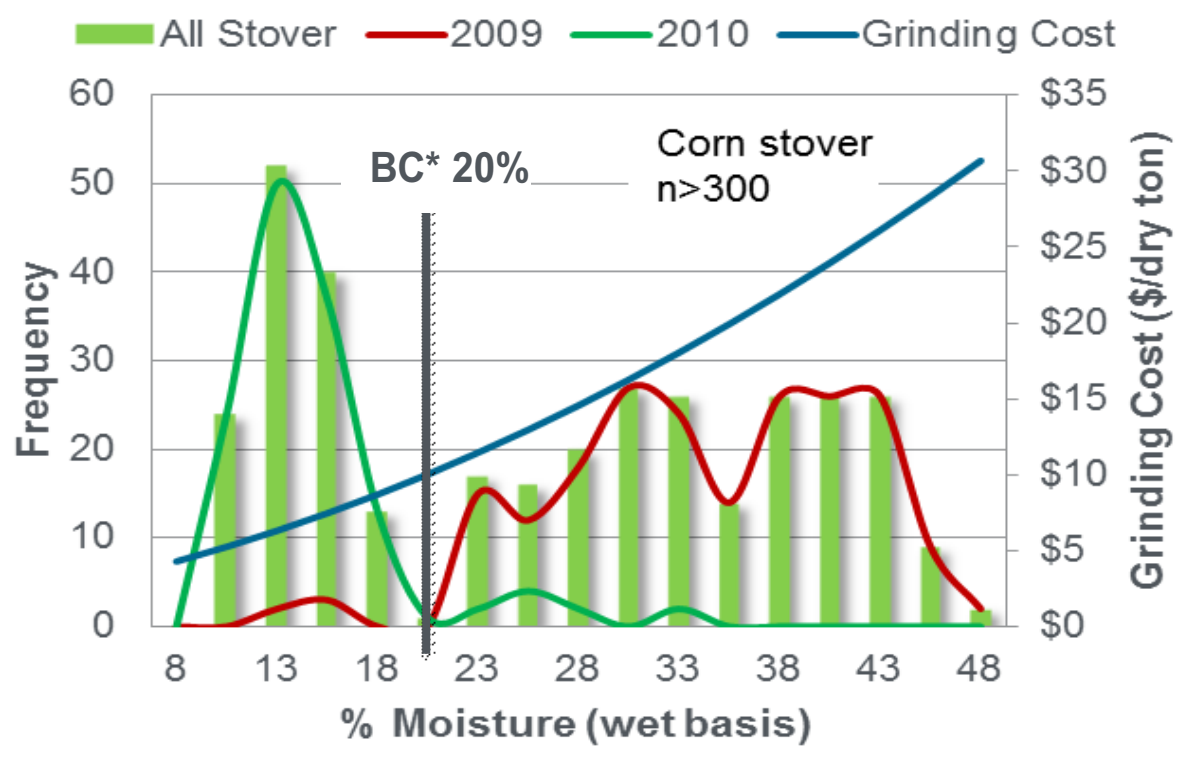

Figure 3:4. Grinding costs are a function of grinding energy needed for corn stover of various moisture contents. Current biochemical conversion pathway assumption is $\mathbf{2 0} \%$ moisture content (Kenney et al., 2013).

*Note: BC stands for current biochemical conversion design case

DML, or feedstock shrinkage, is a prominent constraint to consistent feedstock quality and supply within a conventional feedstock supply system. The key influencing parameters to DML are moisture content at the time of harvest and storage type (Kenney et al. 2013). Post-harvest moisture levels are typically $15-20 \%$ for the U.S. Corn Belt region, but can reach over $50 \%$ due to inclement weather (Hess et al. 2009, Kenney et al. 2013). A limiting factor to reducing initial harvest moisture content is that harvest windows are defined for optimal yield of the primary crop, e.g., corn, not the quality of the residue, e.g., corn stover. Storage is a requirement for most of the year due to the short harvest window. Exposures to weather and temperature variations in storage drive $\mathrm{DML}^{1}$ and feedstock ash content; which in turn influence conversion efficiencies (Figure 3:5). Pelleting as part of the depot concept reduces moisture content and improves storability, thus preventing DML and the build-up of ash (Figure 3:5).

\footnotetext{
${ }^{1}$ In the conventional supply system, where corn stover bales are either 'covered on ground' or 'stacked on improved surface', DML ranges between 2.5-23\% with an average of 13\% (see Hess et al. 2009 for details).
} 

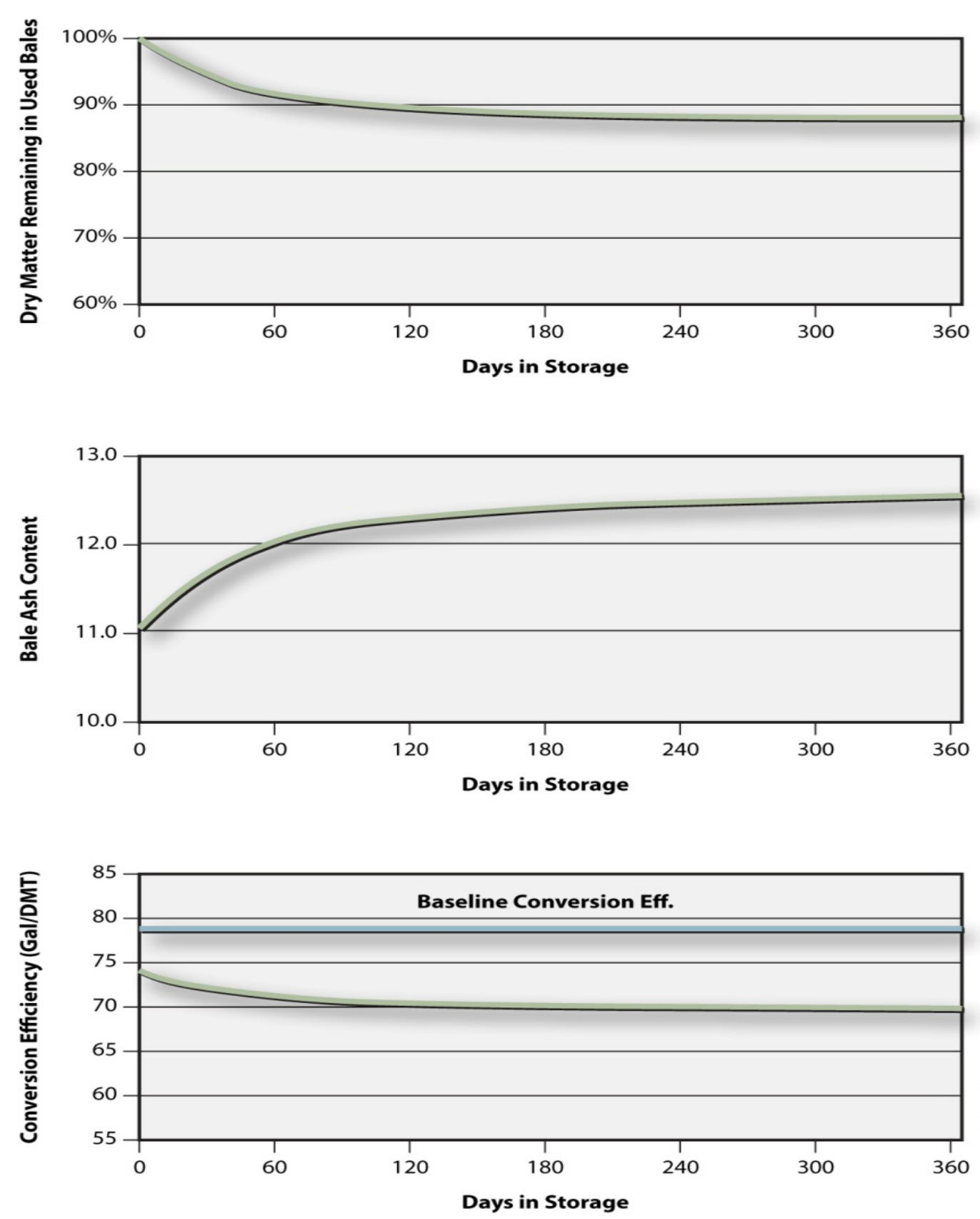

Figure 3:5. The impact of dry matter loss on bale ash content and final conversion efficiency based on a $35 \%$ initial moisture and $10 \%$ ash (INL 2013). Note: The percentage of ash increases do to the overall change in mass of the bale. In other words, as the bale loses moisture the relative $\%$ of ash increases.

*Note: Storage of six bale high stacks covered with tarp at field side or a similar 'unimproved' storage site.

\subsubsection{Managing Sugar Carbohydrate Content}

While carbohydrate content is less critical for thermochemical conversion pathways, biochemical conversion processes are particularly sensitive, specifically to the structural sugars content of the feedstock material (Kenney et al. 2013). The ratio of C5/C6 sugars and their accessibility are also relevant in the optimization of pretreatment and fermentation conditions. Evaluations of cellulosic ethanol production costs from corn stover show that ethanol yield varies linearly with structural sugar content in the amount of $1.38 \mathrm{gal} /$ ton per percent structural carbohydrates Ruth and Thomas 2003. Figure 3:6 shows 
an initial calculation of sugar carbohydrate content with MFSP per gallon (based on data from Ruth and Thomas 2003, Templeton et al. 2009, Kenney et al. 2013).

Corn stover compositional variability appear to vary with harvest year, environment (e.g., soil type, agronomic practices), and feedstock variety (Templeton et al. 2009). As Kenney et al. 2013 discuss, there are limited logistical options to increase intrinsic carbohydrate content other than normalizing year-toyear harvesting practices. Critical post-harvest operations include proper moisture management, especially storage improvements to prevent DML, as compositional variability in feedstock is heavily influenced by degradation and consumption of biomass carbohydrates in storage. Analysis by Shah et al 2011 of single-pass corn stover square bales in Iowa shows increases in the lignin and cellulose fractions and decreases in the hemicellulose fraction as a result of DML. DML in bales is generally not uniform which creates further compositional variability within storage (Kenney et al. 2013). Apart from active moisture management (see above), a depot can also help actively upgrade feedstock carbohydrate content by blending/formulation.

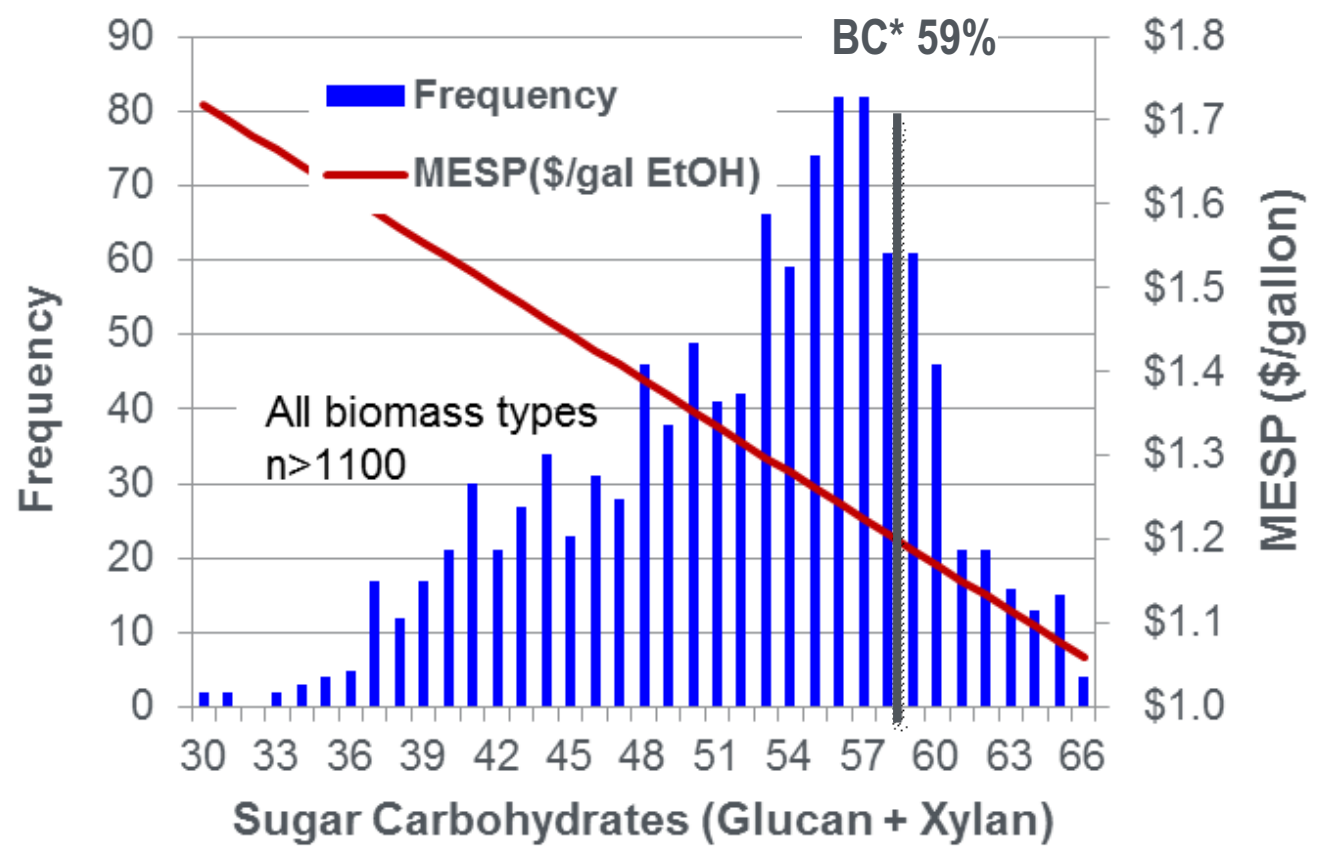

Figure 3:6. MFSP in relation to initial sugar carbohydrate content. Current biochemical conversion pathway assumption is $59 \%$ (Kenney et al. 2013).

* Note: BC stands for current biochemical conversion design case.

\subsubsection{Blending/Least-Cost Formulation (see Appendix for details)}

Blending is common practice in many industries, e.g., in the U.S. grain industry, to adjust quality (Hill 1990). Similarly, different grades of coal are blended to achieve compliance with regulations regarding sulfur and nitrogen emissions in the power generation industry (Shih and Frey 1995, Boavida et al. 2012). Furthermore, the animal feed industry uses a range of feedstocks blended together to meet the specific nutrient requirements of the target animal (Reddy and Krishna 2009). Finally, relatively high-ash content biomass sources are mixed with low-ash coal to allow their economical use in co-fired biopower generation (Sami et al. 2001).

By combining analyses using average farm gate price assumptions with quality information obtained from the INL Biomass R\&D Library, gains in the projected volumes available at cost and conversion in-feed specifications are being realized by transitioning to a blended feedstock approach. Feedstock blending 
allows a biorefinery to collect less of any one type of biomass by collecting a variety of biomass (i.e., corn stover, switchgrass, and sorghum) and thus move down the cost $v s$. supply curve, paying a lower average price for each feedstock (Figure 3:7). Note that this does not change the supply vs. cost curves for each resource, but it instead describes a system where purchasers are using a combination of least-cost resources and blending them to meet the bioenergy application's desired feedstock specification.

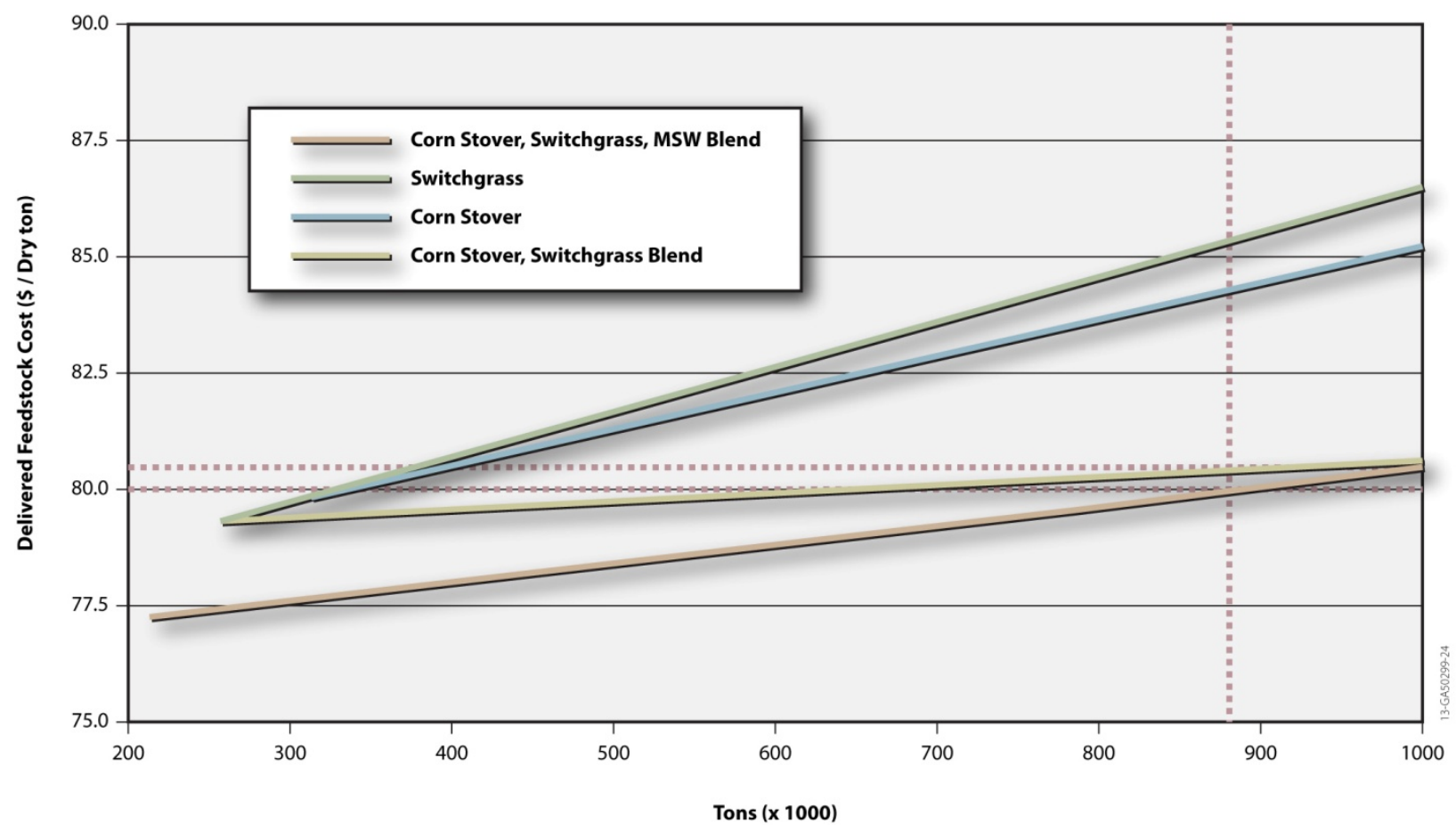

Figure 3:7. Comparison of individual and blended feedstock costs for one county. A blend of $60 \%$ corn stover, $35 \%$ switchgrass, and $5 \%$ municipal solid waste is needed to hit the US\$80 feedstock cost target for a volume of 880,000 DT. The two blended lines are weighted average cost curves of amount of each feedstock with associated delivered feedstock cost. Note: these curves would vary by county by region and by state.

Note: the dotted lines indicate the cost and volume lines for both feedstock blends at a total delivered volume of 880,000 DT (i.e., 800,000 DT plus a $10 \%$ buffer).

With blended feedstocks, biomass quality is a key aspect to consider when analyzing cost and volume availability. Formulating a designed feedstock through blending and other preprocessing logistical methods allows low cost and typically low quality biomass to be blended with biomass of higher cost and typically higher quality to achieve the in-feed specifications at the conversion facility. In combination with densification, wider sourcing areas can be tapped (including resources that are considered stranded using conventional supply systems). Bringing various feedstock streams into the supply system creates cost benefits by reducing overall grower payments (Jacobson et al. 2014).

\subsubsection{Active Ash Reduction}

Ash serves no purpose in a conversion process, and in fact will result in additional costs for the biorefinery in terms of reducing pretreatment efficacy, machine wear, disposal, and reduced conversion performance. Ash comes in several forms including dirt and soil on the outside and structural ash or physiological ash which is internal to the plant. External ash is much easier to remove through washing or best management practices in harvesting and collection.

Physiological ash requires more extensive mechanical or chemical processes to remove. When 
ash content increases, especially due to the addition of a nonbiomass constituent (e.g., soil), the convertible biomass content decreases (Kenney et al. 2013). Any increase in noncarbohydrate constituent reduces the proportion of structural carbohydrates present. Also, ash increases the neutralization capacity of corn stover during dilute-acid pretreatment, which reduces conversion yields (Weiss et al. 2010).

Humbird et al. 2011 calculate biorefinery disposal costs of inherent feedstock ash at US\$0.025 of the US\$2.15 MFSP per gallon, assuming a $5 \mathrm{wt} \%$ physiological ash (i.e., ash from the mineral components of the plant itself) content in corn stover in the biochemical design case. This, however, neglects potentially introduced, non-physiological ash, soil in particular. Kenney et al. 2013 show additional disposal costs for the biorefinery double and triple at $6.3 \%$ and $12.1 \%$ soil contamination levels, respectively. The following cost curve was derived by applying these cost calculations for ash disposal plus replacement costs for the lost material (Figure 3:8). Depot systems can reduce ash through mechanical and chemical preprocessing which will improve the biorefinery economics; however, the key is to off-set the preprocessing costs with improved economics at the biorefinery. Additionally, there may be a market for the removed ash in products like soil amendments and fertilizers which would also help to offset the cost of treatment.

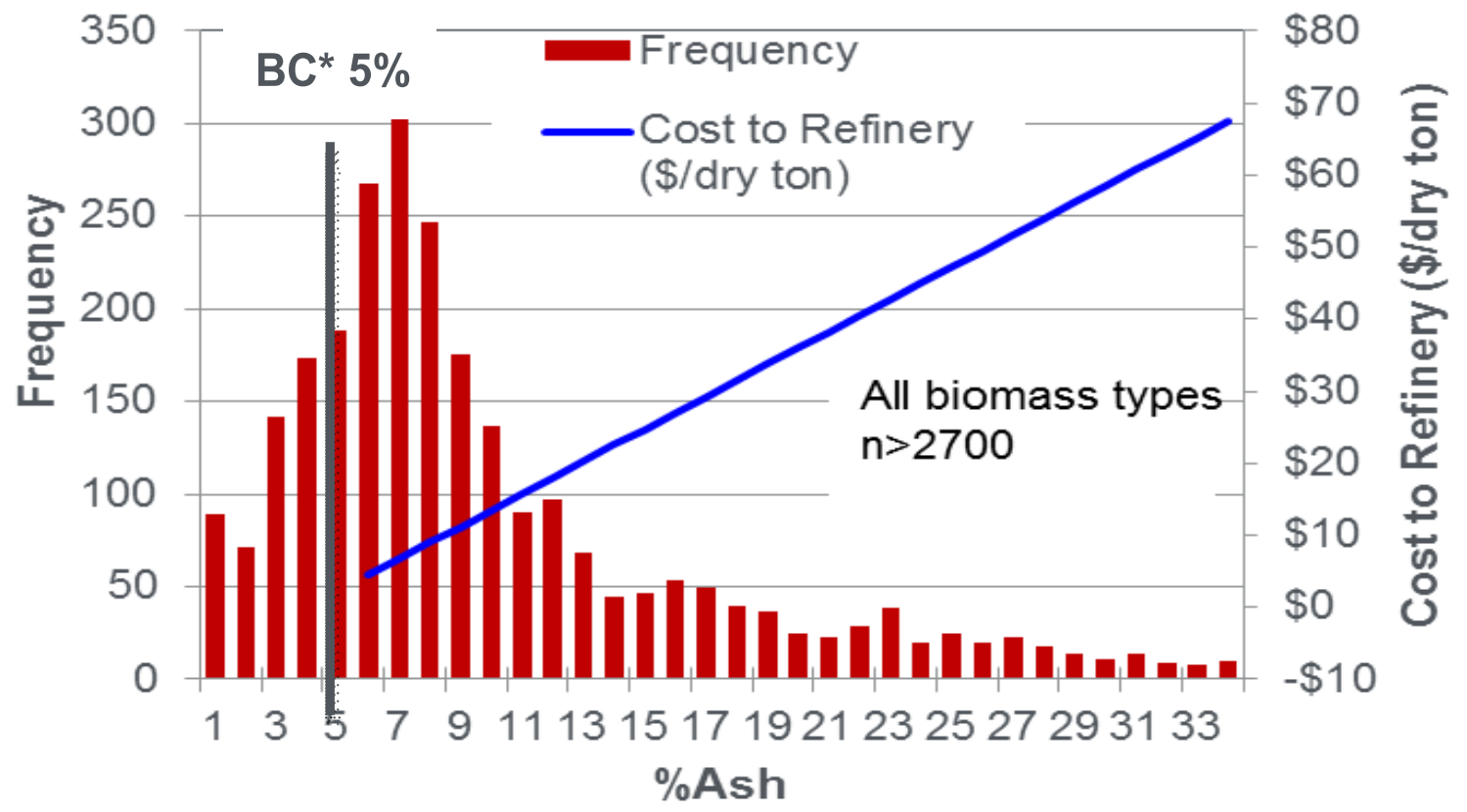

Figure 3:8. Ash removal, disposal, and feedstock replacement costs to the biorefinery depending on ash content. Current biochemical conversion pathway assumption is $\mathbf{5 \%}$. Underlying data for biomass types from Kenney et al. 2013. Ash costs include replacement and disposal ( US\$2.25/ton/\%ash above 5\%). Additional costs not included would be wear in processing equipment, pretreatment, etc.

${ }^{*}$ Note: BC stands for current biochemical conversion design case.

Options to actively reduce ash include biomass selection (woody biomass without bark is generally lower in ash content than herbaceous biomass) and operational improvements, e.g., single-pass harvesting. Preprocessing operations at the depot, e.g., hot water or acid washing, can 
be designed to actively remove ash contamination to pre-defined levels; thereby benefiting the overall process efficiency of the biorefinery.

\subsubsection{Consistent Physical Properties: Reducing Feeding and Handling Costs}

Consistent particle morphology (i.e., feedstock size and shape) and (bulk) density improves flowability and feeding properties, allowing the use of standardized, high-efficiency, highvolume grain handling and transport systems and equipment. It is estimated that feeding and handling problems due to changing and uncertain bulk solids properties can reduce plant throughputs up to $50 \%$, significantly influencing biorefinery efficiency and economics (Kenney et al. 2013). Converting raw biomass into densified, flowable material will improve the storage costs, transportation costs, handling and receiving and feeding costs.

\subsection{Integrated Landscape Management}

Biorefineries that rely on local resources generally only process a single or small number of feedstock types. As such, crop rotation within the 50-mile radius of a biorefinery may negatively influence a consistent feedstock supply and is thus not always feasible. Co-locating the biorefinery with the feedstock supply does not necessarily encourage sustainable agriculture practices. The depot concept facilitates sustainable land practices and allows biorefineries to be efficiently sited and optimized for market demand, distribution infrastructure, proximity to utilities, and access to skilled workers.

As depots enable the system to use various feedstocks from a wider sourcing range, different cropping system can be applied. This includes areas outside the typical "rule of thumb" 50-mile biorefinery sourcing radius (i.e., the so-called 'geographically stranded' feedstock producers).

The incorporation of dedicated herbaceous energy crops, such as switchgrass, into row crop landscapes (e.g., corn) is one potential option to expand the biorefinery feedstock supply while at the same time increasing biomass yields, benefiting soil and water quality, and increasing biodiversity. Bonner et al. 2014 demonstrate how subfield decision making can be used to target candidate areas for conversion to energy crop production in a test area in Hardin County, Iowa. The study integrates switchgrass into subfield landscape positions where corn grain is modeled to return a net economic loss. Results show that switchgrass integration has the potential to increase sustainable biomass production by 48 to $99 \%$ (depending on the rigor of conservation practices applied to corn stover collection) while also improving field level profitability. While the candidate land area is highly sensitive to grain price and dependent on the acceptable net profit for corn production. Bonner et al. 2014 essentially prove that switchgrass can be economically incorporated into row crop landscapes when management decisions are applied at a subfield scale.

\subsection{Reducing Operational Risks}

The temporal and spatial variability of feedstock supply to biorefineries (due to yield variations, incremental weather, etc.) creates uncertainties and is recognized as an investment risk by financial institutions. Investment risks directly translate into loan interest rates. The advanced system reduces the variability of feedstock supply by allowing wider sourcing ranges. This reduces associated project risks and will be reflected in a lower annual percentage rate (APR) for financing biorefineries. Jacobson and Cafferty 2013 calculated a US\$350 million reduction in interest paid over a 20 -year lifespan for a $\$ 500$ million dollar facility should the investment loan rate drop from $10 \%$ to $5 \%$. This translates roughly into US $\$ 0.25$ per gallon of fuel produced. 
Furthermore, advanced system preprocessing reduces the storage footprint and environmental impacts, such as fire hazards, rodent infestation, and localized odors normally associated with large-scale storage of non-aerobically stable feedstock in conventional systems. 


\section{Optional Depot Configurations}

\subsection{Depot Concepts}

Traditional thinking suggests biorefinery locations in high yield areas are designed to handle single feedstock of similar format such as corn stover or wheat straw bales (Carolan et al. 2007, Hess et al. 2009). More recent insights however indicate that with the support of depots, biorefineries could be built almost anywhere, including lower yield areas (Argo et al. 2013), where a network of biomass depots would supply biorefineries with sufficient feedstock, possibly from different biomass in a variety of forms (e.g., square and/or round bales, chipped, bundled, raw, etc.). As a result, a depot could take on many forms.

To achieve the supply system benefits discussed in Section 3, a standard depot must at least include particle size reduction, moisture mitigation, and densification. To address feedstock quality specifications to improve functions at the biorefinery, quality depots may include additional preprocessing steps (e.g., leaching, chemical treatment, or washing). These two distinct set-ups characterize the potential structure of a depot (see Table 4:1 for an overview)

Standard Depot: The primary function of the Standard Depot is to improve feedstock stability (for storage), increase bulk density (for transport), improve flowability (for stable in-feed rates), and reduce DML. Influencing feedstock quality is a result of these activities rather than a primary target of the operation. Passive quality management is optionally possible via feedstock blending.

Indirect quality impacts include, for example, drying, which is done to prevent DML. Consistent moisture levels however also benefit conversion efficiency and improve in-feed. Pelleting is done to increase bulk density and transportability, a key aspect in de-risking the feedstock supply system (Lamers et al. 2014). At the same time, using pelleted feedstock also reduces contamination as it sterilizes (through compression and drying). Small diameter components, including impurities such as soil are drained in the liquor stream of the conversion pretreatment steps (e.g., deacetylation) (Naegle 2014).

The organizational structure of a Standard Depot can be independent from the biorefinery. While the biorefinery may own one or several Standard Depots, the depots could also be owned and operated by farmer cooperatives, in-line with the historical growth of the U.S. grain elevators (see Section 6.3 for a wider discussion on ownership and industry trends). The location decision for a depot is driven by the feedstock supply and existing logistical infrastructure (e.g., rail lines, shipping terminals) and other factors (e.g., socio-economic). It becomes more independent from the biorefinery location as the improved feedstock material can be transported over long distances with minimal additional costs. This decentralizes biorefinery locations and also incorporates biomass from low-yield areas that would currently be too costly for a conventional supply system.

Quality Depot: A Quality Depot actively addresses feedstock quality aspects specific to the enduse market it targets, e.g., cellulosic biorefineries, animal feed, or the heat and power sector. It produces enhanced feedstock (with lower contamination levels) or even process intermediates and thus reduces the pretreatment requirements at the client facility. To match its final markets, various kinds of pretreatment steps are possible within an advanced depot. Thermal pretreatment technologies (e.g., torrefaction) create feedstock with structural homogeneity and superior 
handling, milling, and co-firing properties. Chemical pretreatment changes the composition and structure of the biomass. This reduces the energy required to grind or densify the feedstock, improves flowability and storage stability, and removes contaminants detrimental to downstream biorefinery processes.

Participants of an INL organized workshop on densification technologies (DOE 2012) stated that chemical pretreatment has the potential to improve feedstock value for biochemical, thermochemical, and biopower conversion processes, as well as improve feedstock stability. At the same time, participants were divided as to where chemical pretreatment would be best located, with suggestions for both decentralized depots and proximate to the biorefinery.

Table 4:1. Comparison of depot concepts and their main characteristics. A standard depot is focused on drying and densifying while the quality depot include more aggressive quality processes such as mechanical and chemical preconversion.

\begin{tabular}{|c|c|c|}
\hline & Standard Depot & Quality Depot \\
\hline Primary function & $\begin{array}{l}\text { Improve feedstock stability, } \\
\text { storability, flowability, bulk } \\
\text { density by creating physically } \\
\text { (and chemically) homogeneous } \\
\text { feedstock }\end{array}$ & $\begin{array}{l}\text { In addition to the standard } \\
\text { function: Create on-spec } \\
\text { feedstock by actively } \\
\text { addressing feedstock quality }\end{array}$ \\
\hline Secondary function & & $\begin{array}{l}\text { In addition to the standard } \\
\text { function: Create intermediates } \\
\text { that meet specific biorefinery } \\
\text { needs and reduce } \\
\text { preprocessing intensity } \\
\text { downstream }\end{array}$ \\
\hline Location & \multicolumn{2}{|c|}{$\begin{array}{l}\text { Driven by feedstock supply, logistical infrastructure, community } \\
\text { support, social capital, potential link to existing industry (e.g., } \\
\text { agriculture or wood processing), low energy prices }\end{array}$} \\
\hline Feedstock quality control & Only passive via blending & Active control \\
\hline Technologies applied & $\begin{array}{l}\text { Mechanical and thermal } \\
\text { preprocessing (grinding, } \\
\text { drying, pelleting) }\end{array}$ & $\begin{array}{l}\text { Mechanical and thermal } \\
\text { preprocessing plus } \\
\text { chemical/thermochemical } \\
\text { preconversion }\end{array}$ \\
\hline Status/timeline for adoption & $\begin{array}{l}\text { Already applied in woody } \\
\text { biomass industry, pilot scale } \\
\text { for herbaceous biomass }\end{array}$ & Pilot scale (expected) \\
\hline Other & $\begin{array}{l}\text { Moisture control (quality } \\
\text { aspect) is done to prevent dry } \\
\text { matter loss and reach primary } \\
\text { goals }\end{array}$ & $\begin{array}{l}\text { Active management of } \\
\text { feedstock specifics allows } \\
\text { advanced depots to target } \\
\text { different end-use markets } \\
\text { (fodder, energy, plastics, etc.) }\end{array}$ \\
\hline
\end{tabular}

\subsection{Standard Depot Scenarios}

As stated previously, the Standard Depot classification is meant to address feedstock stability, bulk density, and flowability issues to obtain benefits outline in Section 3. The process flow includes particle size reduction, moisture mitigation and densification. An example of a Standard 
Depot is a conventional pelleting process (CPP) involving two stage size reduction (grinding), drying, and pelleting.

Additional modifications within a Standard Depot could be made to make the process more efficient. Examples of such modifications could include a high moisture pelleting process (HMPP) and a HMPP plus fractional milling (HMPPFM). These vary in process sequence, dryer type and size compared to the conventional pelleting process (CPP).

Conventional Pelleting Process (CPP): Conventional biomass pellet production includes initial size reduction to a $<2$-in. particle size, followed by drying to 10 to $12 \%$ moisture content (MC) (wet basis) using a rotary dryer. The dried biomass is then passed through a second stage grinding process to reduce the particle size to $<3 / 16$-in. (typically to $2 \mathrm{~mm}$ ), steam conditioned, and pelletized (INL 2013). The steam conditioning prior to pelleting increases moisture content, which helps to gelatinize the starch, denature protein, and change the glass transition temperature of lignin (Tumuluru et al. 2014). Figure 4:1 outlines the various unit operations and energy consumption associated with each step. Drying is the major energy consumption unit operation in this process, accounting for about $70 \%$ of the total pelleting energy.

Conventional milling operations involve two sequential size-reduction steps to arrive at the final particle-size specification (INL 2013). The first stage of the size reduction process takes the asreceived biomass and converts it through grinding or chipping into a product that can be further preprocessed. The first stage size reduction is followed by drying and second-stage size reduction. The configuration of the first-stage grinding/chipping process uses a 2- to 3-in. screen for coarse size reduction. This size and type of screen provides enough size reduction for subsequent drying and final grinding. The role of the second-stage grinder is to reduce the particle size further in order to meet particle size distribution requirements for pelleting. A typical second-stage size reduction process will use a 0.75 - to 1 -in. screen to produce a mean particle size of 0.1 - to 0.15 -in. Material that flows through a screen is smaller than the actual screen size, as is demonstrated by the distribution seen above.

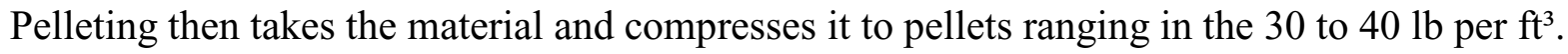
These pellets are hydrophobically stable and are high quality to sustain transportation with minimum losses.

High-Moisture Pelleting Process (HMPP): In the HMPP depot configuration, high-moisture $(<30 \% \mathrm{MC})$ biomass is preheated and pelletized instead of dried prior to pelleting as in the CPP. The final pellets are then dried in a (vertical) grain dryer to reduce the moisture and stabilize the pellets. This option offers cost reductions as it eliminates the energy intensive, expensive, horizontal (larger footprint) rotary drying process prior to pelleting. The high-temperature (typically 160 to $180^{\circ} \mathrm{C}$ ) drying step is replaced with a low-temperature (approximately $80^{\circ} \mathrm{C}$ ), short duration (typically several minutes) preheating step. The combination of preheating with the additional frictional heat generated in the pellet die and further cooling results in a reduction of feedstock moisture content by about $5 \%$ to $10 \%$ to produce partially dried pellets. These partially dried pellets still have a high moisture content and require further drying to under $9 \%$ moisture content for safe storage and transportation (Tumuluru et al. 2014). This reduction in moisture in the partially dried pellets can be achieved using low-cost and energy-efficient grain or belt dryers. Figure 4:1 indicates the various unit operations and energy consumption associated with each step. HMPP does not include the addition of a binder. 

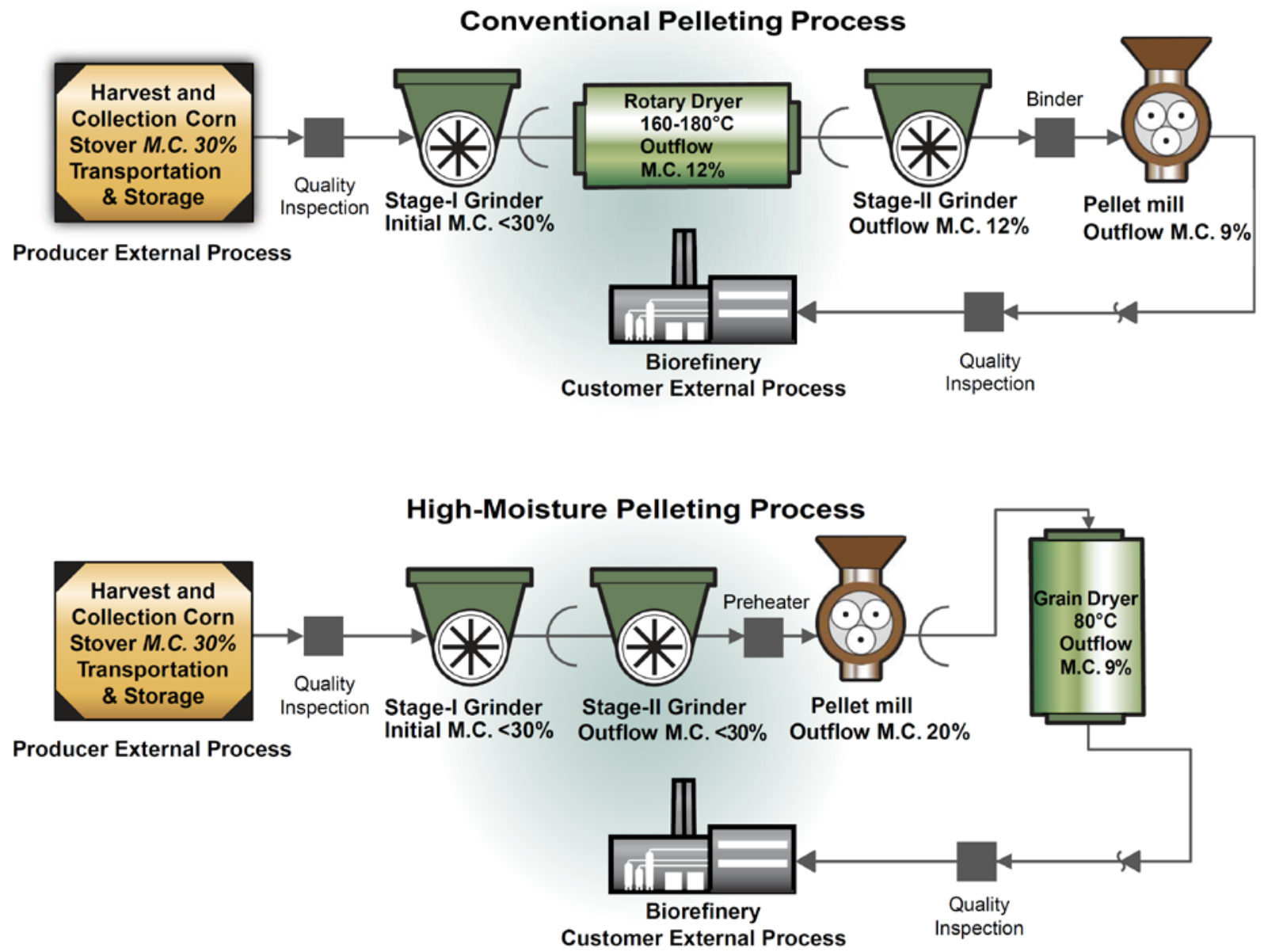

High-Moisture Pelleting Process with Fractional Milling

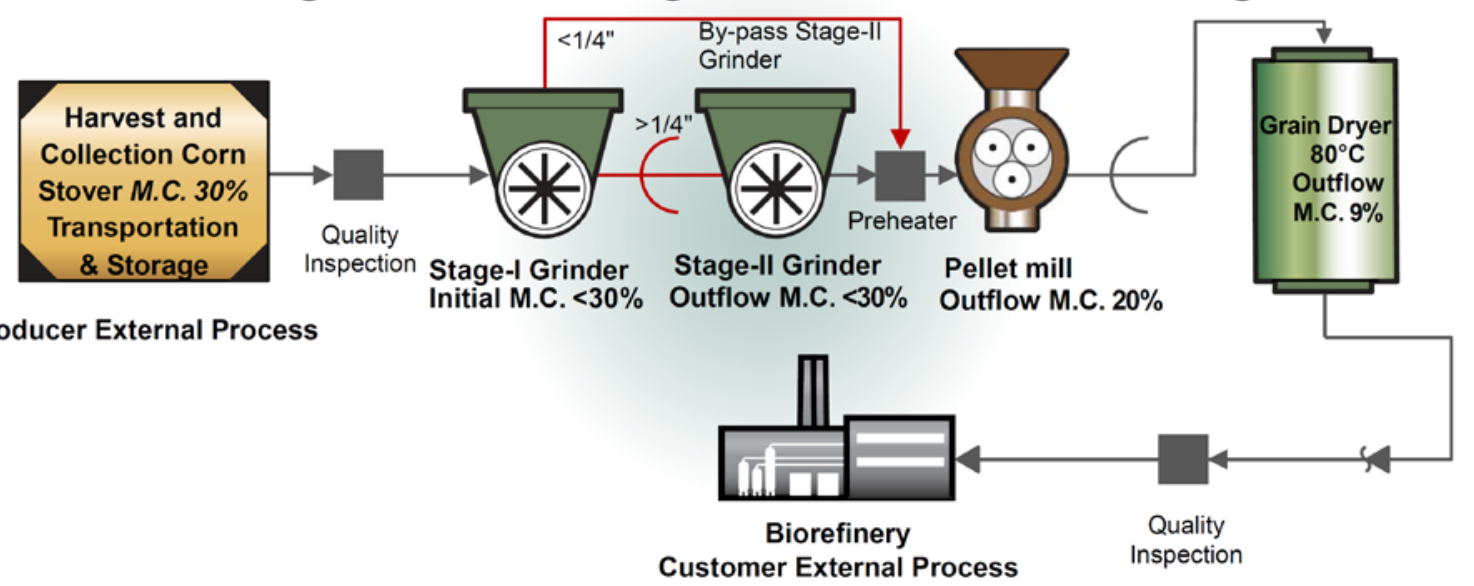

Figure 4:1. The three Standard Depot configurations.

High-Moisture Pelleting Process with Fractional Milling (HMPPFM): While conventional milling processes achieve the desired mean particle size, they often have wide particle-size distributions, with a large percentage of undersized particles (fines). INL research showed that after first-stage grinding much of the material already meets particle-size specifications (INL 2013). In the conventional, two-stage grinding approach, the stage-one grinded material would 
be further processed in the second-stage grinder resulting in over-processing, generating more fines, and unnecessarily increasing grinding energy consumption. The HMPPFM solves this problem by introducing a separation step between the first and second-stage grinding operations to remove the material that already meets the size specification (Figure 4:1). This way only the oversized material is passed along for further size reduction, which reduces the cost of the second grind by reducing the amount of material that flows through it and also removes the fines that tend to bog down the grinder.

With conventional, two-stage milling, the choice of the screen size in the first-stage mill is based on balancing energy consumption and mass flow rates through the two operations. With larger first-stage screen sizes, the second-stage grinder has to work harder, reducing its capacity and that of the upstream grinder feeding (INL 2013). Decoupling the two sequential grinding operations provides an opportunity to optimize the two systems independently.

Optimization of the two stage grinding process in the fractional milling design is accomplished by using a 6-in. screen to maximize throughput and to minimize the amount of fines produced (INL 2013). Hammer mill systems tend to be highly sensitive to biomass moisture content, with energy consumption increasing dramatically as moisture content increases. Therefore, when establishing the fractional milling design basis, targets were first set on a dry biomass scenario and extrapolated using more limited data sets to a higher moisture scenario.

\subsection{Quality Depot Scenarios}

Quality Depots may cover any preprocessing steps (e.g., leaching, chemical treatment, or washing) designed to preserve or enhance the quality aspects of the biomass. The next selection was based on conversion route relevance, data availability, and an economic pre-screening.

AFEX Pretreatment: Ammonia Fiber Expansion (AFEX) is a promising pretreatment that involves an ammonia-based process resulting in physical and chemical alterations to lignocellulosic biomass that improves their susceptibility to enzymatic attack (Bals et al. 2011) (Figure 4:2). AFEX pretreatment has increased glucan and xylan conversion and ethanol yields for a variety of feedstocks, including corn stover and switchgrass (Teymouri et al. 2005, Balan et al. 2009, Campbell et al. 2013).

As part of a depot concept, AFEX pretreatment of corn stover and switchgrass have shown to generate a higher return on investment compared to other depot configurations, e.g., wood-based pyrolysis facilities (Bals and Dale 2012). At the same time, AFEX depots in these designs also sold part of their output to animal feed operations (Carolan et al. 2007).

Similar to the Standard Depot, AFEX material needs to be pelleted prior to transport/distribution to biorefineries. ${ }^{2}$ Campbell et al. 2013 indicate that high-quality pellets (in terms of density and durability) can be produced after the AFEX process. The effects of different pelleting process conditions on the quality of pellets and sugar yields was further studied by Hoover et al. 2014 . Bals et al. 2014 suggest that AFEX pelleting could have additional advantages beyond improved logistical handling of biomass. Modeling enzymatic hydrolysis of pelleted AFEX-treated corn stover at high solid loadings, the authors found that water absorption and retention by the pellets was low compared to raw corn stover, which allowed enzymatic hydrolysis slurries to remain well mixed without the need for fed-batch addition. Pelleted AFEX-treated corn stover also

\footnotetext{
${ }^{2}$ AFEX material for animal feed operations is typically not pelleted (Bals and Dale 2012).
} 
achieved higher glucose and xylose yields, and slightly increased the initial rate of hydrolysis as compared to raw material (Bals et al. 2014).

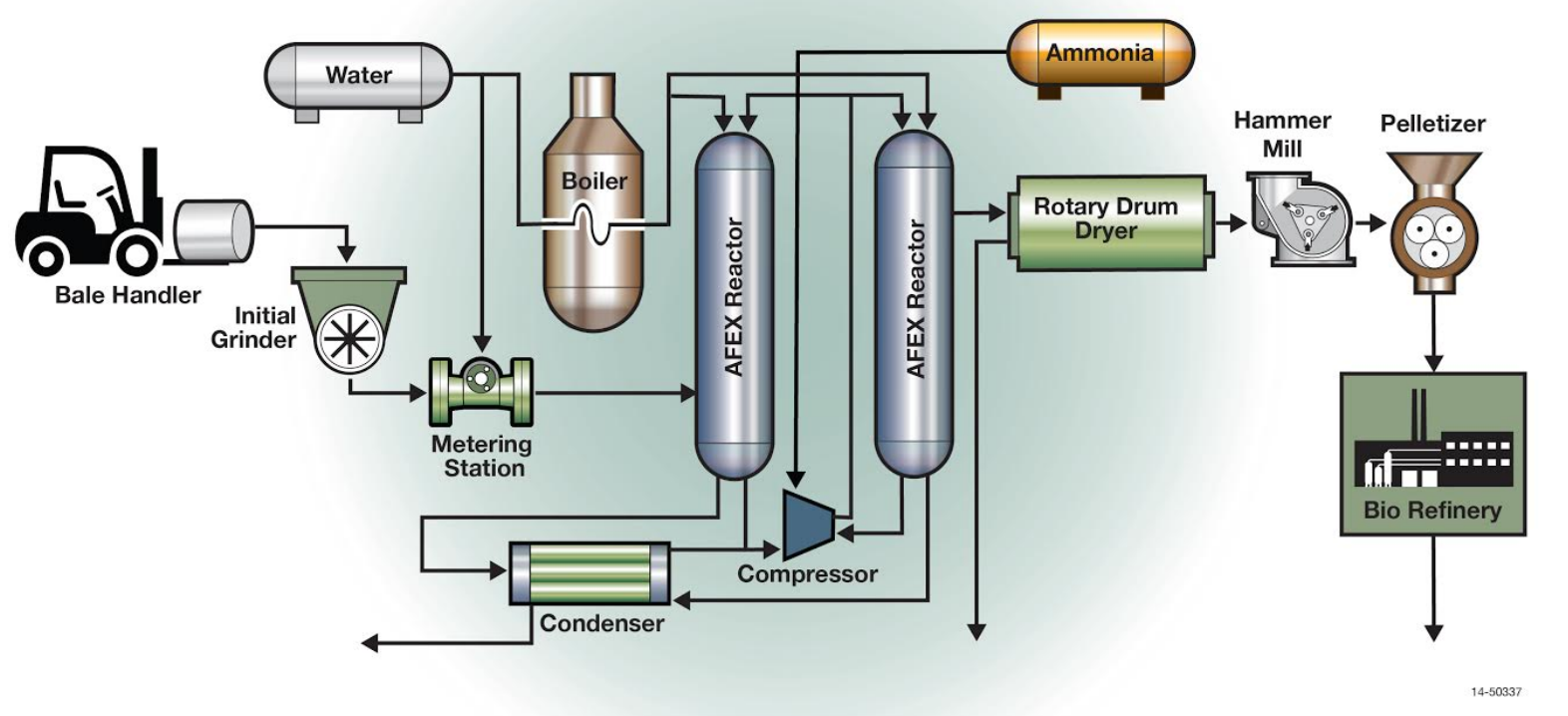

Figure 4:2. Ammonia Fiber Expansion (AFEX) process flow diagram (Source: MBI).

Deacetylation and Dilute-Acid Pretreatment: In addition to AFEX, we also investigated the option to evaluate the pretreatment options currently applied in the biological conversion route of sugars to hydrocarbons (and the prior enzymatic deconstruction of biomass to sugars) (Davis et al. 2013). In comparison to previous reports (e.g., Humbird et al. 2011), Davis et al. 2013 catalyzed pretreatment reactions first by using dilute sodium hydroxide, followed by dilute sulfuric acid. This two-stage design of dilute alkaline deacetylation combined with low acid pretreatment process steps has shown improvements in ethanol yields and calculated MFSP for cellulosic ethanol production (Shekiro et al. 2014). Investment costs for this pretreatment step in a biorefinery set-up with an annual feedstock demand of 724,000 DT sums up to US\$ 51,400,000 installed plus a waste water treatment (WWT) facility to manage the effluents from both steps for an additional US\$ 60,100,000 installed. Despite the significant difference in size to a depot with an annual production of 40,000 tons, the requirement of a WWT facility will not prove cost efficient for a single-depot. Unless effluents can be recycled within the process, much like the AFEX pretreatment step, several depots are combined, or directly connected to an existing WWT (e.g., at a biorefinery), the inclusion of this pretreatment step in decentralized depots appears unreasonable. 


\section{Results}

The depot equipment size was calculated based on depot capacity. In this report, we assume a maximum depot capacity of 10 DT/hour, which is the current design size for AFEX. The depots operate 8,000 hours a year, producing 80,000 DT annually (see Section 2). The individual depots are modular, i.e., in areas with high quantities of biomass, multiple depots would be built at the same location. Thus depot sizes grow in increments of $10 \mathrm{DT} /$ hour. We did not assume any cost savings for larger depot sizes but economies of scale may be possible.

\subsection{Standard Depot: Conventional Pelleting Process (CPP)}

\subsubsection{Herbaceous Biomass Case}

Table 5:1 lists the direct and indirect costs for equipment at a conventional pellet plant using corn stover, based on an operational capacity of 10 DT per hour.

Table 5:1. CPP total capital investment costs (herbaceous case).

\begin{tabular}{|c|c|c|}
\hline Direct Cost & (US\$) & \\
\hline Horizontal bale grinder & 810,400 & \\
\hline Rotary dryer & $1,579,200$ & \\
\hline Hammer mill & 515,200 & \\
\hline Pellet mill & 630,400 & \\
\hline Conveyor equipment $^{3}$ & 268,800 & \\
\hline Dust collection equipment ${ }^{4}$ & 286,400 & \\
\hline Surge bin & 96,800 & \\
\hline Miscellaneous equipment $^{5}$ & 84,000 & \\
\hline Total fixed capital cost & & $\$ 4,271,200$ \\
\hline Other Direct Cost & $\begin{array}{r}\text { (\% of total fixed capital } \\
\text { cost) }\end{array}$ & \\
\hline Instrumentation and control & $2 \%$ & \\
\hline Piping (installed) & $3 \%$ & \\
\hline Electrical (installed) & $2 \%$ & \\
\hline Building (including services) & $3 \%$ & \\
\hline Yard improvements & $2 \%$ & \\
\hline Service facilities (installed) & $8 \%$ & \\
\hline Land & $1 \%$ & \\
\hline Total other direct cost & $21 \%$ & $\$ 896,952$ \\
\hline Indirect Cost & $\begin{array}{r}\text { (\% of total fixed capital } \\
\text { cost) }\end{array}$ & \\
\hline Engineering and supervision & $4 \%$ & \\
\hline Construction expenses & $4 \%$ & \\
\hline Contractor's fee & $2 \%$ & \\
\hline Contingency & $5 \%$ & \\
\hline
\end{tabular}

${ }^{3}$ Schuon Twin Bale Infeed, Schuon Bale Merge, Schuon Single Bale Infeed

${ }^{4}$ Primary Cyclone, Material handling fan with dust hood,

${ }^{5}$ W\&B Twine Remover, Danske Moisture Meter, Dings Electro Magnet, Kelderman Baler Rejector 


\begin{tabular}{lrr}
\hline Total indirect cost & $15 \%$ & $\$ 640,680$ \\
\hline Total capital investment & $\$ 5,808,832$ \\
\hline
\end{tabular}

Table 5:2 portions the equipment costs by ownership and operating costs. The ownership costs are further split into Interest and Depreciation (I\&D) and Insurance, Housing and Taxes (IH\&T). The operation costs are broken into Repair and Maintenance (R\&M), Fuel, and Labor costs.

Table 5:2. CPP operating and fixed costs (US\$/DT) (herbaceous case).

\begin{tabular}{|c|c|c|c|c|c|c|}
\hline \multirow[b]{2}{*}{ Machine Type* } & \multicolumn{2}{|c|}{ Ownership cost } & \multicolumn{3}{|c|}{ Operating cost } & \multirow[b]{2}{*}{ Total } \\
\hline & I\&D & IH\&T & R\&M & Fuel & Labor & \\
\hline Horizontal bale grinder & 4.30 & 0.15 & 6.00 & 2.62 & 3.76 & 16.83 \\
\hline Rotary dryer & 1.63 & 0.29 & 0.26 & 19.65 & 2.93 & 24.74 \\
\hline Hammer mill & 1.25 & 0.09 & 1.43 & 5.10 & 3.76 & 11.63 \\
\hline Pellet mill & 0.84 & 0.06 & 0.70 & 4.91 & 1.17 & 7.68 \\
\hline Conveyor equipment $^{6}$ & 0.22 & 0.04 & 0 & 0.01 & 0 & 0.27 \\
\hline Dust collection equipment $^{7}$ & 0.23 & 0.04 & 0 & 0.51 & 0 & 0.78 \\
\hline Surge bin & 0.08 & 0.01 & 0 & 0.01 & 0 & 0.10 \\
\hline Miscellaneous equipment $^{8}$ & 0.15 & 0 & 0 & 0.02 & 0 & 0.17 \\
\hline Total & 8.70 & 0.68 & 8.39 & 32.81 & 11.62 & 62.20 \\
\hline
\end{tabular}

*Legend (see Appendix for Formulae): I\&D: Interest and Depreciation; IH\&T: Insurance, Housing and Taxes; R\&M: Repairs and Maintenance

\subsubsection{Woody Biomass Case}

In this section we quantify the costs assuming that pulpwood will be preprocessed at the CPP depot. For woody feedstock, first stage grinding is done during the harvesting and collecting process (or at the landing site). Therefore, first stage grinding is not considered. Table 5:3 lists the equipment costs for a conventional pellet plant based on an operational capacity of 10 DT/hour.

\footnotetext{
${ }^{6}$ Schuon Twin Bale Infeed, Schuon Bale Merge, Schuon Single Bale Infeed

${ }^{7}$ Primary Cyclone, Material handling fan with dust hood,

${ }^{8}$ W\&B Twine Remover, Danske Moisture Meter, Dings Electro Magnet, Kelderman Baler Rejector
} 
Table 5:3. CPP total capital investment costs (woody case).

Direct Cost

(US\$)

\begin{tabular}{lr}
\hline Rotary dryer & $1,579,200$ \\
\hline Hammer mill & 515,200 \\
\hline Pellet mill & 630,400 \\
\hline Conveyor equipment & 146,400 \\
\hline Dust collection equipment & \\
\hline Surge bin & 286,400 \\
\hline Miscellaneous equipment $^{10}$ & 96,800 \\
\hline
\end{tabular}

Total fixed capital cost

$\$ 3,295,200$

Other Direct Cost

\begin{tabular}{lll}
\hline Instrumentation and control & $2 \%$ \\
\hline Piping (installed) & $3 \%$ & \\
\hline Electrical (installed) & $2 \%$ & \\
\hline Building (including services) & $3 \%$ & \\
\hline Yard improvements & $2 \%$ & \\
\hline Service facilities (installed) & $8 \%$ & \\
\hline Land & $1 \%$ & \\
\hline Total other direct cost & $21 \%$ & $\$ 691,992$
\end{tabular}

Indirect Cost (\% of total fixed capital cost)

\begin{tabular}{lcc}
\hline Engineering and supervision & $4 \%$ & \\
\hline Construction expenses & $4 \%$ & \\
\hline Contractor's fee & $2 \%$ & \\
\hline Contingency & $5 \%$ & \\
\hline Total indirect cost & $15 \%$ & $\$ 494,280$ \\
\hline Total capital investment & & $\$ 4,481,472$
\end{tabular}

${ }^{9}$ Primary Cyclone, Material handling fan with dust hood

${ }^{10} 100$ ton Truck Scale, Danske Moisture Meter, Dings Electro Magnet 
Table 5:4. CPP operating and fixed costs (US\$/DT) (woody case).

\begin{tabular}{|c|c|c|c|c|c|c|}
\hline \multirow[b]{2}{*}{ Machine Type } & \multicolumn{2}{|c|}{ Ownership cost } & \multicolumn{3}{|c|}{ Operating Cost } & \multirow[t]{2}{*}{ Total } \\
\hline & I\&D & IH\&T & R\&M & Fuel & Labor & \\
\hline Rotary dryer & 1.63 & 0.29 & 0.26 & 26.17 & 2.93 & 31.28 \\
\hline Hammer mill & 1.25 & 0.09 & 1.43 & 2.81 & 3.76 & 9.34 \\
\hline Pellet mill & 0.84 & 0.06 & 0.7 & 3.21 & 1.17 & 5.98 \\
\hline Conveyor equipment ${ }^{11}$ & 0.61 & 0.06 & 0.09 & 0.80 & 0.24 & 1.80 \\
\hline Dust collection equipment ${ }^{12}$ & 0.23 & 0.04 & 0 & 0.51 & 0 & 0.78 \\
\hline Surge bin & 0.08 & 0.01 & 0 & 0.01 & 0 & 0.10 \\
\hline Miscellaneous equipment ${ }^{13}$ & 0.08 & 0 & 0 & 0 & 0 & 0.08 \\
\hline Total & 4.72 & 0.55 & 2.48 & 33.51 & 8.10 & 49.36 \\
\hline
\end{tabular}

\subsection{Standard Depot: High-Moisture Pelleting Process (HMPP)}

Total capital investment costs for a HMPP depot are shown in Table 5:5. The various operating and fixed costs (in US\$/DT) are given in Table 5:6. Compared to CPP, HMPP is more cost efficient due to a decrease in total fixed and operation costs by about US\$32.40 per DT. The majority of this gain is linked to the use of energy efficient dryers like grain dryers over the more expensive rotary dryers used in the CPP depot. Results shows that estimated fixed and operations costs of the HMPP depot is US\$29.80 per DT.

\footnotetext{
${ }^{11}$ Crumbler, 30000 BPH $110 \mathrm{ft}$ En Masse Conveyor,

${ }^{12}$ Primary Cyclone, Material handling fan with dust hood,

${ }^{13} 100$ ton Truck Scale, Danske Moisture Meter, Dings Electro Magnet
} 
Table 5:5. HMPP total capital investment costs.

\begin{tabular}{|c|c|c|}
\hline Direct Cost & (US\$) & \\
\hline Horizontal bale grinder & 324,000 & \\
\hline Hammer mill & 206,400 & \\
\hline Pellet mill & 630,400 & \\
\hline Cross flow pellet dryer & 64,000 & \\
\hline Conveyor equipment $^{14}$ & 268,800 & \\
\hline Dust collection equipment ${ }^{15}$ & 286,400 & \\
\hline Surge bin & 96,800 & \\
\hline Miscellaneous equipment ${ }^{16}$ & 84,000 & \\
\hline Total fixed capital cost & & $\$ 1,960,800$ \\
\hline Other Direct Cost & $\begin{array}{l}\text { (\% of total fixed capital } \\
\text { cost) }\end{array}$ & (US\$) \\
\hline Instrumentation and control & $2 \%$ & \\
\hline Piping (installed) & $3 \%$ & \\
\hline Electrical (installed) & $2 \%$ & \\
\hline Building (including services) & $3 \%$ & \\
\hline Yard improvements & $2 \%$ & \\
\hline Service facilities (installed) & $8 \%$ & \\
\hline Land & $1 \%$ & \\
\hline Total other direct cost & $21 \%$ & $\$ 411,768$ \\
\hline Indirect Cost & $\begin{array}{l}\text { (\% of total fixed capital } \\
\text { cost) }\end{array}$ & (US\$) \\
\hline Engineering and supervision & $4 \%$ & \\
\hline Construction expenses & $4 \%$ & \\
\hline Contractor's fee & $2 \%$ & \\
\hline Contingency & $5 \%$ & \\
\hline Total indirect cost & $15 \%$ & $\$ 294,120$ \\
\hline Total Capital Investment & & $\$ 2,666,688$ \\
\hline
\end{tabular}

${ }^{14}$ Schuon Twin Bale Infeed, Schuon Bale Merge, Schuon Single Bale Infeed

${ }^{15}$ Primary Cyclone, Material handling fan with dust hood,

${ }^{16}$ W\&B Twine Remover, Danske Moisture Meter, Dings Electro Magnet, Kelderman Baler Rejector 
Table 5:6. HMPP fixed and operations costs (US\$/DT).

\begin{tabular}{|c|c|c|c|c|c|c|}
\hline \multirow[b]{2}{*}{ Machine Type } & \multicolumn{2}{|c|}{ Ownership Cost } & \multicolumn{3}{|c|}{ Operating Cost } & \multirow[b]{2}{*}{ Total } \\
\hline & I\&D & IH\&T & R\&M & Fuel & Labor & \\
\hline Horizontal bale grinder & 1.72 & 0.06 & 2.40 & 2.62 & 1.50 & 8.30 \\
\hline Hammer mill & 0.50 & 0.04 & 0.57 & 7.00 & 1.50 & 9.61 \\
\hline Pellet mill & 0.84 & 0.06 & 0.70 & 3.27 & 1.17 & 6.04 \\
\hline Cross flow pellet dryer & 0.07 & 0.01 & 0.01 & 3.27 & 1.17 & 4.53 \\
\hline Conveyor equipment $^{17}$ & 0.22 & 0.04 & 0 & 0.01 & 0 & 0.27 \\
\hline Dust collection equipment ${ }^{18}$ & 0.23 & 0.04 & 0 & 0.51 & 0 & 0.78 \\
\hline Surge bin & 0.08 & 0.01 & 0 & 0.01 & 0 & 0.10 \\
\hline Misc equipment ${ }^{19}$ & 0.15 & 0 & 0 & 0.02 & 0 & 0.17 \\
\hline Total & 3.81 & 0.26 & 3.68 & 16.71 & 5.34 & 29.80 \\
\hline
\end{tabular}

\subsection{Standard Depot: High-Moisture Pelleting Process plus Fractional Milling (HMPPFM)}

Table 5:7 and 5:8 show the total capital investment costs and the various operating and fixed costs in US\$/DT for the production of pellets using HMPPFM. Compared to HMPP, HMPPFM is more cost efficient. This is achieved by reducing grinding energy consumption.

\footnotetext{
${ }^{17}$ Schuon Twin Bale Infeed, Schuon Bale Merge, Schuon Single Bale Infeed

${ }^{18}$ Primary Cyclone, Material handling fan with dust hood,

${ }^{19}$ W\&B Twine Remover, Danske Moisture Meter, Dings Electro Magnet, Kelderman Baler Rejector
} 
Table 5:7. HMPPFM capital investment costs.

\begin{tabular}{|c|c|c|}
\hline Direct Cost & (US\$) & \\
\hline Horizontal bale grinder & 791,200 & \\
\hline Hammer mill & 103,200 & \\
\hline Pellet mill & 630,400 & \\
\hline Cross flow pellet dryer & 64,000 & \\
\hline Conveyor equipment $^{20}$ & 268,800 & \\
\hline Dust collection equipment ${ }^{21}$ & 286,400 & \\
\hline Surge bin & 96,800 & \\
\hline Miscellaneous equipment ${ }^{22}$ & 84,000 & \\
\hline Total fixed capital cost & & $\$ 2,324,800$ \\
\hline Other Direct Cost & $\begin{array}{c}\text { (\% of total fixed } \\
\text { capital cost) }\end{array}$ & (US\$) \\
\hline Instrumentation and control & $2 \%$ & \\
\hline Piping(installed) & $3 \%$ & \\
\hline Electrical (installed) & $2 \%$ & \\
\hline Building (including services) & $3 \%$ & \\
\hline Yard improvements & $2 \%$ & \\
\hline Service facilities (installed) & $8 \%$ & \\
\hline Land & $1 \%$ & \\
\hline Total other direct cost & $21 \%$ & $\$ 488,208$ \\
\hline Indirect Cost & $\begin{array}{c}\text { (\% of total fixed } \\
\text { capital cost) }\end{array}$ & (US\$) \\
\hline Engineering and supervision & $4 \%$ & \\
\hline Construction expenses & $4 \%$ & \\
\hline Contractor's fee & $2 \%$ & \\
\hline Contingency & $5 \%$ & \\
\hline Total indirect cost & $15 \%$ & $\$ 348,720$ \\
\hline Total capital investment & & $\$ 3,161,728$ \\
\hline
\end{tabular}

${ }^{20}$ Schuon Twin Bale Infeed, Schuon Bale Merge, Schuon Single Bale Infeed

${ }^{21}$ Primary Cyclone, Material handling fan with dust hood,

${ }^{22}$ W\&B Twine Remover, Danske Moisture Meter, Dings Electro Magnet, Kelderman Baler Rejector 
Table 5:8. HMPPFM fixed and operations costs (US\$/DT).

\begin{tabular}{|c|c|c|c|c|c|c|}
\hline \multirow{2}{*}{ Machine Type } & \multicolumn{2}{|c|}{ Ownership cost } & \multicolumn{3}{|c|}{ Operating Cost } & \multirow{2}{*}{ Total } \\
\hline & I\&D & IH\&T & R\&M & Fuel & Labor & \\
\hline Horizontal bale grinder & 1.51 & 0.06 & 5.78 & 2.92 & 0.94 & 11.21 \\
\hline Hammer mill & 0.25 & 0.02 & 0.29 & 3.50 & 0.75 & 4.81 \\
\hline Pellet mill & 0.84 & 0.06 & 0.70 & 3.27 & 1.17 & 6.04 \\
\hline Cross flow pellet dryer & 0.07 & 0.01 & 0.01 & 3.27 & 1.17 & 4.53 \\
\hline Conveyor equipment $^{23}$ & 0.22 & 0.04 & 0 & 0.01 & 0 & 0.27 \\
\hline Dust collection equipment ${ }^{24}$ & 0.23 & 0.04 & 0 & 0.51 & 0 & 0.78 \\
\hline Surge bin & 0.08 & 0.01 & 0 & 0.01 & 0 & 0.10 \\
\hline Miscellaneous equipment ${ }^{25}$ & 1.05 & 0.15 & 0 & 0 & 0.02 & 0 \\
\hline Total & 3.35 & 0.24 & 6.78 & 13.51 & 4.03 & 27.91 \\
\hline
\end{tabular}

\subsection{Quality Depot: AFEX}

Table 5:9 and Table 5:10 show the total capital investment costs and the various operating and fixed costs (in US\$/DT) for the production of AFEX pellets. Compared to the Standard Depot configurations, the AFEX pretreatment option requires more process steps, and thus more equipment, which increases the total investment costs. The eventual costs per DT output however are relatively competitive to the CPP due to higher throughput rates and lower repair and maintenance costs per DT output. For equipment details see Appendix.

\footnotetext{
${ }^{23}$ Schuon Twin Bale Infeed, Schuon Bale Merge, Schuon Single Bale Infeed

${ }^{24}$ Primary Cyclone, Material handling fan with dust hood,

${ }^{25}$ W\&B Twine Remover, Danske Moisture Meter, Dings Electro Magnet, Kelderman Baler Rejector
} 
Table 5:9. AFEX total capital investment costs.

\begin{tabular}{|c|c|c|}
\hline Direct Cost & (US\$) & (US\$) \\
\hline AFEX grinder & 296,000 & \\
\hline Chemical pretreatment & $5,129,600$ & \\
\hline AFEX dryer & $2,384,800$ & \\
\hline AFEX hammer mill & 236,000 & \\
\hline AFEX pellet mill & $1,089,600$ & \\
\hline Conveyor equipment $^{26}$ & 268,800 & \\
\hline Dust collection equipment ${ }^{27}$ & 286,400 & \\
\hline Surge bin & 96,800 & \\
\hline Miscellaneous equipment ${ }^{28}$ & 84,000 & \\
\hline Total fixed capital cost & & $\$ 9,872,000$ \\
\hline Other Direct Cost & (\% of total fixed capital cost) & \\
\hline Instrumentation and control & $2 \%$ & \\
\hline Piping (installed) & $3 \%$ & \\
\hline Electrical (installed) & $2 \%$ & \\
\hline Building (including services) & $3 \%$ & \\
\hline Yard improvements & $2 \%$ & \\
\hline Service facilities (installed) & $8 \%$ & \\
\hline Land & $1 \%$ & \\
\hline Total other direct cost & $21 \%$ & $\$ 2,073,120$ \\
\hline Indirect Cost & (\% of total fixed capital cost) & \\
\hline Engineering and supervision & $4 \%$ & \\
\hline Construction expenses & $4 \%$ & \\
\hline Contractor's fee & $2 \%$ & \\
\hline Contingency & $5 \%$ & \\
\hline Total indirect cost & $15 \%$ & $\$ 1,480,800$ \\
\hline Total capital investment & & $\$ 13,425,920$ \\
\hline
\end{tabular}

${ }^{26}$ Schuon Twin Bale Infeed, Schuon Bale Merge, Schuon Single Bale Infeed

${ }^{27}$ Primary Cyclone, Material handling fan with dust hood,

${ }^{28}$ W\&B Twine Remover, Danske Moisture Meter, Dings Electro Magnet, Kelderman Baler Rejector 
Table 5:10. AFEX fixed and operations costs (US\$/DT).

\begin{tabular}{lcrrrrr}
\hline \multirow{2}{*}{ Machine Type } & \multicolumn{2}{c}{ Ownership Cost } & \multicolumn{2}{c}{ Operating Cost } & Total \\
\cline { 2 - 6 } & I\&D & IH\&T & R\&M & Fuel & Labor & 3.18 \\
\hline AFEX grinder & 1.13 & 0.05 & 0.04 & 1.14 & 0.82 & 30.35 \\
\hline Chemical pretreatment & 4.63 & 0.82 & 1.18 & 22.90 & 0.82 & 25.46 \\
\hline AFEX dryer & 2.51 & 0.36 & 0.03 & 19.63 & 2.93 & 3.73 \\
\hline AFEX hammer mill & 0.97 & 0.02 & 0.03 & 1.89 & 0.82 & 5.75 \\
\hline AFEX pellet mill & 1.10 & 0.08 & 0.02 & 3.91 & 0.64 & 0.27 \\
\hline Conveyor equipment & 3.36 & 0.22 & 0.04 & 0 & 0.01 & 0.78 \\
\hline Dust collection equipment & 3.58 & 0.23 & 0.04 & 0 & 0.51 & 0 \\
\hline Surge bin & 0.07 & 0.01 & 0 & 0 & 0.08 \\
\hline Miscellaneous equipment & 0.15 & 0 & 0 & 0.02 & 0 & 0.17 \\
\hline Total & $\mathbf{1 1 . 0 1}$ & $\mathbf{1 . 4 2}$ & $\mathbf{1 . 3 0}$ & $\mathbf{5 0 . 0 1}$ & $\mathbf{6 . 0 3}$ & $\mathbf{6 9 . 7 7}$ \\
\hline
\end{tabular}

\subsection{Overall Comparison}

The overall comparison for the configurations shows the cost savings achieved in total investment and per unit DT from the CPP, to the HMPP, and HMPPFM depots (Figure 5:1). Improved process flows in the HMPP and HMPPFM can reduce unit output costs by over 50\% in comparison to the standard CPP depot (Figure 5:2).

The cost reductions are achieved by several improvements. First, the transition from a rotary dryer in CPP to a cross flow pellet dryer in HMPP and HMPPFM. Secondly, by increasing the machine capacity, reducing the number of equipment necessary to process material, consequently lowering capital costs. Note that the capacity of the first stage grind for CPP, HMPP, and HMPPMF are 2 DT per hour, 5 DT per hour, and 8 DT per hour respectively (see Appendix for details). Finally, the addition of fractional milling in HMPPFM increases capital costs, but leads to lower operating costs due to an increase in energy efficiency.

The chemical pretreatment in the AFEX configuration drives total fixed investment costs to about US\$ 13.4 million which is then also reflected in the higher other direct and indirect costs. 


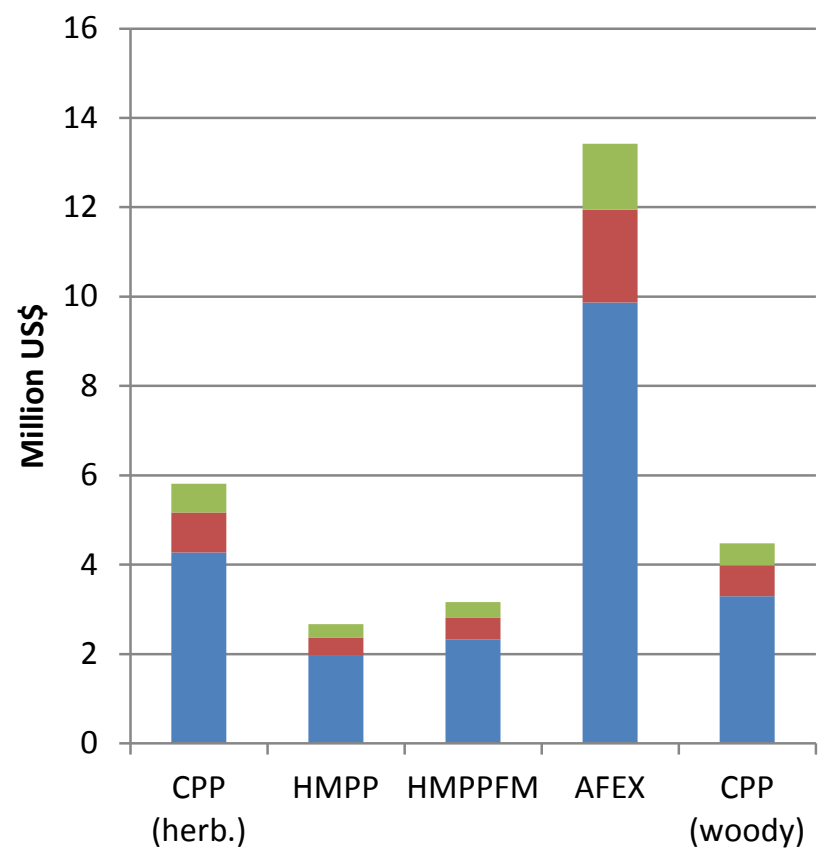

Total Indirect cost (15\% total fixed capital cost)

- Total Other Direct Cost (21\% of total fixed capital cost)

- Total fixed capital Cost (US\$)

Figure 5:1. Comparison of total investment costs per configuration.

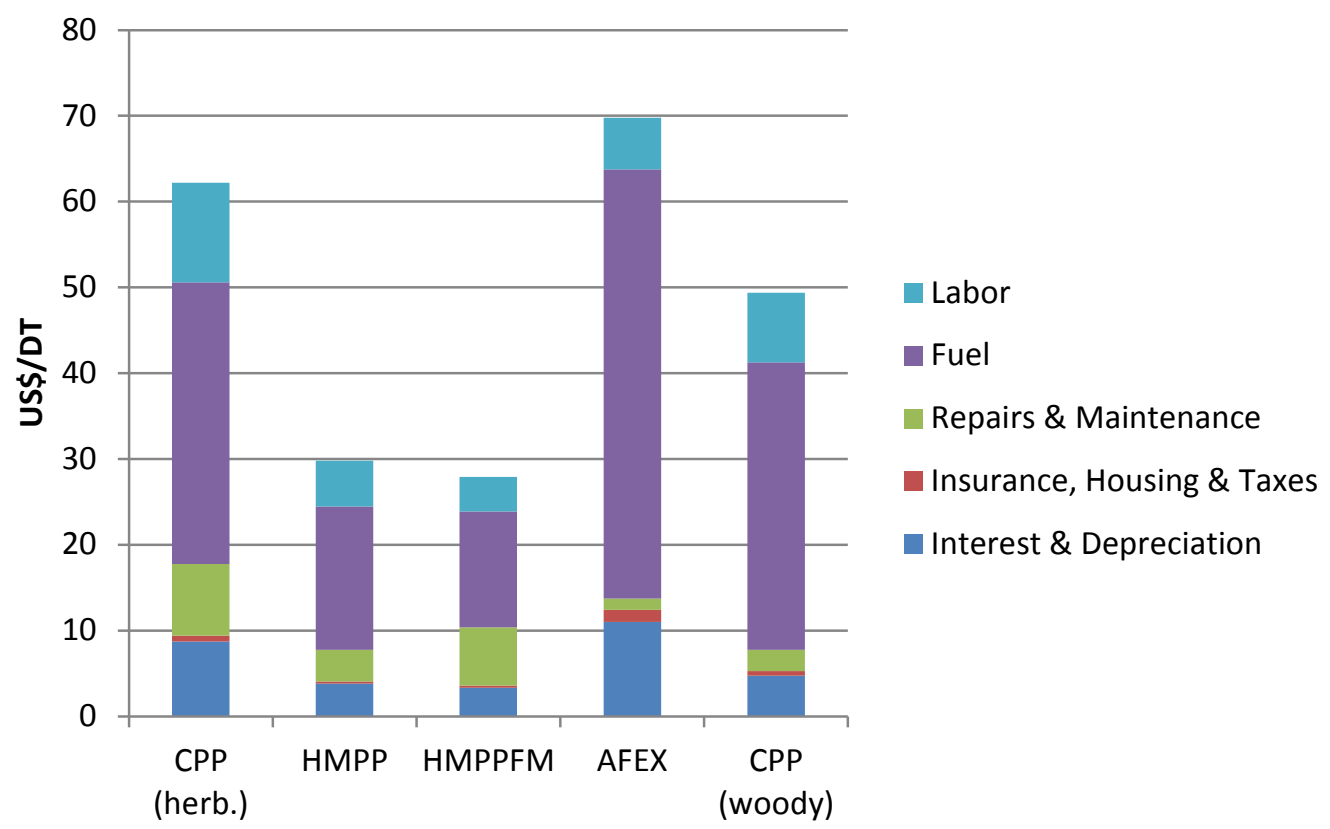

Figure 5:2. Cost comparison per dry ton (DT) output and configuration.

Note: Ownership costs include Interest and Depreciation (I\&D) and Insurance, Housing and Taxes (IH\&T). Operation costs cover Repairs and Maintenance (R\&M), Fuel, and Labor. 
The AFEX depot output price is in-line with previous calculations from Carolan et al. 2007 who performed a TEA of different size AFEX depots. The authors' simulated sizes between 28 and 185 DT per hour, i.e., larger depots than assumed in this TEA (10 DT/hour). Their calculations show that economies of scale can improve overall costs (Figure 5:3). To directly compare the results by Carolan et al. 2007 with this study, we needed to extrapolate their data into the lower size range. This rough estimate indicates similar price ranges as found within this report (Figure $5: 3)$.

Carolan et al. 2007 include a full cost efficiency calculation with a 12\% return on investment. They also include three scenarios for the sale of the produced feedstock, split between customers in the biorefinery and the cattle industry: No sales as animal feed (only biorefinery), and 25\% of the production to as animal feed at two different sale prices (US\$ 73.05 and US\$ 98.47 per ton).

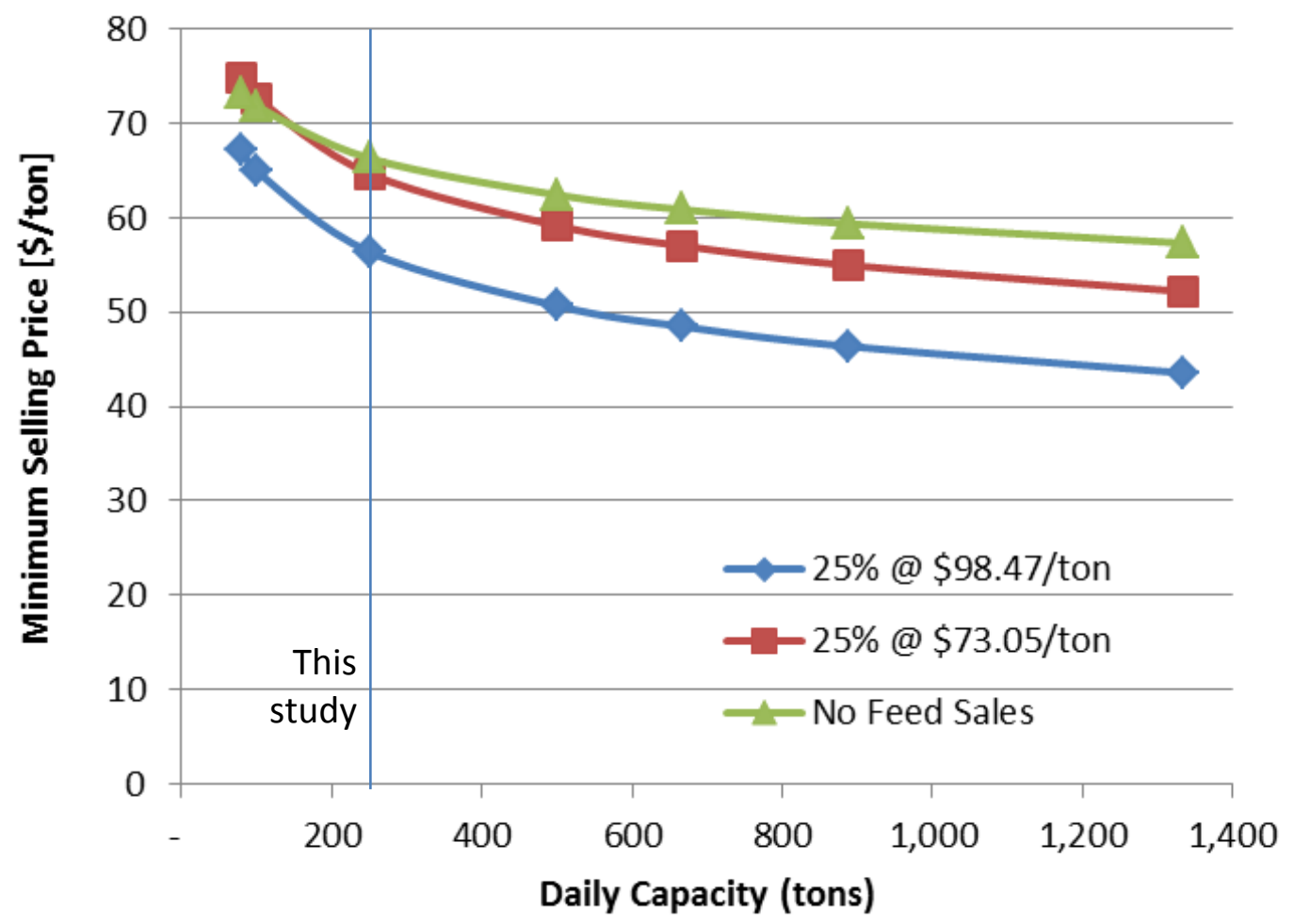

Figure 5:3. Minimum selling price of AFEX product to gain a $12 \%$ return on investment for different depot sizes and sale scenarios.

\subsection{Sensitivity Analysis}

A sensitivity analysis was performed for different input parameters to show their impact on total depot ownership and operating cost. The parameters include depot size, electricity price, and energy consumption of the different equipment used. It is assumed that the variation of input parameters follows a triangular distribution. This is a simplification due to limited data availability. A triangular distribution requires the median (most likely), minimum and maximum expected values. For this exploratory analysis it will generate sufficient randomness to identify 
sensitive parameters. The variation parameters of the triangular distributions are depicted in Table 5:11.

Table 5:11. Parameter ranges and variations for a triangular distribution-based sensitivity analysis.

\begin{tabular}{lccccccccccccccc}
\hline & \multicolumn{3}{c}{ CPP (herb.) } & \multicolumn{3}{c}{ HMPP } & \multicolumn{3}{c}{ HMPPFM } & \multicolumn{3}{c}{ AFEX } & \multicolumn{3}{c}{ CPP (woody) } \\
\hline Parameter & Min & Max & Pk* & Min & Max & Pk & Min & Max & Pk & Min & Max & Pk & Min & Max & Pk \\
\hline $\begin{array}{l}\text { Electricity price } \\
\text { (US\$cents/kWh) }\end{array}$ & 4 & 14 & 6 & 4 & 14 & 6 & 4 & 14 & 6 & 4 & 14 & 6 & 4 & 14 & 6 \\
\hline $\begin{array}{l}\text { Depot size } \\
\text { (DT/hour) }\end{array}$ & 5 & 20 & 10 & 5 & 20 & 10 & 5 & 20 & 10 & 5 & 20 & 10 & 5 & 20 & 10 \\
\hline $\begin{array}{l}\text { Grinder energy } \\
\text { (kWh/DT) }\end{array}$ & 20 & 80 & 40 & 20 & 80 & 40 & 20 & 40 & 80 & 10 & 40 & 17.4 & N/A & N/A & N/A \\
\hline $\begin{array}{l}\text { Hammer mill } \\
\text { (kWh/DT) }\end{array}$ & 40 & 150 & 80 & 60 & 200 & 107 & 30 & 100 & 53.5 & 10 & 50 & 29 & 20 & 60 & 43 \\
\hline $\begin{array}{l}\text { Pellet mill } \\
\text { (kWh/DT) }\end{array}$ & 35 & 150 & 75 & 30 & 80 & 50 & 30 & 80 & 50 & 30 & 90 & 60 & 30 & 80 & 49 \\
\hline Dryer (kWh/DT) & 200 & 500 & 300 & 30 & 80 & 50 & 30 & 90 & 50 & 150 & 400 & 300 & 200 & 600 & 400 \\
\hline
\end{tabular}

* Pk: Peak

Electricity prices have the greatest influence on any configuration (Figures 5:4-5:8). The depot fixed and operation costs per DT vary between US\$54-105 for the CPP herbaceous case, US\$3992 for the CPP woody case, US\$25-53 for HMPP, US\$24-46 for HMPPFM, and US\$57-140 for AFEX. Clearly, the wider ranges and strongest impact are experienced by configurations with higher energy consumption. Drying (and thus dryer type) is the most critical process and equipment part of the respective configuration and its sensitivity regarding energy cost variations.

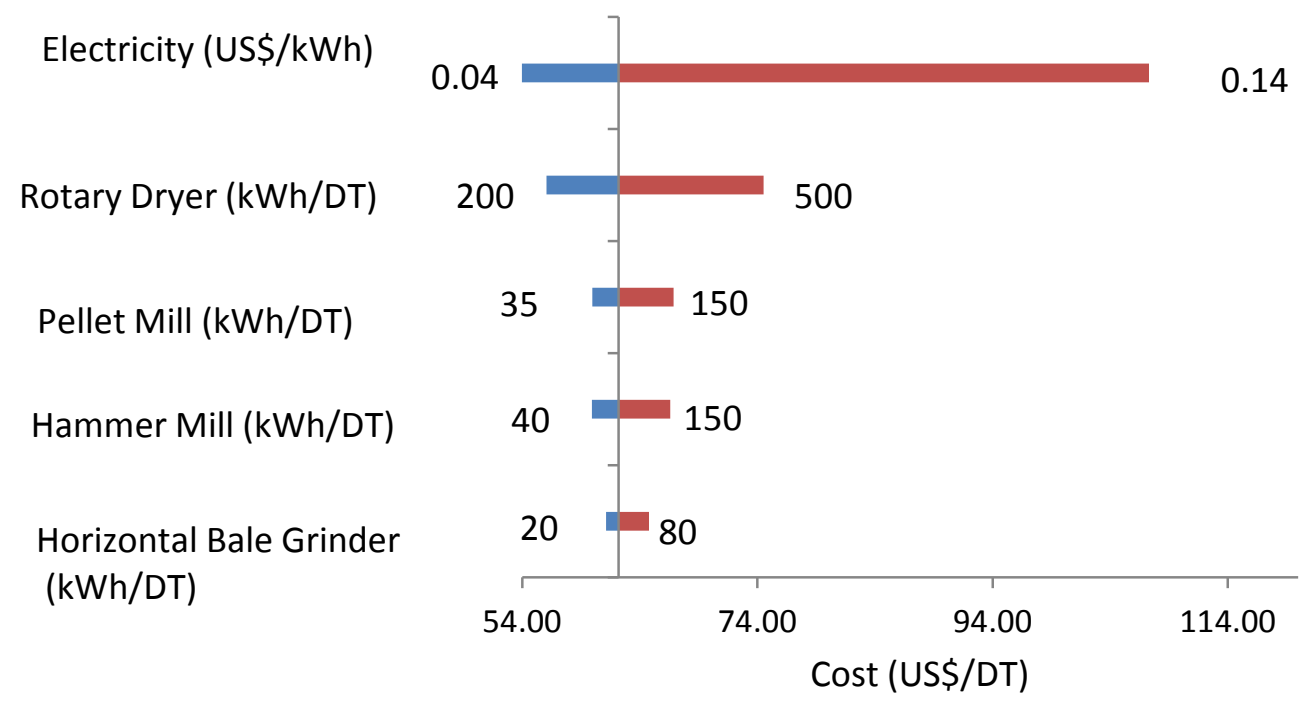

Figure 5:4. The impact of electricity price, energy consumption of different equipment used at CPP (herbaceous case) on depot fixed and operations cost. 


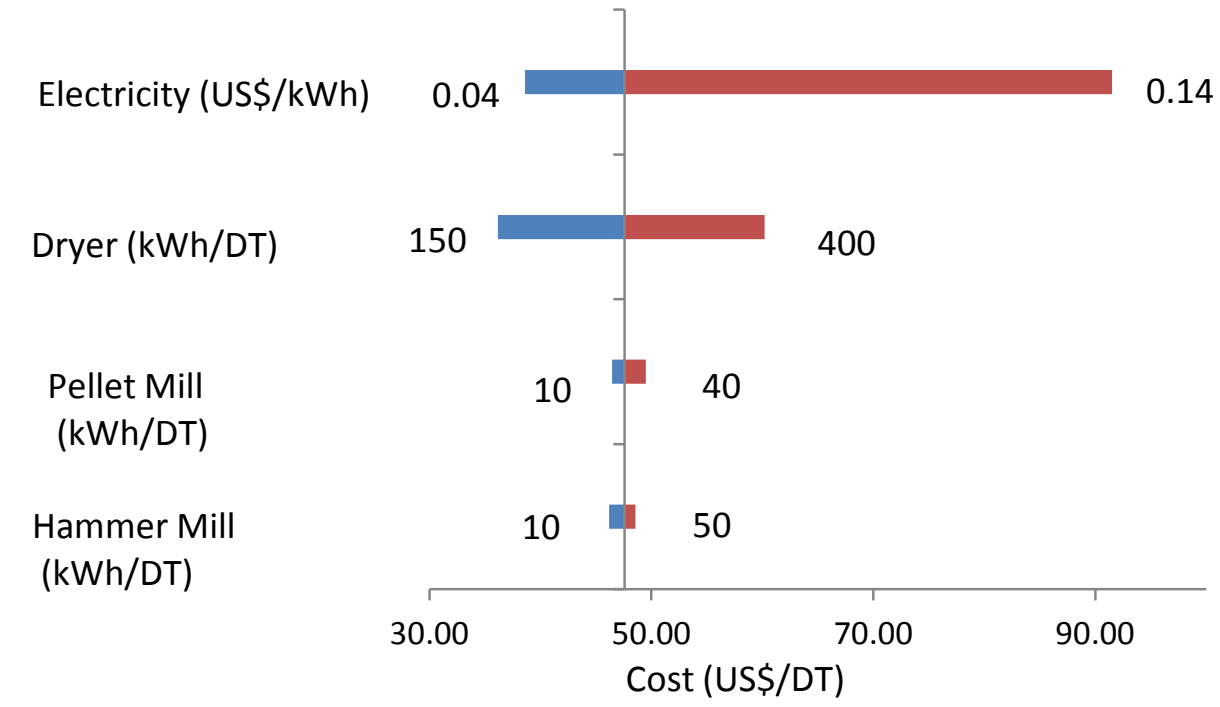

Figure 5:5. The impact of electricity price, energy consumption of different equipment used at CPP (woody case) on depot fixed and operations cost.

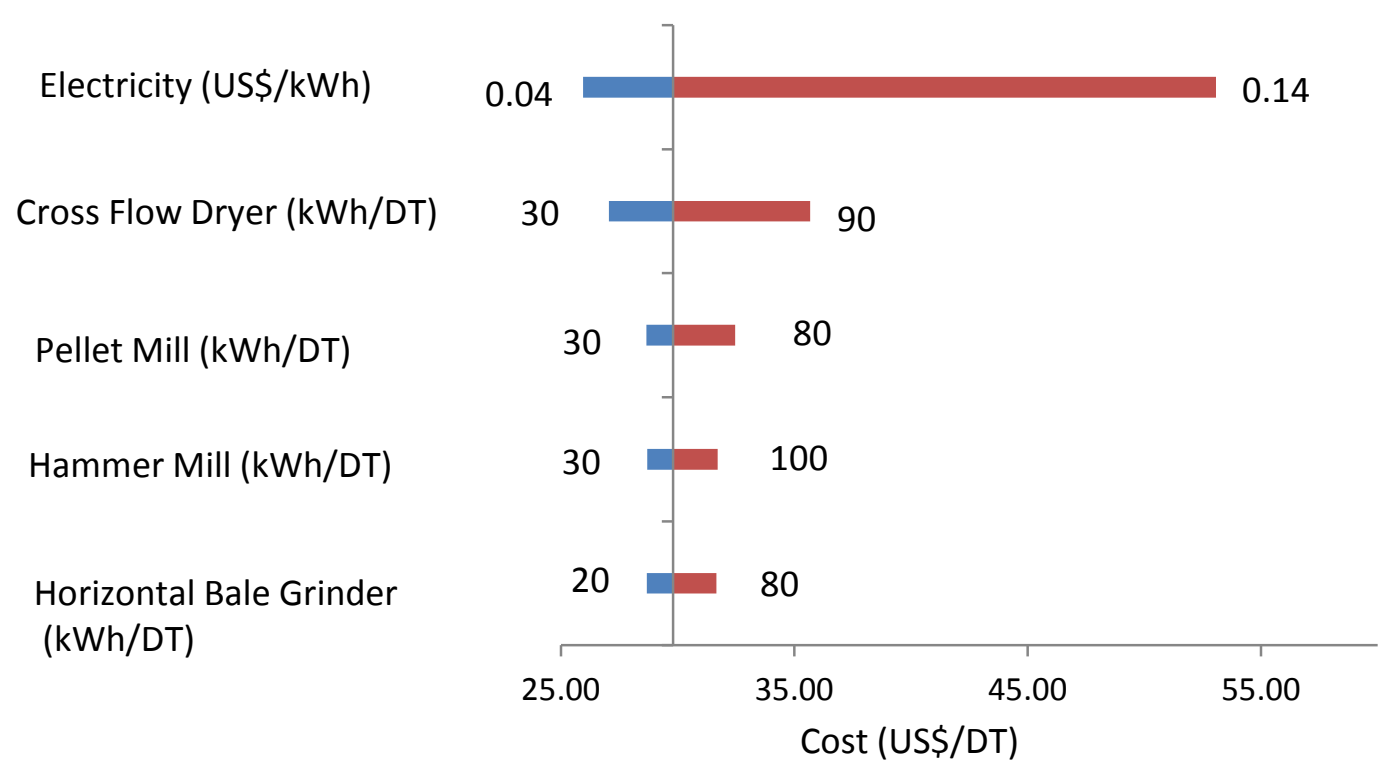

Figure 5:6. The impact of electricity price, energy consumption of different equipment used at HMPP on depot fixed and operations cost. 


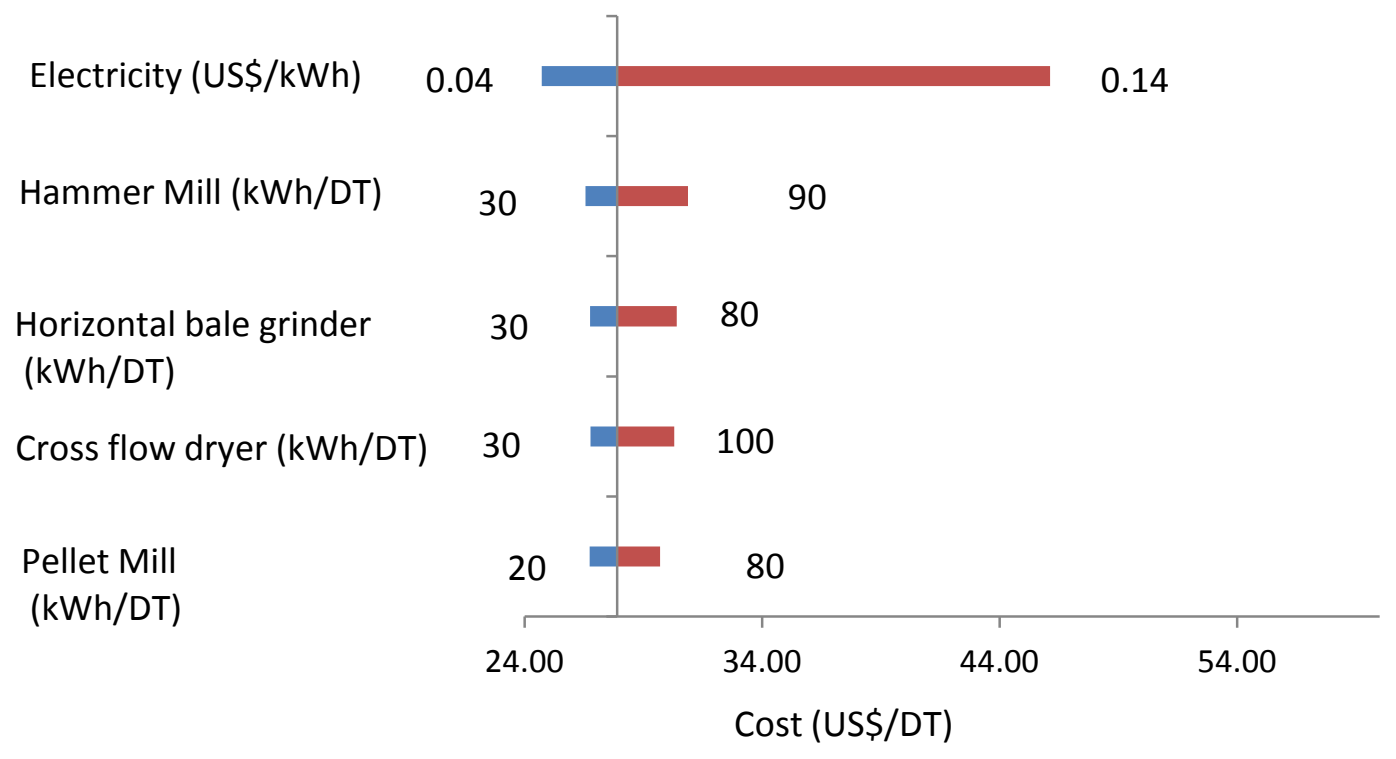

Figure 5:7. The impact of electricity price, energy consumption of different equipment used at HMPPFM on depot fixed and operations cost.

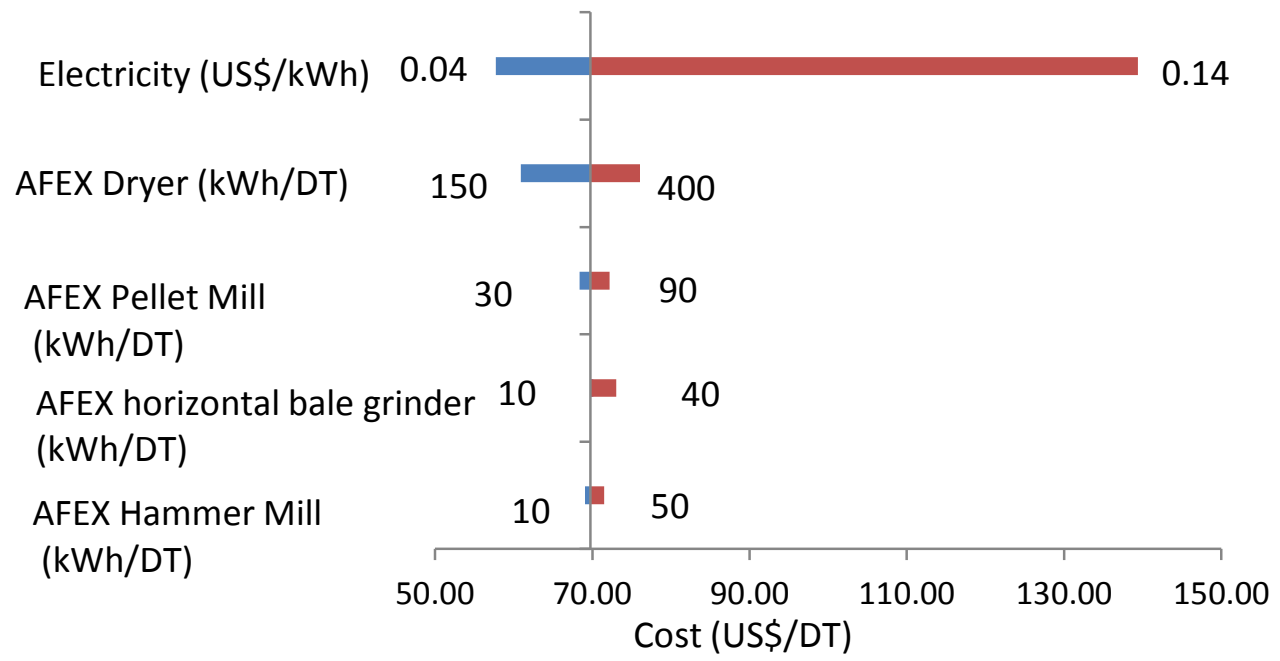

Figure 5:8. The impact of electricity price, energy consumption of different equipment used at AFEX on depot fixed and operations cost.

Figure 5:9 shows the impact of depot size on fixed and operating cost at different depot operating scenarios. We can see that as the depot size increases, fixed and operations cost decrease. Cost variations seem to be fairly small. As the depot size increases from 5 to $20 \mathrm{DT} /$ hour, the fixed and operations costs per DT vary from US\$62.06-63.27/DT for the CPP herbaceous case, US\$49.25-49.96 for the CPP woody case, US\$29.70-30.90/DT for the HMPP, US\$27.8028.80/DT for the HMPPFM, and US\$68.10-70.40/DT for the AFEX process. 
The slight increase in the AFEX configuration between 10-12 DT/hour is due to an increase in adding another dryer in whole increments.

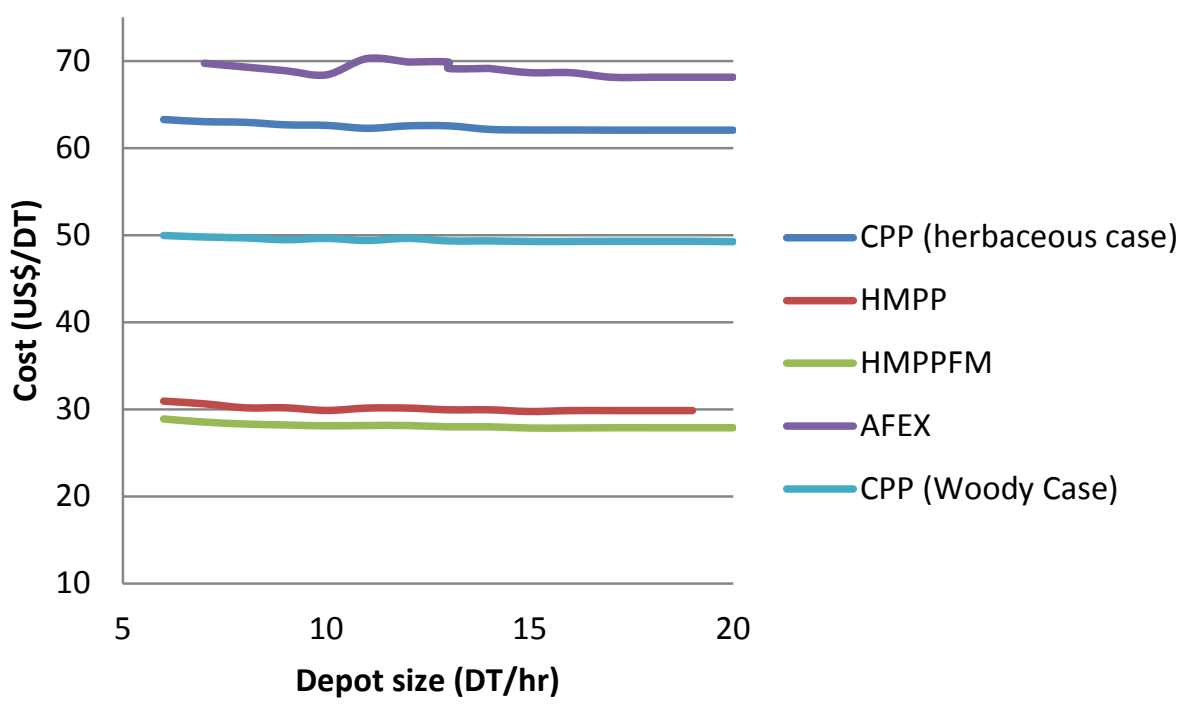

Figure 5:9. Impact of depot size on fixed and operations cost at different depot scenarios.

We also assessed the impact of variations of all sensitivity parameters simultaneously on depot fixed and operations cost at different depot configurations (Figures 5:10-5:14). This was done by generating random variations of different sensitivity parameters from the triangular distribution (showed in Table 5:11) and running the model 500 times with randomly selected different combinations of sensitivity parameters.

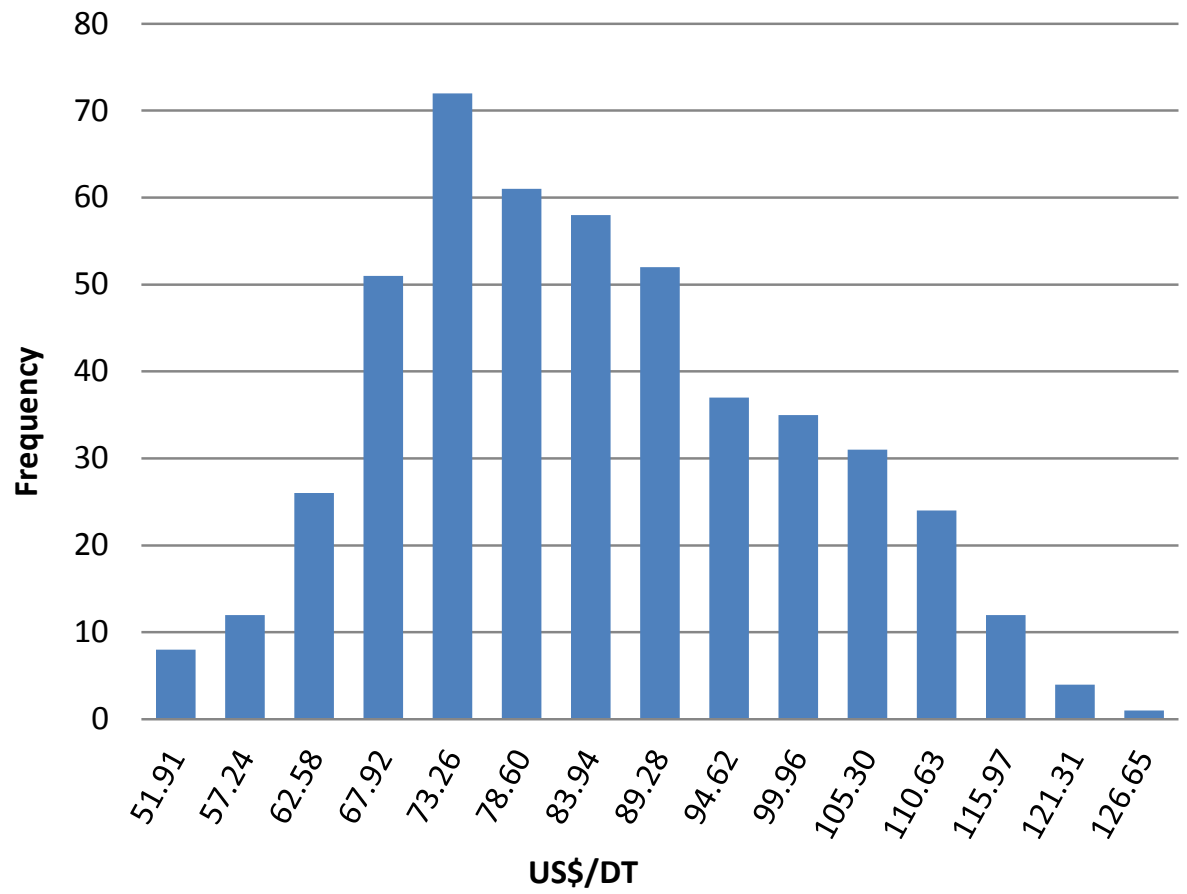

Figure 5:10. Impact of all sensitivity parameters on depot fixed and operations cost for CPP, herbaceous case. 


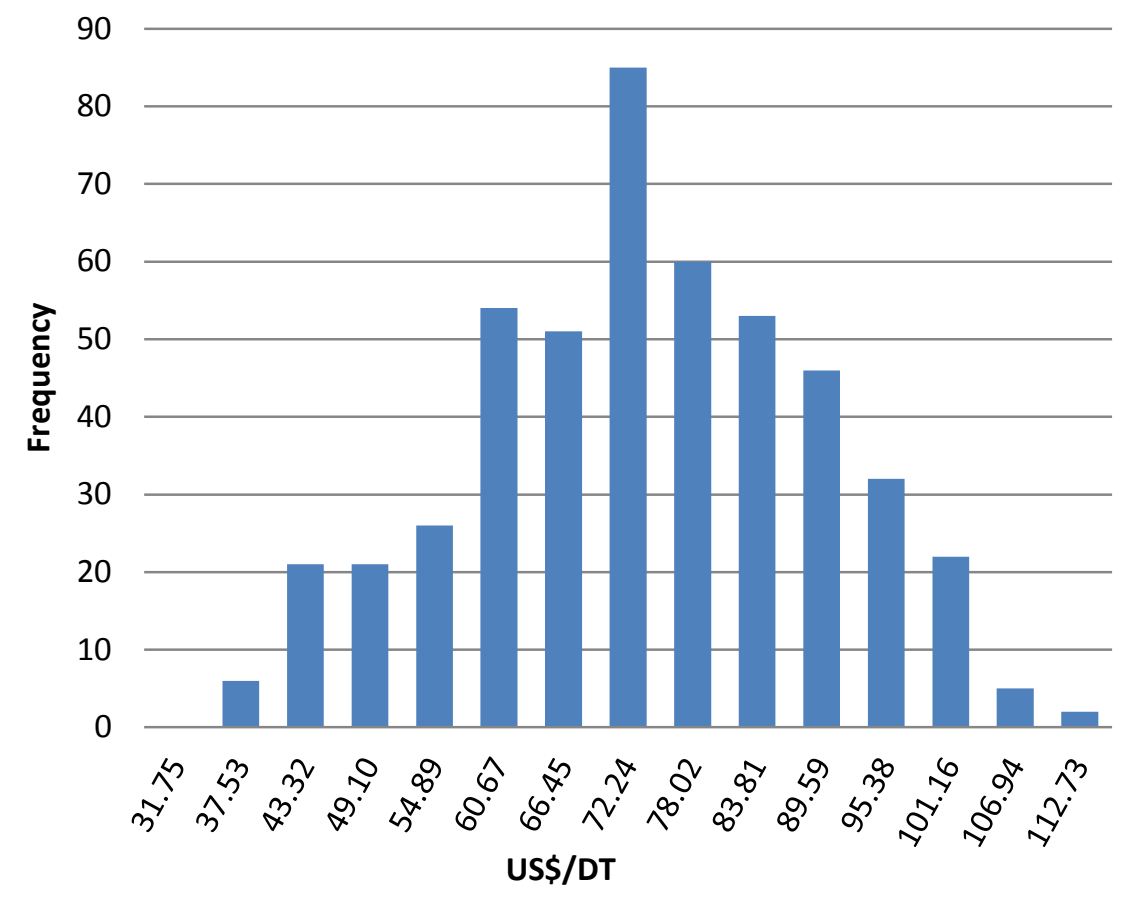

Figure 5:11. Impact of all sensitivity parameters on depot fixed and operations cost for CPP, woody case.

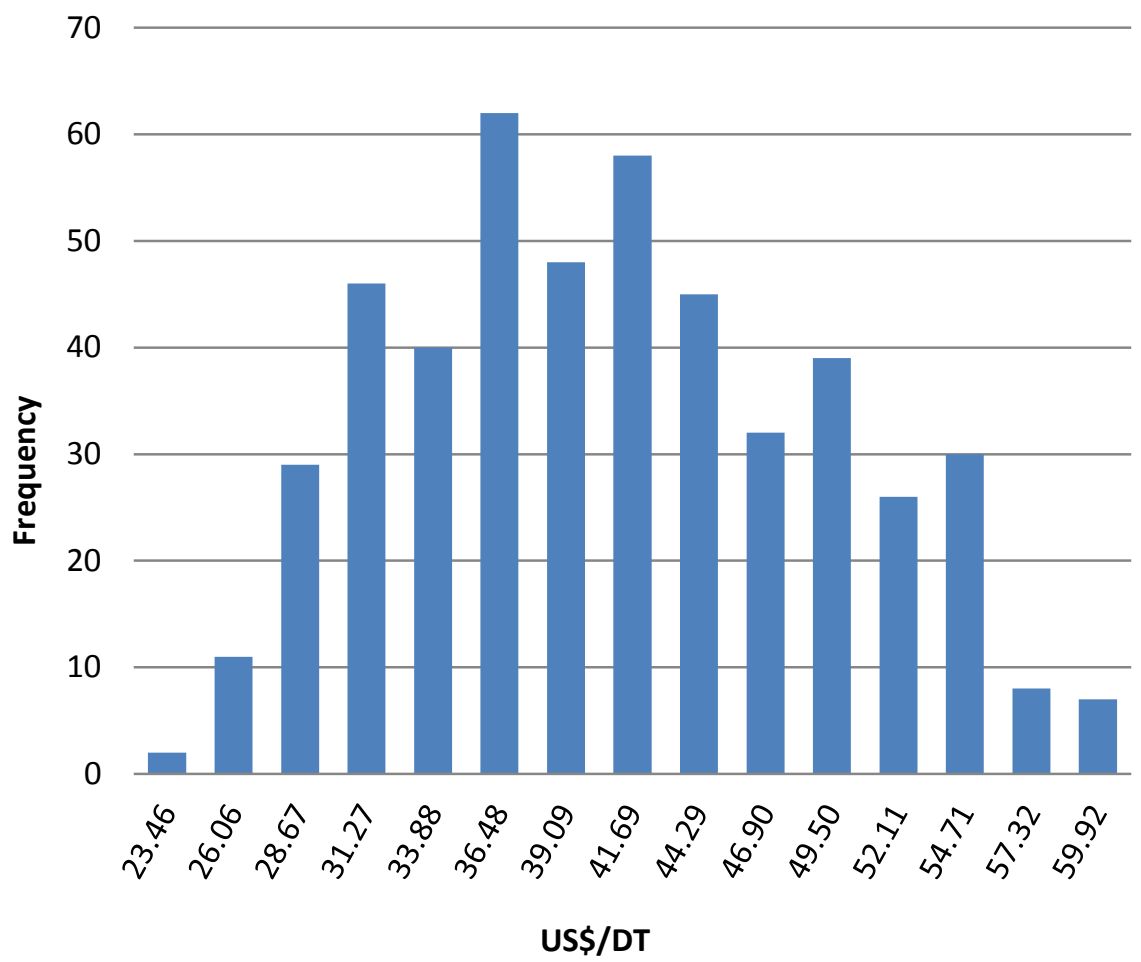

Figure 5:12. Impact of all sensitivity parameters on depot fixed and operations cost for HMPP. 


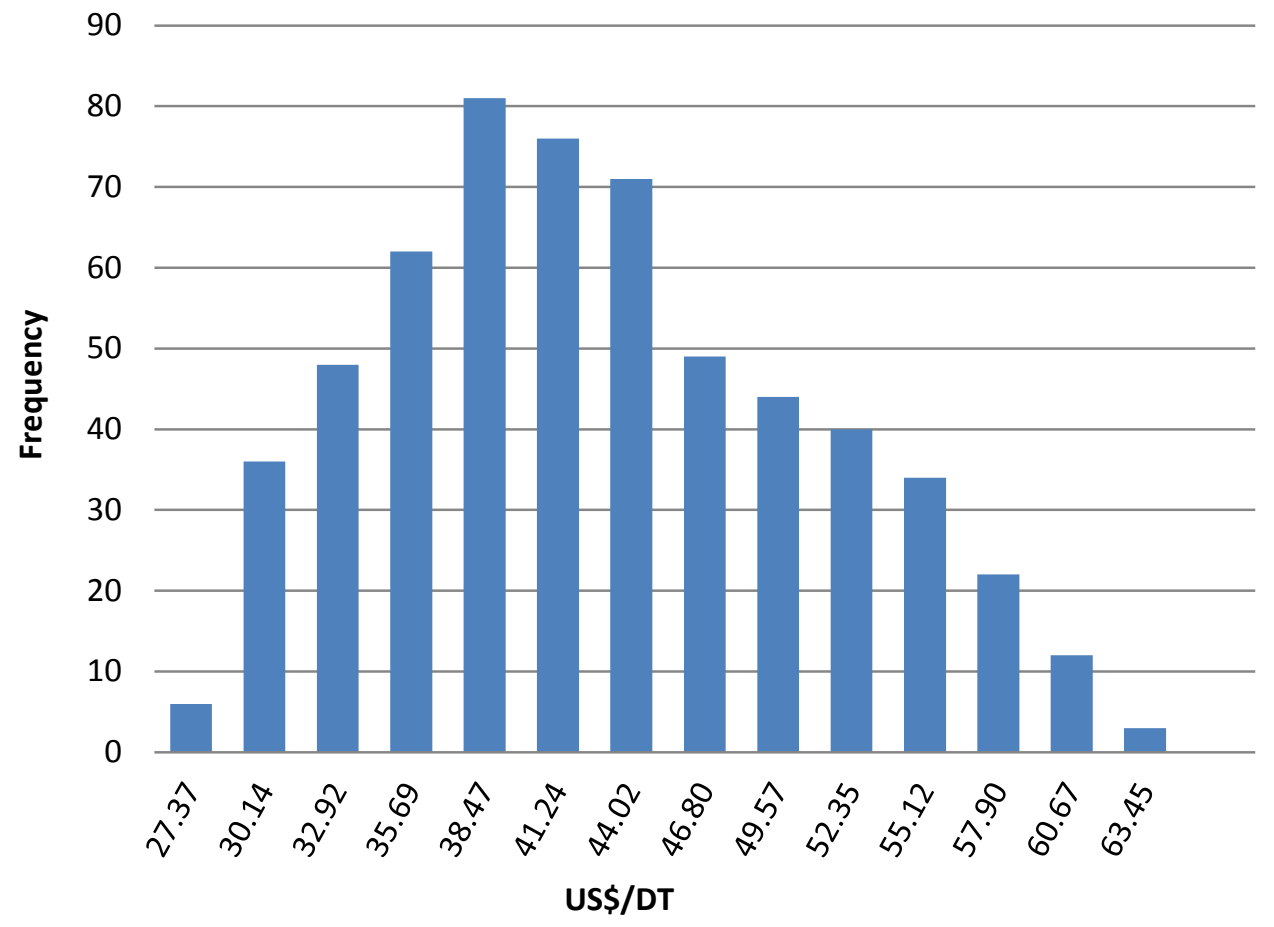

Figure 5:13. Impact of all sensitivity parameters on depot fixed and operations cost for HMPPFM.

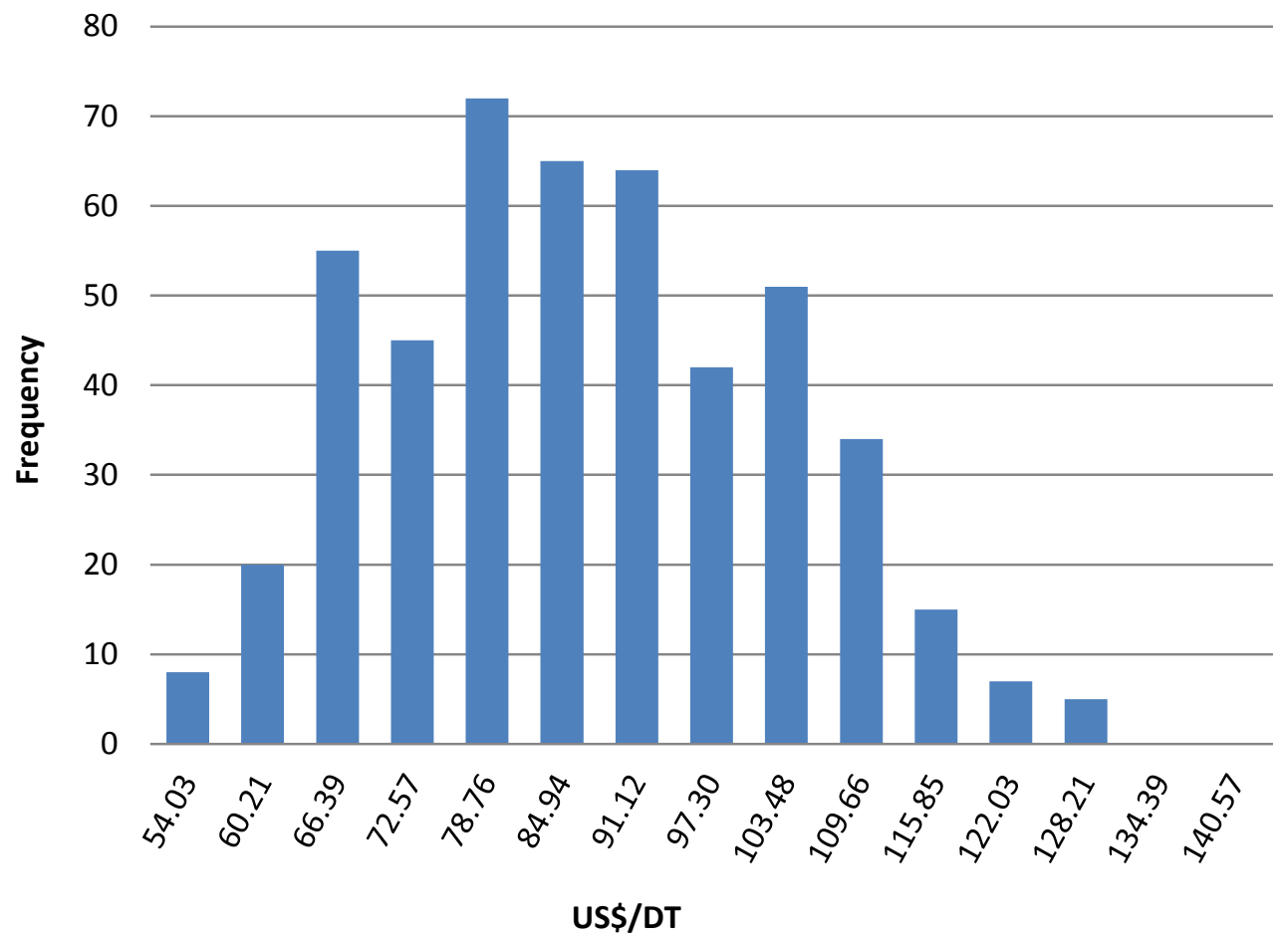

Figure 5:14. Impact of all sensitivity parameters on depot fixed and operations cost for AFEX. 


\section{Discussion}

\subsection{Overview of the Challenges and Opportunities}

There are numerous challenges and uncertainties but also opportunities that influence depot structures, design options, location decisions, and others. Not all of these aspects can be addressed by the means of a TEA. Table 6:1 provides a selection of aspects of which the most critical ones are further discussed in this section.

Table 6:1. Overview of potential challenges and opportunities linked to the implementation of the depot concept.

\begin{tabular}{|c|c|}
\hline Challenges/Opportunities & Explanation \\
\hline Transition & $\begin{array}{l}\text { How will the current, conventional supply system transition towards an } \\
\text { advanced supply system? (Section 6.2). }\end{array}$ \\
\hline Ownership & $\begin{array}{l}\text { The ownership and organizational structure behind a depot directly } \\
\text { influences the business strategy/behavior (including contractual issues } \\
\text { between a depot and biorefineries, etc.) (Section 6.3). }\end{array}$ \\
\hline Sizing and location & $\begin{array}{l}\text { The initial depot concept entails distributed entities located in proximity } \\
\text { to the biomass source; potentially follow by connections to terminals } \\
\text { where feedstock is consolidated prior to further (bulk) distribution. } \\
\text { Depot size will be defined by the sourcing radius and the respective } \\
\text { biomass availability (year-round). Depot size influences economies of } \\
\text { scale. The resulting question is whether optimal depot sizes exist and to } \\
\text { what extent economies of scale can be utilized (Section 6.4). }\end{array}$ \\
\hline Single vs. multi-feedstock & $\begin{array}{l}\text { Feedstock availability/seasonality will influence the depot size and } \\
\text { technical layout. To be operating all year, feedstock flexibility will be key. } \\
\text { Most likely depots will rely on field-storage options as the conventional } \\
\text { system (Section 6.4). }\end{array}$ \\
\hline Preprocessing intensity & $\begin{array}{l}\text { The level of preprocessing intensity at the depot depends on a number } \\
\text { of factors including the typical markets it will sell to, size (economies of } \\
\text { scale), biomass availability, access to capital, business strategy, etc. }\end{array}$ \\
\hline \multirow[t]{2}{*}{$\begin{array}{l}\text { Waste streams and } \\
\text { treatment }\end{array}$} & $\begin{array}{l}\text { Depending on the involved technical processes, depots may generate } \\
\text { waste streams effluents that require treatment. The economic viability } \\
\text { of a WWT facility at a depot directly relates to depot size and profit. } \\
\text { Thus, it appears that only larger, highly specialized depots would be able } \\
\text { to compensate for such an investment. }\end{array}$ \\
\hline & $\begin{array}{l}\text { Depots as well as biorefinery feedstock reception stations will create } \\
\text { solid waste (e.g., broken bales). Creating this organic material closer to } \\
\text { the field creates options for reuse and reduction of transport costs to do } \\
\text { so. Also, it may serve as a second income stream for the depot. }\end{array}$ \\
\hline $\begin{array}{l}\text { Additional costs and the } \\
\text { attribution of supply chain } \\
\text { savings }\end{array}$ & $\begin{array}{l}\text { The advanced supply system entails larger direct investment costs than } \\
\text { the conventional supply system. At the same time it creates wider } \\
\text { system cost benefits, in particular at the conversion end. It will be } \\
\text { challenging to justify the larger initial investments without a full } \\
\text { appreciation of the downstream cost savings. }\end{array}$ \\
\hline
\end{tabular}


This TEA does not account for environmental impacts and thus the respective differences between the selected depot concepts. As Argo et al. 2013 pointed out, the advanced supply system may entail higher energy costs and a potentially higher global warming potential.

Permitting

The U.S. Standard Industrial Classification (SIC) for biorefineries and depots may be similar and thus permit application would need to be combined if the depots are in a relative proximity to the refinery. The permit application determines limits for air and water emissions, etc.

\subsection{The Transition Period}

Depots are currently not utilized by the biomass industry but their appearance in the system is expected to occur organically as industry adds preprocessing equipment and storage to existing biorefinery infrastructure to help the biorefinery buffer supply volume and price risks as the primary goal. Carnohan et al. 2014 provided a conceptual cost evaluation of this concept as part of an exploration of different feedstock supply management strategies via systems dynamic modeling. In a series of simulations, the authors show the resilience of the concept under several perturbation scenarios, such as weather related regional supply shortages. The configuration does entail higher cost to the biorefinery but proved to handle volume and price risks better than without storage options. Thus, the investment in small-scale pelleting for short-term volume buffering provides long-term benefits to the biorefinery and becomes a critical element in derisking the supply system.

In terms of organizational structure, the depot would probably be owned by the biorefinery at first. At a later stage, it may be outsourced and become an independent business. At that stage, different types of ownership become possible (e.g., farmer cooperatives) and the depot will have a requirement to be a self-sufficient, cost effective business entity (see Section 6.3 for a wider discussion). As an extension of the biorefinery itself, profitability is not a prerequisite but it will be essential when operated as a separate business. In contrast to biorefineries integrating upstream, depots may also originate from the farmer side when multiple producers ban together in order to take advantages of economies of scale, etc.

In terms of the two depot classes, a Standard Depot is most likely to be independent from the biorefinery, while a Quality Depot is more likely to be owned by the biorefinery due to the ties to the downstream conversion process and the need for waste treatment. Additionally, Standard Depots may be owned by the biorefinery, but operated by the producer consistent with the U.S. grain elevators (see Section 6.3 for a wider discussion on ownership and industry trends). The location of either a Standard or Quality Depot will most likely be driven by the ownership profile (biorefinery vs. cooperation) as well as the existing logistical infrastructure (e.g., rail lines, shipping terminals) and it is more likely that as quality becomes more uniform the further away the depot will be located from the biorefinery. This makes decentralized locations possible, also in low-yield areas.

The transition from the current, conventional feedstock supply system to an advanced, depot based supply system can take on various forms. Table 6:2 provides a suggestion including an element of time along several key depot characteristics. The main influencing factors include ownership structures, as well as location and sizing decisions, which relate to specialized (singlefeedstock) or flexible (multi-feedstock) depots. Also, end-use markets may change over time and 
some (e.g., cattle feed operations) may actually provide stepping-stones or intermediate stages for a full-fledged distribution of the depot concept.

Table 6:2. Depot transition periods by elements of characteristics.

\begin{tabular}{|c|c|c|c|}
\hline & Short-term & Medium-term & Long-term \\
\hline Ownership & $\begin{array}{l}\text { Biorefineries (upstream } \\
\text { investment) }\end{array}$ & + Farmer cooperatives & $\begin{array}{l}\text { + Third-party (proven } \\
\text { business model) }\end{array}$ \\
\hline Location & At the biorefinery & $\begin{array}{l}\text { + High-yield areas, } \\
\text { centralized location }\end{array}$ & $\begin{array}{l}\text { + Decentralized, low- } \\
\text { yield, stranded } \\
\text { feedstock areas with } \\
\text { conglomeration in } \\
\text { terminals }\end{array}$ \\
\hline $\begin{array}{l}\text { Single- vs. multi- } \\
\text { feedstock }\end{array}$ & Single feedstock & $\begin{array}{l}\text { + Specialized depots, } \\
\text { high-yield producing } \\
\text { regions }\end{array}$ & $\begin{array}{l}\text { + multiple feedstock, } \\
\text { blending option }\end{array}$ \\
\hline Sizing & $\begin{array}{l}\text { Pilot and small-scale } \\
\text { (<40,000 tons/year.) }\end{array}$ & $\begin{array}{l}\text { + Medium to large-scale } \\
\text { (> 80,000 tons/year) }\end{array}$ & \\
\hline Preprocessing intensity & Conventional pelleting & $\begin{array}{l}\text { + Advanced } \\
\text { (multiple markets) }\end{array}$ & \\
\hline End-use markets & Biorefineries & $\begin{array}{l}\text { Multiple U.S. markets, } \\
\text { e.g., cattle feed, } \\
\text { biorefineries }\end{array}$ & $\begin{array}{l}\text { Multiple international } \\
\text { markets }\end{array}$ \\
\hline
\end{tabular}

\subsection{Ownership Structures}

As a business entity, biomass depots could be organized under a variety of ownership structures. First, as part of an organic industry growth (or vertical integration of the biorefinery), biomass depots may evolve as part of the biorefinery to help buffer feedstock supply and reduce potential dependence on emergency markets. This could eventually reduce business risks and capital costs to biorefineries (Carnohan et al. 2014). Second, it may be run as an independent and necessarily profitable business entity. As such, it can be part of different ownerships: completely independent, as a biorefinery subsidiary, or as a farmer cooperative. A final option entails independent or farmer-owned franchises (Carolan et al. 2007).

As discussed in detail below, there are several striking similarities between the historic development of U.S. farmer grain cooperatives in the late $19^{\text {th }}$ early $20^{\text {th }}$ century and current herbaceous biomass supply activities. This applies particularly to the requirements to deliver onspec material (or feedstock with limited quality fluctuations) to the biorefinery. When faced with requirements for consistent grain quality in geographically distant markets, farmers formed cooperatives, which supported the construction and operation of grain elevators, a concept that is similar to that of the biomass depot.

\section{Development of cooperative agreements in the US grain industry}

The U.S. grain industry has always been an oligopsony (i.e., a limited number of buyers whereas the number of sellers could be very large). Previous to the westward expansion and simultaneous 
increase in industrialization and urbanization in the 1830's and 1840's, the effects of this structure were minimized by the agrarian nature of the society in which farms produced for selfsufficiency purposes, only selling excess product (Thrush 2003).

With increasing urban manufacturing, labor organization and rising wages in the cities, urbanization created the need for more foods to be sold into the non-farm population centers, especially in the Eastern U.S., and trade for grain needed to be expanded. In addition, the simultaneous expansion of settlements into the prairies of the Midwest created increasing grain surpluses. With the further development of the transportation systems via railroads grain began to move from surplus areas of the Midwest to deficit areas in the East (Thrush 2003). This time in the 1830's and 1840's was also the time of the repeal of the "Corn Laws" in Britain, which created much more demand for U.S. grains to Britain (Morgan 1979).

Grain cooperatives formed in the US Midwest as grain production increased and farmers needed a way to consolidate their individual farm production for markets in the Eastern US and elsewhere (Karlen 2014). Many such cooperatives grew up along rail lines (Karlen 2014).

Similarity: Oligopsony situation (high number of producers and limited buyers), (increasing) distance between supply and demand centers, consolidation along logistical hubs.

Grain marketing firms were typically engaged in two primary operations: (1) physical handling of product from time of production to ultimate consumption (processing), and (2) pricing of the product at various stages in the marketing process (Thrush 2003). Encountered difficulties in grain marketing included (Thrush 2003):

- $\quad$ varying grades and size of shipments,

- varying terms of payment,

- $\quad$ secret prices,

- reliability of buyers and sellers,

- damaged goods (or wrong quality) on arrival, and

- difficulty in finding new buyers (Gold 1975).

Similarity: Supply variability in volume and quality are key risks for biorefineries (i.e., the previous grain marketing problems reflect current biomass sourcing difficulties).

Grain elevators became critical junctures in the grain marketing system. They accumulate grain in quantities to make longer-distance markets economically feasible (Vachal and Tolliver 2001). In this role, they provide various marketing, production, and crop conditioning services (Vachal and Tolliver 2001). Previously, farmers took the risk of falling prices, bad weather, and governmental policies (that may depress farm prices) whereas grain companies, one stage removed from the production process, could make money whether prices were rising or falling (Morgan 1979) due to storage and hedging opportunities.

Recognized as the oldest continuous active cooperative elevator in the nation, the Farmers Cooperative Elevator of Marcus (IA) was incorporated on December 12, $1887 .{ }^{29}$ Most U.S.

\footnotetext{
${ }^{29}$ The cooperative was formed by 161 grain farmers who invested US $\$ 20$ apiece. Their investment helped build a wooden elevator to handle the wheat, oats, barley, and flax that were grown in the area at the time.
} 
agricultural cooperatives originated in the early 1900's (Cook 1995). During the ensuing forty years, US farmer cooperatives slowly but consistently increased their aggregate market shares of input handled, farm marketing operations, and services provided (Cook 1995). Later on, the industry saw a consolidation of elevators and cooperatives due to construction changes from wood to concrete and steel (higher capital costs), which increased the size/capacity and thus sourcing range of modern elevators; coupled with transportation network improvements to allow for (even) longer distance transport (Brown 2009).

Similarity: Biomass Depots could fulfil a similar role within the biorefinery chain as grain elevators in the grain chain.

Traffic congestion due to high transport loads, e.g., into Chicago in the early 1850's forced farmers to sell for whatever prices they could get (Kroll and Shishko 1973). Eventually, contracts began to be offered to deliver a specified quantity at a designated place within a given number of days (Thrush 2003). These 'futures contracts' were a major advance in grain marketing and shifted some or most of the burden of price risk from the producer to the buyer. Varying grade and quality, payment terms and lack of contract compliance were standardized with the development of the futures contract (Thrush 2003). An additional step of market organization created commodity exchanges, which are - to the present day - an effective mechanism for setting prices and facilitate grain movement through all stages of production and distribution.

Similarity: Biomass depots could help create commodity type products (standardized products for various markets) which can eventually be traded under future contracts and via commodity exchanges.

\section{Sharing the Risk}

The feedstock supply chain entails profit risks for all parties involved. Biorefineries face that risk with relation to off-spec quality or reduced feedstock volume, causing reduced output and machine idle times. To circumvent this, biorefineries may impose dockage fees on farmers when biomass quality and quantity are delivered outside of agreed upon contractual terms. Dockage fees however reduce farmer profits. Depots create an opportunity for profit risk sharing between biorefineries and farmers supplying feedstock. For instance, if the contract between the biorefinery and the farmer specifies that biomass shall be delivered with ash content not to exceed $5 \%$, and then biomass arrives with ash content greater than $5 \%$ the biorefinery charges the farmer a dockage to cover biorefinery costs for removing ash from the feedstock. Preliminary INL analysis suggests that farmers can increase farm level profitability by investing in preprocessing depots. The modeling shows that when farmers jointly invest in a depot, as in a cooperative ownership structure, the individual farmer can reduce profit risk by processing biomass prior to delivery to the biorefinery. Preprocessing allows the farmer to meet contract specifications with greater ease therefore reducing dockages. Hence the depot reduces the farmer's risk of greater dockages and it reduces volume and quality risk to the biorefinery. 


\subsection{Sizing and Location}

Depot size will vary with three major indicators feedstock availability, infrastructure, and preprocessing intensity (depot type). The latter is also related to economies of scale, especially for Advanced Depots. Granted that some preprocessing steps require waste effluent treatment, all three major sizing aspects are directly related to spatial information, i.e., location questions. Biorefinery demand and distance are assumed to be less critical than feedstock supply since transport costs are reduced significantly (Inman et al. 2010). For an in-depth analysis of depot location optimization, we refer to Webb et al. 2014.

Sizes debated in literature: Depot sizes debated in literature range from 3.5 to 42 DT per hour, equaling 85 to 1,000 DT per day, or 28,000 to 336,000 DT per year (Hess et al. 2009, Eranki et al. 2011, Bals and Dale 2012, Argo et al. 2013). Truck traffic at the lower end of the scale would be between 8-10 trucks per day. Depot size options in the upper range would ultimately lead to a more than tenfold increase in truck traffic.

Analysis by Sultana et al. 2010 on optimal sizes for straw pelleting plants in Alberta, Canada showed that capital costs drop significantly until the plant reaches a capacity of 110,000 DT per year or 12-13 DT per hour (equaling roughly 100,000 metric tonnes per year, see Figure 6:2). Further capacity increases have limited capital cost gains while feedstock supply prices (within a circular supply radius) would increase above US\$40 per DT for facilities larger than 110,000 DT per year, excluding unit operation costs (Sultana et al. 2010).

Further analysis on depot size optimization with respect to location and feedstock blend (options) is necessary. While the general hypothesis is that larger facilities could benefit from economies of scale, larger depots will start to encounter operational limitations, including feedstock supply issues (just as biorefineries in the conventional system), particularly due to seasonality and competition between different depots, and traffic congestion. It is therefore more likely that depots will have different 'optimal' sizes across different locations, feedstock options, and possibly other influencing factors (e.g., ownership structures).

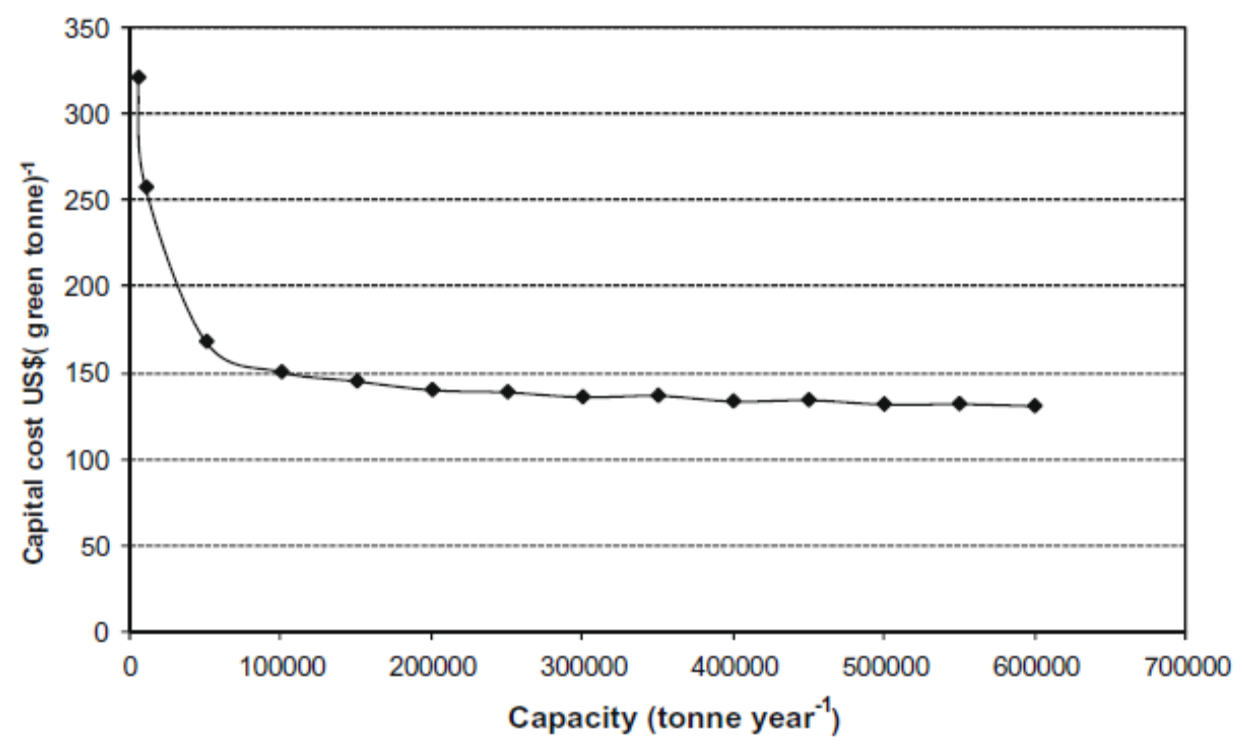

Figure 6:1. Change of unit capital cost of pellet production plant with capacity (Sultana et al. 2010). 
Planned commercial pilot depot by MBI: The Michigan Biotechnology Institute (MBI) is planning to build a biomass depot pilot plant with 35,000 DT per year (4-5 DT per hour) capacity and an AFEX pretreatment process. The aim is to demonstrate the ability of a biomass depot to be an independent, self-sustaining business entity. The price target for the output material is US\$80-100 per DT; and it may be sold to cattle feed operations and biochemical refineries. The AFEX output is hydrophobic and may be stored outside which reduces capital costs (no silage necessary). The process input material would be herbaceous residues, primarily corn stover.

Feedstock availability: The volume and diversity of biomass available to a depot depends primarily on its location and sourcing radius. In this analysis, we assume a 50-mile biomass sourcing radius, in-line with the assumption for conventional biorefinery supply systems (Aden et al. 2002). Feedstock diversity and volumes will also differ between years due to yield variations (unless it is an industrial residue stream).

The size of the depot is also defined whether it is a seasonal or annual operation. In this analysis, we assume a year-round operation implying that sufficient feedstock will be stored at the facility or in the field (similar to corn stover bales under tarps).

To enable annual full-scale operations, depots may preprocess different types of biomass (e.g., baled herbaceous residues or chipped woody residues). Such feedstock flexibility requires different in-feed machinery, affecting the footprint and costs of a depot.

It is relatively certain that depots in low-yield or stranded feedstock supply regions will need to be more flexible than those in high-yield regions such as the U.S. Corn Belt. Here, singlefeedstock depots may operate year-round based on corn stover, which is temporarily stored in the field (similar to the conventional system). However, even in Iowa parcels exist on sub-field level that produce corn at net negative costs (Bonner et al. 2014). Hence, herbaceous or woody energy crops may eventually become part of the feedstock mix for depots even in high-yield regions.

Decentralized vs. centralized (economies of scale): The depot concept is based on the assumption that biomass is preprocessed in proximity to the source and feedstock and is shipped in bulk over longer distance to the respective clients. Apart from equipment costs, the size of the depot will be directly related to the volume and seasonality of the respective biomass source; which in turn will depend on the sourcing radius of the depot. As pointed out by Aden et al. 2002, sourcing beyond a 50-mile radius becomes increasingly non-economical. While this assumption was kept for this TEA, it should be held-up against potential benefits an increased sourcing radius might provide in a specific location.

Thus, high-yield areas may generate larger, centralized depots that generally stand a better chance to integrate advanced preprocessing equipment cost efficiently due to a rather continuous in-feed of the same feedstock, allowing pre-defined equipment in larger size, enabling economies of scale, and an option to access a WWT facility. In low-yield or stranded feedstock regions, depots are likely to remain small and may require flexible equipment to cope with different biomass input streams (in type, shape, etc.). Once the markets for depot products reach maturity, i.e., 'commodity-scale', smaller, decentralized depots may consolidate into larger, centralized preprocessing centers in logistically strategic positions (e.g., along waterways).

Single vs. multi feedstock systems: As stated above, single-feedstock depots are only likely in high-yield areas (e.g., the U.S. Midwest for corn stover, the U.S. South-East for pulpwood, or 
large urban conglomerations for municipal solid waste). To reach economic viability and become a reliable source of feedstock for its clients (e.g., biorefinery industry), a depot needs to operate year-round. Thus, it needs to buffer seasonally available biomass, herbaceous material in particular. Essentially, a depot will face similar supply risks (volume and price) as biorefineries do under the current, conventional feedstock supply system. Key differences are that depots can better buffer quality variations, may have a direct link (in ownership) to the agricultural sector, and generally will have a much smaller annual demand.

At the same time, depots need to guarantee a sufficient load factor to prevent under-usage of equipment and capital cost intensification (Eranki et al. 2011). Thus depots may need to rely on several feedstock options, in particular in low-yield regions where depot locations may be dispersed and depots smaller in size. At the same time, this provides disadvantageous economies of scale. Plus, multi-feedstock set-ups will require different in-feed trains and densification machinery; increasing capital costs. This suggests that depots may not be economically viable in all locations and evolve differently.

Infrastructure: Logistical infrastructure is important to minimize long distance trucking (prior to more efficient modes such as rail or ship transport). It is expected that biorefinery locations will also be determined by transport nodes. Thus, the connection between depots and biorefineries will be improved. Other infrastructure requirements for the depot, as with any commercial, technical operation include access to electricity, water, and labor. In the case of intensive preprocessing, a connection to an existing WWT facility will be cost beneficial.

\subsection{End-Use Market Diversity}

Depending on the business structure and ownership, depots may evolve to become specialized and target single or multiple end-use markets for their main product (independent of effluents or waste streams such as mulch that can be marketed). As wood pellet production and distribution shows today, the same products can be utilized for several purposes (e.g., animal bedding and energy applications). The same could be true for depots, unless they are upstream investments (e.g., by biorefineries or cattle feed operations).

\subsection{Cost-Benefit Comparison of a Conventional and an Advanced Feedstock Supply System based on Depots}

The primary aim of this report is to analyze different biomass depot design options from a technical and economic perspective. It does not set out to evaluate the cost impacts, a network of depots may have on the rest of the supply chain. However, to put the costs associated with preprocessing at the depot into a wider supply chain perspective. This section outlines and roughly quantifies the four major cost reductions that can be achieved across the value chain by applying the depot concept: risk mitigation, economies of scale, conversion efficiency improvements, and the reduction of equipment (i.e., capital and operational costs) at the biorefinery.

Supply risk mitigation leading to loan cost reduction: Advanced supply systems mitigate supply risks associated with feedstock outages, such as those associated with local weather, pests, and diseases. Since feedstocks are processed as commodities in an advanced system, the biorefinery should also be less vulnerable to price volatility and may not need to contract directly with feedstock producers. 
Feedstock volume and price variations are commonly identified as a key sensitivity to breakeven in biorefinery investments (Davis et al. 2013). Mitigating the feedstock supply uncertainty via an advanced system will make the biorefinery investment less risky, which will be reflected in the annual interest rate for the biorefinery loan.

NREL design reports assume an $8 \%$ interest rate over the course of a 10 year loan for $40 \%$ of the total capital investment for a biochemical or thermochemical biorefinery based on an advanced supply system (Dutta et al. 2011, Humbird et al. 2011). Current biorefinery investments, relying on a conventional feedstock supply system, are assumed to face much higher interest rates due to the early industry stage and opportunity costs for investors (to invest in other, more lucrative endeavors). At the same time, $\mathrm{n}^{\text {th }}$-plant assumptions, including an $8 \%$ interest rate, can also be seen as optimistic (Anex et al. 2010). A mature industry, with limited feedstock supply risks due to an advanced supply system will however be able to achieve a lower interest rate than current, conventional supply system based biorefinery investment. Figure 6:2 compares the total annual interest paid for biorefinery investments over various interest rates and the respective impact per GGE produced.

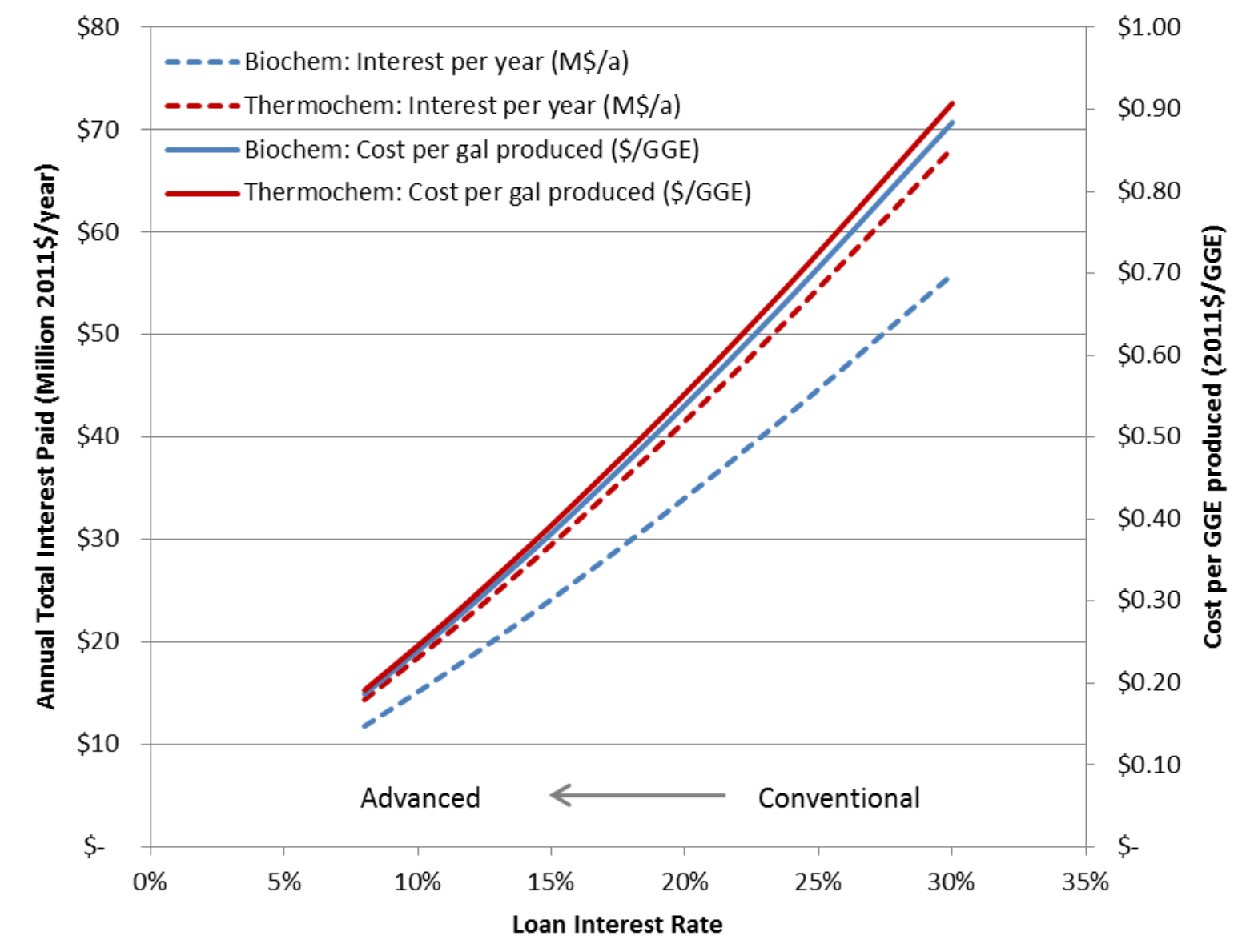

Figure 6:2. Annual total interest for biorefinery investments of 800,000 DT annual capacity facilities across varying interest rates and their respective impact on the production costs per GGE.

For this comparison, it is less important to identify and compare exact interest rates for current, conventional $v s$. advanced supply systems. It is more important to observe the trend. Interest rate 
reductions by $-2 \%$ to $-15 \%$ across an interest rate range of $8-30 \%$ lead to cost savings per GGE from US\$0.05 to US\$0.51 (Table 6:3).

Table 6:3. Impact of interest rate reductions between calculated impacts per GGE for interest rates in the range of $\mathbf{8 - 3 0 \%}$ for a 10 year loan for $\mathbf{4 0 \%}$ of the total capital investment for a biochemical or thermochemical conversion facility of 800,000 DT annual capacity.

\begin{tabular}{rrr}
\multicolumn{1}{l|}{ Interest rate reduction } & Reduction in unit production costs (2011\$/GGE) \\
\hline$-2 \%$ & $0.05-0.07$ \\
\hline$-3 \%$ & $0.08-0.11$ \\
\hline$-5 \%$ & $0.14-0.18$ \\
\hline$-10 \%$ & $0.29-0.35$ \\
\hline$-15 \%$ & $0.45-0.51$
\end{tabular}

Economies of Scale: The higher bulk density of advanced 'commodity' feedstock allows larger volumes to be transported to the biorefinery with the same amount of truck loads. This allows the biorefinery to increase its size, which has the potential to reduce unit production costs per GGE for thermochemical and biochemical conversion pathways (Argo et al. 2013, Muth et al. 2014).

Table 6:4 summarizes the findings of two sizing papers (Argo et al. 2013, Muth et al. 2014). It shows the additional cost reductions per unit produced for biorefineries over 2 Million DT per year capacity, supplied via an advanced feedstock supply system, compared to the baseline of an 800,000 DT per year biorefinery with a conventional feedstock supply system. Note that the thermochemical comparisons compare the advanced system to an average value from conventional systems under low and high yield.

Table 6:4. Additional cost reductions per unit produced (in 2011\$/GGE) for biorefineries relying on an advanced feedstock supply system over 2 Million DT per year capacity compared to a 800,000 DT per year biorefinery baseline with a conventional feedstock supply system.

\begin{tabular}{lccc}
\multicolumn{1}{c}{ Capacity } & 2 Million DT/yr & 3 Million DT/yr & 4 Million DT/yr \\
Case & & 0.50 & 0.57 \\
\hline $\begin{array}{l}\text { Thermochemical: } \\
\text { Low ash, low moisture woody biomass }\end{array}$ & $0.10-0.19$ & 0.50 & 0.57 \\
\hline $\begin{array}{l}\text { Thermochemical: } \\
\text { Low ash, high moisture woody biomass }\end{array}$ & $0.03-0.08$ & 0.52 & 0.60 \\
\hline $\begin{array}{l}\text { Thermochemical: } \\
\text { High ash, low moisture woody biomass }\end{array}$ & $0.04-0.09$ & 0.52 & 0.60 \\
\hline $\begin{array}{l}\text { Thermochemical: } \\
\text { High ash, high moisture woody biomass }\end{array}$ & $0.04-0.08$ & & 0.23 \\
\hline $\begin{array}{l}\text { Biochemical: Corn stover } \\
\end{array}$ & 0.07 & 0.17 & \\
\end{tabular}


Conversion efficiency improvements: Preprocessing changes the feedstock's physical and chemical characteristics. Pretreatment, such as AFEX, is specifically designed to alter the physical and chemical characteristics of lignocellulosic biomass to improve its susceptibility to enzymatic attack (Bals et al. 2011). The advanced supply system also puts active controls in the supply system to manage moisture. Active moisture controls are a key element of current grain commodity systems. Preprocessing stabilizes feedstock material and facilitates commodity scale distribution of the biomass materials. The ability to manage moisture allows more biomass into the supply system and reduced risk for the biorefinery in feedstock quality.

Muth et al. 2014 calculated the mixed alcohol yields of woody feedstock with varying ash and moisture levels and different preprocessing levels in a thermochemical conversion unit. They found that yields were generally higher for preprocessed, homogeneous over non-preprocessed feedstock of varying quality. Assuming a baseline of an 800,000 DT per year thermochemical facility, the additional yield per ton of feedstock results in a cost reduction of US\$0.14 up to US\$0.51 per GGE produced (Table 6:5).

Table 6:5. Mixed alcohol yields (in gal/DT) as a function of preprocessing levels for different feedstock qualities and the respective impact per unit produced (in 2011\$/GGE).

\begin{tabular}{lrrr} 
Feedstock quality characteristics & $\begin{array}{r}\text { Conventional } \\
\text { (gal/DT) }\end{array}$ & $\begin{array}{r}\text { Advanced } \\
\text { (gal/DT) }\end{array}$ & $\begin{array}{r}\text { Cost reduction } \\
(2011 \$ / G G E)\end{array}$ \\
\hline Low ash, low moisture content & 93.86 & 98.47 & $\$ 0.14$ \\
\hline Low ash, high moisture content & 83.48 & 98.47 & $\$ 0.46$ \\
\hline High ash, low moisture content & 85.29 & 90.21 & $\$ 0.16$ \\
\hline High ash, high moisture content & 74.92 & 90.21 & $\$ 0.51$
\end{tabular}

Reduction of capital and operational costs at the biorefinery: The network of depots reduces capital investment and operational costs at the biorefinery in a variety of ways: preprocessing, storage, and potentially even pretreatment.

For example, a biochemical conversion facility based on a conventional, baled corn stover supply system requires different storage, receiving and handling equipment, plus the preprocessing (grinding, etc.) prior to pretreatment. Preprocessing at the depot eliminates bale storage, handling, and grinding. This also reduces the footprint and environmental impacts at the biorefinery, including fire hazards, rodent infestation, and localized odors normally associated with large-scale storage of non-aerobically stable feedstock such as corn stover bales. In situations where biorefineries source multiple feedstock types or forms, savings are even higher since the equipment for handling and prepossessing are eliminated for all feedstock types and forms (e.g., round corn stover bales, square wheat straw bales, woody and herbaceous biomass, etc.).

Table 6:6 outlines the respective costs associated with handling raw feedstock at the biorefinery in the conventional system, based on the latest INL SOT report. The total feedstock costs per pathway are currently above the US\$80 per ton cost target. The relative share of the handling costs in the total supply costs (US\$139.70 in the biochemical and US\$102.12 in the 
thermochemical case) were related to the US\$80 per ton cost target to achieve a cost reduction estimate per GGE.

The preprocessing steps accounted for in Table 6:6 are associated with a Standard Depot. A Quality Depot, e.g., with an AFEX pretreatment process, additionally eliminates the necessity for a pretreatment step at the biorefinery. Humbird et al. 2011 quantified the total installed costs for a dilute-acid pretreatment in a biochemical conversion facility of 800,000 DT per year at US\$29,900,000 (2007\$). This translates into US\$0.29 MFSP or US\$0.45 GGE (2011\$).

Table 6:6. Preprocessing costs at the biorefinery in a conventional supply system and savings achieved by outsourcing these steps to a depot.

\begin{tabular}{lrr} 
& Biochemical conversion & Thermochemical conversion \\
\hline $\begin{array}{l}\text { Total costs for handling at the } \\
\text { biorefinery (2011\$/DT) }\end{array}$ & $\$ 43.60$ & $\$ 22.61$ \\
\hline Share of total supply cost & $31 \%$ & $22 \%$ \\
\hline In relation to US\$80 supply cost target & $\$ 24.97$ & $\$ 17.71$ \\
\hline Cost per gal (2011\$/MFSP) & $\$ 0.32$ & $\$ 0.19$ \\
\hline Savings (2011\$/GGE) & $\$ 0.48$ & $\$ 0.29$
\end{tabular}

With respect to storage, current industry practice (e.g., at POET) is to have at least a 14 day storage of baled corn stover. A mature industry is expected to rely only on a 72 hour storage buffer at the biorefinery (Davis et al. 2013). Table 6:7 compares the storage types and costs for a conventional and advanced supply system at a biorefinery of 800,000 DT per year capacity. It shows that the advanced system is able to reduce costs associated with a more efficient storage and handling by US\$0.20 per GGE.

Table 6:7. Storage sizes, type, and cost comparison.

\begin{tabular}{lrr} 
& Conventional system & Advanced system \\
\hline Storage buffer & $\begin{array}{r}14 \text { days } \\
(30,865 \text { tons })\end{array}$ & 3 days \\
& Bale storage & $(6,614$ tons $)$ \\
\hline Storage type & $\$ 1.03$ & Bin storage \\
\hline Cost per ton & $\$ 31,767$ & $\$ 1.30$ \\
\hline Cost per day & $\$ 11,594,931$ & $\$ 8,598$ \\
\hline Total costs per year & $\$ 0.18$ & $\$ 3,138,277$ \\
\hline $\begin{array}{l}\text { Cost per gal } \\
(2011 \$ / M F S P)\end{array}$ & & $\$ 0.05$ \\
\hline Savings (2011\$GGE) & & $\$ 0.20$
\end{tabular}


Table 6:8 summarizes the system benefits for the different conversion pathway and depot options. We compare them to the annual depot network costs per GGE where 10 depots with an 80,000 DT per year output capacity are required per 800,000 DT per year biorefinery, and each depot is given a lifetime of 10 years. We see that overall system benefits well exceed the additional costs associated with the depot concept. Note that this is a preliminary analysis and not all benefits associated with the depot concept have been quantified and included in Table 6:7.

Table 6:8. Comparison of the additional preprocessing costs for a depot based supply system and its biorefinery investment and operation cost-benefits (based on 2011\$/GEE).

\begin{tabular}{|c|c|c|c|}
\hline & $\begin{array}{r}\text { Biochemical } \\
(2011 \$ / G G E)\end{array}$ & $\begin{array}{r}\text { Thermochemical } \\
(2011 \$ / G G E)\end{array}$ & $\begin{array}{r}\text { AFEX pretreatment } \\
(2011 \$ / G G E)\end{array}$ \\
\hline Depot costs & $+\$ 0.06$ to $+\$ 0.14$ & Up to $+\$ 0.11$ & Up to $+\$ 0.32$ \\
\hline \multicolumn{4}{|l|}{ Biorefinery benefits } \\
\hline $\begin{array}{l}\text { Supply risk (interest rate) } \\
\text { reduction by }-2 \% \text { to }-5 \%\end{array}$ & $-\$ 0.05$ to $-\$ 0.18$ & $-\$ 0.05$ to $-\$ 0.18$ & $-\$ 0.05$ to $-\$ 0.18$ \\
\hline $\begin{array}{r}\text { Economies of scale } \\
\text { (for biorefinery capital } \\
\text { equipment) }\end{array}$ & $-\$ 0.07$ to $-\$ 0.23$ & $-\$ 0.06$ to $-\$ 0.60$ & $-\$ 0.07$ to $-\$ 0.23$ \\
\hline $\begin{array}{r}\text { Conversion efficiency } \\
\text { improvements }\end{array}$ & (lack of data) & $-\$ 0.14$ to $-\$ 0.51$ & (lack of data) \\
\hline $\begin{array}{r}\text { Reduced storage and } \\
\text { handling equipment }\end{array}$ & Up to $-\$ 0.20$ & Up to $-\$ 0.20$ & Up to $-\$ 0.20$ \\
\hline $\begin{array}{r}\text { Reduced preprocessing } \\
\text { equipment }\end{array}$ & Up to $-\$ 0.48$ & Up to $-\$ 0.29$ & Up to $-\$ 0.48$ \\
\hline $\begin{array}{r}\text { Reduced pretreatment } \\
\text { equipment }\end{array}$ & (not applicable) & (not applicable) & Up to $-\$ 0.45$ \\
\hline TOTAL & $-\$ 0.75$ to $-\$ 0.96$ & $-\$ 0.63$ to $-\$ 1.67$ & $-\$ 0.94$ to $-\$ 1.22$ \\
\hline
\end{tabular}

Note: not all benefits associated with the depot concept have been quantified and included in this table.

Additional benefits (not quantified): Advanced supply systems largely decouple the biorefinery location from feedstock location. Preprocessed feedstock is more easily and efficiently transported to the biorefinery (e.g., via rail), allowing access to isolated and low yield areas, and thereby increasing the volume of material that can cost effectively enter the system. In this way, it provides additional market options for geographically stranded feedstock producers (i.e., fragmented feedstock, not within a 50-mile biorefinery radius that cannot be collected economically with conventional system), letting them sell excess product in a commodity market.

Preprocessed feedstock has consistent physical properties, allowing it to use standardized, highefficiency, high-volume grain handling and transport systems and equipment. Standardization of feedstocks also allows biorefineries to establish tight operating specifications and optimize the conversion process based on narrow feedstock characteristics. The similarity to bulk-solid grain commodity system advantages can be illustrated by the key benefits described in Schnepf 2006: 
- Aerobically stable and flowable product,

- Storability,

- Replicable high-capacity equipment can be used to economically connect supplies with markets across large distances without spoiling,

- Ability to economically connect feedstock with markets 200 or more miles away ensures reliable supply by reducing production risks, and broadens accessibility by creating regional and national markets.

- Organized and predictable commodity transfer between buyers and sellers and among markets limits spatial price differences, and therefore facilitating remote resources to enter the market.

Benefits mentioned here are realized because of the diversification that the advanced system allows. Analysis in forthcoming research quantifies these benefits that are realized by sourcing feedstock from diverse geographic locations. The findings suggest that the advanced system reduces the uncertainty and therefore the volume risk exposure to the biorefinery as compared to the conventional supply system.

Finally, advanced supply systems facilitate more sustainable land practices since several crop types can be used. It also allows biorefineries to be efficiently sited and optimized for market demand, distribution infrastructure, proximity to utilities, and access to skilled workers. 


\section{Conclusions}

Depot systems dramatically reduce both the temporal and spatial biomass cost variability and allow access to substantially larger quantities of biomass by decoupling the biorefinery from feedstock location. Preprocessed feedstock is higher in bulk density and has better flow characteristics which eases and improves transport to and within the biorefinery (via rail, ship, conveyor belts, etc.). This increases the volume of material that can cost effectively enter the system by providing access to isolated and/or low yield areas, and extends the sourcing radius for the biorefinery well beyond the 50-mile radius limitation typical for conventional bale supply and mitigates risks associated with feedstock outtakes (e.g., due to adverse weather, pests, and resulting competition for the remaining feedstock within close range). The biorefinery should thus be less vulnerable to price volatility and may not need to contract directly with feedstock producers. This could also help leverage the reluctance from the investment community to invest in large facilities, dependent on regional feedstock only.

The variability of biomass supply to biorefineries is recognized as an investment risk by financial institutions. Reducing the variability of feedstock supply will reduce associated project risks which will be reflected in the annual percentage rate (APR) for financing biorefineries. Also, depots will reduce the handling infrastructure (for raw biomass in various formats) at the biorefinery and thus reduce investment and operating costs. This should further reduce investment risks. Furthermore, depot preprocessing reduces the storage footprint and environmental impacts, such as the fire hazards, rodent infestation, and localized odors normally associated with large-scale storage of non-aerobically stable feedstock that are typical of using conventional supply systems.

The depot concept does not imply a particular set-up or limitation in the type of depot or its configuration. A multitude of configurations is possible. However, to achieve the supply system benefits, a standard depot should at least include particle size reduction, moisture mitigation, and densification. If a depot also addresses feedstock quality specifications, to improve functions at the biorefinery, quality depots may include additional preprocessing steps (e.g., leaching, chemical treatment, or washing).

We apply these two distinct set-ups, Standard and Quality Depot, to characterize the main structures of a depot. For each type, we develop specific configurations that are analyzed from a technical and economic viewpoint. For the Standard Depot, we analyze three design concepts each a step improvement over its counterpart; a Conventional Pelleting Process (CPP), a HighMoisture Pelleting Process (HMPP), and a HMPP with Fractional Milling (HMPPFM). The Quality Depot includes active quality management processes. We analyzed the Ammonia Fiber Expansion (AFEX) process as a representative design but more specifically because we had data and information available.

The economic depot assessment reveals medium (Standard Depot) to high (Quality Depot) initial investment costs. The production costs per DT vary significantly across the configurations, with the HMPP and HMPPFM being the lowest (US\$30 and US\$28 per DT, respectively), the CPP for woody biomass representing the medium (US\$49 per DT), and the CPP for corn stover and AFEX representing the high cost ranges (US\$62 and US\$70 per DT, respectively). Each configuration is shown to be heavily dependent on electricity prices, due to the energy consumption levels for grinders and dryers, particularly in the CPP and AFEX configurations. 
Across and within the configurations assessed in this report, depots may evolve differently. They may be owned, organized, and designed differently. The latter in particular with respect to the regional biomass supply (seasonality, mixture, storability, etc.).

The transition from the current, conventional feedstock supply system to an advanced, depot based supply system can take on various forms. Depots are currently not utilized by the biomass industry but their appearance in the system is expected to occur organically as industry adds preprocessing equipment and storage to existing biorefinery infrastructure to help the biorefinery buffer supply volume and price risks as the primary goal. At first, quality control may not be of major importance to the biorefinery. It may however become a secondary driver at a later stage; especially with increases in depot capacity. The equipment would essentially be located within or close proximity to the compounds of the biorefinery.

In terms of organizational structure, the depot would probably be owned by the biorefinery at first. At a later stage, it may be outsourced and become an independent business entity. At that stage, different types of ownership become possible (e.g., farmer cooperatives) and the depot will have a requirement to be a self-sufficient, cost effective business entity. In contrast to biorefineries integrating upstream, depots may also originate from the farmer side when multiple producers ban together to take advantages of economies of scale or mitigate business risks.

In terms of the two depot classes, Standard Depots are most likely to be independent from the biorefinery while Quality Depots are more likely to be owned by the biorefinery due to the ties to the downstream conversion process. Additionally, Standard Depots may be owned by the biorefinery, but operated by the producer consistent with the U.S. grain elevators. The location of either a Standard or Quality Depot will most likely be driven by the ownership profile (biorefinery vs. cooperation) as well as the existing logistical infrastructure (e.g., rail lines, shipping terminals). It is also more likely that as quality becomes more uniform, the further away the depot will be located from the biorefinery. This makes decentralized locations possible, also in low-yield areas. The key depot characteristics, in our view, influencing the transition period include ownership structures, location, and sizing decisions, which relate to specialized (single feedstock) or flexible (multi-feedstock) depots.

The transition from the current, conventional feedstock supply, to an advanced, depot based supply system faces several challenges. The main one is that the advanced supply system entails larger direct investment costs than the conventional supply system. At the same time it creates wider system cost benefits, in particular at the conversion end. It will be challenging to justify the larger initial investments without a full appreciation of the downstream cost savings.

Future research with respect to the depot concept should entail an overall system analysis quantifying the economic and energy balance across the whole biorefinery chain; essentially helping to optimize depot size and location. Also, this report does not account for environmental impacts and thus the respective differences between the selected depot concepts. While Argo et al. 2013 pointed out that the advanced supply system may entail higher energy costs and a potentially higher global warming potential, process flow and dryer technology improvements in recent years suggest that this picture may have changed and a new comparison is needed.

Different depot configurations should be assessed and compared with respect to their lifecycle emissions. AFEX, e.g., has been shown to have the highest direct $\mathrm{CO}_{2}$ emissions in a comparison to six other pretreatment technologies (Tao et al. 2014). 


\section{References}

AAEA (2000). Commodity costs and returns estimation handbook, report of the AAEA Task Force on Commodity Costs and Returns. Ames, IA, USA, Agricultural \& Applied Economics Association.

Aden, A., M. Ruth, K. Ibsen, J. Jechura, K. Neeves, J. Sheehan, B. Wallace, L. Montague, A. Slayton and J. Lukas (2002). Lignocellulosic Biomass to Ethanol Process Design and Economics Utilizing Co-Current Dilute Acid Prehydrolysis and Enzymatic Hydrolysis for Corn Stover. Golden, CO, USA, National Renewable Energy Laboratory. NREL/TP-51032438: 154.

Anex, R. P., A. Aden, F. K. Kazi, J. Fortman, R. M. Swanson, M. M. Wright, J. A. Satrio, R. C. Brown, D. E. Daugaard, A. Platon, G. Kothandaraman, D. D. Hsu and A. Dutta (2010). "Techno-economic comparison of biomass-to-transportation fuels via pyrolysis, gasification, and biochemical pathways." Fuel 89, Supplement 1(0): S29-S35.

Argo, A. M., E. C. D. Tan, D. Inman, M. H. Langholtz, L. M. Eaton, J. J. Jacobson, C. T. Wright, D. J. Muth, M. M. Wu, Y.-W. Chiu and R. L. Graham (2013). "Investigation of biochemical biorefinery sizing and environmental sustainability impacts for conventional bale system and advanced uniform biomass logistics designs." Biofuels, Bioproducts and Biorefining 7(3): 282-302.

ASABE (2006). ASABE Standards: Agricultural Machinery Management Data, America Society of Agricultural and Biological Engineers. http://asae.frymulti.com/standards.asp.

Balan, V., B. Bals, S. P. S. Chundawat, D. Marshall and B. Dale (2009). Lignocellulosic biomass pretreatment using AFEX. Biofuels: Methods and Protocols. J. R. Mielenz. New York, NY, USA, Methods in Molecular Biology, Humana Press. 581: 61-77.

Bals, B., C. Wedding, V. Balan, E. Sendich and B. Dale (2011). "Evaluating the impact of ammonia fiber expansion (AFEX) pretreatment conditions on the cost of ethanol production." Bioresource Technology 102(2): 1277-1283.

Bals, B. D. and B. E. Dale (2012). "Developing a model for assessing biomass processing technologies within a local biomass processing depot." Bioresource Technology 106(0): 161 169.

Bals, B. D., C. Gunawan, J. Moore, F. Teymouri and B. E. Dale (2014). "Enzymatic hydrolysis of pelletized AFEX ${ }^{\mathrm{TM}}$-treated corn stover at high solid loadings." Biotechnology and Bioengineering 111(2): 264-271.

Boavida, D., P. Abelha, I. Gulyurtlu, B. Valentim and M. J. L. D. Sousa (2012). "A study on coal blending for reducing NOx and N2O levels during fluidized bed combustion." Clean Air 5: 175-191.

Bonner, I. J., K. G. Cafferty, D. J. Muth, M. D. Tomer, D. E. James, S. A. Porter and D. L. Karlen (2014). "Opportunities for enrgy crop production based on subfield scale distribution of profitability." Under Review at 'Energies' 7(1).

Brown, W. J. (2009). American Colossus: The Grain Elevator, 1843 to 1943. New York, NY, USA, Colossal Books.

Cafferty, K. G., D. J. Muth, J. J. Jacobson and K. M. Bryden (2013). Model Based Biomass System Design of Feedstock Supply Systems for Bioenergy Production. ASME 2013 International Design Engineering Technical Conferences and Computers and Information in Engineering Conference, Portland, OR, USA, ASME.

Campbell, T. J., F. Teymouri, B. Bals, J. Glassbrook, C. D. Nielson and J. Videto (2013). "A packed bed ammonia fiber expansion reactor system for pretreatment of agricultural residues at regional depots." Biofuels 4(1): 23-34. 
Carnohan, S., J. J. Jacobson, A. Ford and A. Beall (2014). Simulating Pelletization Strategies to Reduce the Biomass Supply Risk at America's Biorefineries. Delf.

Carolan, J., S. Joshi and B. E. Dale (2007). "Technical and Financial Feasibility Analysis of Distributed Bioprocessing Using Regional Biomass Pre-Processing Centers." Journal of Agricultural \& Food Industrial Organization 5(2): 1203-1230.

CEM (2011). Plant Cost Index. Chemical Engineering Magazine.

Cook, M. L. (1995). "The Future of US Agricultural Cooperatives: A Neo-Institutional Approach." American Journal of Agricultural Economics 77(December): 1153-1159.

Davis, R., L. Tao, E. C. D. Tan, M. J. Biddy, G. T. Beckham, C. Scarlata, J. Jacobson, K. Cafferty, J. Ross, J. Lukas, D. Knorr and P. Schoen (2013). Process Design and Economics for the Conversion of Lignocellulosic Biomass to Hydrocarbons: Dilute-Acid and Enzymatic Deconstruction of Biomass to Sugars and Biological Conversion of Sugars to Hydrocarbons. Golden, CO, USA, National Renewable Energy Laboratory, Idaho National Laboratory, Harris Group Inc. http://www.nrel.gov/docs/fy14osti/60223.pdf

DOE (2011). U.S. Billion-Ton Update: Biomass Supply for a Bioenergy and Bioproducts Industry. R. D. Perlack and B. J. Stokes. Oak Ridge National Laboratory, Oak Ridge, TN, U.S. Department of Energy: 227.

DOE (2012). Biomass Densification Workshop: Transforming Raw Biomass to Feedstock Summary Report. K. Kenney, L. Ovard and J. R. Hess. Idaho Falls, ID, USA, U.S. Department of Energy, Idaho National Laboratory.

DOE (2013). Multi-Year Program Plan, US Department of Energy, Energy Efficiency and Renewable Energy, Bioenergy Technology Office. https://www1.eere.energy.gov/bioenergy/pdfs/mypp_may_2013.pdf Accessed July 1, 2014.

Dutta, A., M. Talmadge, J. Hensley, M. Worley, D. Dudgeon, D. Barton, P. Groenendijk, D. Ferrari, B. Stears, E. Searcy, C. Wright and J. Hess (2011). Process Design and Economics for Conversion of Lignocellulosic Biomass to Ethanol - Thermochemical Pathway by Indirect Gasification and Mixed Alcohol Synthesis. Golden, CO, National Renewable Energy Laboratory.

Eranki, P. L., B. D. Bals and B. E. Dale (2011). "Advanced Regional Biomass Processing Depots: a key to the logistical challenges of the cellulosic biofuel industry." Biofuels, Bioproducts and Biorefining 5(6): 621-630.

Gold, G. (1975). Modern Commodity Futures Trading, Commodity Research Bureau, Inc.

Hess, J. R., K. L. Kenney, L. P. Ovard, E. M. Searcy and C. T. Wright (2009). Commodity-Scale Production of an infrastructure-compatible bulk solid from herbaceous lignocellulosic biomass. Uniform-format Bioenergy feedstock supply system design report series, Idaho National Laboratory, USA.

Hill, L. D. (1990). Grain grades and standards: Historical issues shaping the future. Chicago, IL, USA, University of Illinois Press.

Hoover, A. N., J. S. Tumuluru, F. Teymouri, J. Moore and G. Gresham (2014). "Effect of pelleting process variables on physical properties and sugar yields of ammonia fiber expansion pretreated corn stover." Bioresource Technology 164(0): 128-135.

Humbird, D., R. Davis, L. Tao, C. Kinchin, D. Hsu, A. Aden, P. Schoen, J. Lukas, B. Olthof, M. Worley, D. Sexton and D. Dudgeon (2011). Process Design and Economics for the Conversion of Lignocellulosic Biomass to Ethanol: Dilute-Acid Pretreatment and Enzymatic Hydrolysis of Corn Stover. Golden, CO, USA, National Renewable Energy Laboratory: 147. http://www.nrel.gov/biomass/pdfs/47764.pdf Accessed June 30, 2014.

INL (2013). Feedstock Supply System Design and Economics for Conversion of Lignocellulosic Biomass to Hydrocarbon Fuels - Conversion Pathway: Biological Conversion of Sugars to Hydrocarbons: The 2017 Design Case, Idaho National Laboratory. 
Inman, D., N. Nagle, J. Jacobson, E. Searcy and A. E. Ray (2010). "Feedstock handling and processing effects on biochemical conversion to biofuels." Biofuels, Bioproducts and Biorefining 4(5): 562-573.

Jacobson, J. and K. Cafferty (2013). Define Approach and metrics for optimizing feedstock production. Idaho Falls, ID, USA, Idaho National Laboratory. ID\#: 4.1.2.20ML1.

Jacobson, J., K. Cafferty and I. Bonner (2014). A comparison of the Conventional and Blended Feedstock design cases will be completed to demonstrate the potential of each design to meet the \$3/GGE BETO goal. Idaho Falls, ID, USA, Idaho National Laboratory. ID\#: 4.1.2.20ML2.

Karlen, D. (2014). E-Mail Exchange on Grain Cooperatives, USDA, May 12.

Kenney, K. L., W. A. Smith, G. L. Gresham and T. L. Westover (2013). "Understanding biomass feedstock variability." Biofuels 4: 111-127.

Kroll, S. and I. Shishko (1973). The Commodity Futures Market Guide, Harper and Row.

Lamers, P., J. K. Hansen, J. J. Jacobson and K. Cafferty (2014). "How feedstock supply system design influences the biorefinery's operational risk and profitability." In preparation for submission.

Morgan, D. (1979). Merchants of Grain. New York, NY; USA, Viking.

Muth, D., J. Jacobson, K. Cafferty and R. Jeffers (2013). Feedstock Pathways for Bio-oil and Syngas Conversion Pathways. Idaho Falls, ID, USA, Idaho National Laboratory.

Muth, D. J., M. H. Langholtz, E. C. D. Tan, J. J. Jacobson, A. Schwab, M. M. Wu, A. Argo, C. C. Brandt, K. G. Cafferty, Y.-W. Chiu, A. Dutta, L. M. Eaton and E. M. Searcy (2014). "Investigation of thermochemical biorefinery sizing and environmental sustainability impacts for conventional supply system and distributed pre-processing supply system designs." Biofuels, Bioproducts and Biorefining 8: 545-567.

Naegle, N. (2014). Update on NREL IBRF findings - interface meeting April 15. Golden, CO, USA, National Renewable Energy Laboratory.

Peters, M. S., C. D. Timmurhaus and R. E. West (1968). Plant design and economics for chemical engineers. New York, NY, McGraw-Hill.

Reddy, D. V. and N. Krishna (2009). "Precision animal nutrition: A tool for economic and ecofriendly animal production in ruminants." Livestock Research for Rural Development 21(3).

Ruth, M. L. and S. R. Thomas (2003). The effect of corn stover composition on ethanol process economics. The 25th Symposium on Biotechnology for Fuels and Chemicals, Breckenridge, CO, USA, 4-7 May.

Sami, M., K. Annamalai and M. Wooldridge (2001). "Co-firing of coal and biomass fuel blends." Progress in Energy and Combustion Science 27(2): 171-214.

Schnepf, R. (2006). Price Determination in Agricultural Commodity Markets: A Primer. $\underline{\text { CRS }}$ Report for Congress. Washington, DC, USA, Congressional Research Service (CRS). http://research.policyarchive.org/2678.pdf Accessed June 30, 2014.

Searcy, E. M., D. B. Blackwelder, M. E. Delwiche, A. E. Ray and K. L. Kenney (2011). Validate the cost of feedstock at $\$ 61.57 /$ dry US ton for the production of ethanol via thermochemical conversion. Idaho National Laboratory (INL).

Shah, A., M. J. Darr, K. Webster and C. Hoffman (2011). "Outdoor storage characteristics of single-pass large square bales in Iowa." Energies 4(10): 1687-1695.

Shekiro, J., E. M. Kuhn, N. J. Nagle, M. P. Tucker, R. T. Elander and D. J. Schell (2014). "Characterization of Pilot-Scale Dilute Acid Pretreatment Performance using Deacetylated Corn Stover." Biotechnology for Biofuels 7(23): 10.

Shih, J.-S. and H. C. Frey (1995). "Coal blending optimization under uncertainty." European Journal of Operational Research 83(3): 452-465. 
Sultana, A., A. Kumar and D. Harfield (2010). "Development of agri-pellet production cost and optimum size." Bioresource Technology 101(14): 5609-5621.

Tao, L., E. C. D. Tan, A. Aden and R. T. Elander (2014). CHAPTER 19 Techno-Economic Analysis and Life-Cycle Assessment of Lignocellulosic Biomass to Sugars Using Various Pretreatment Technologies. Biological Conversion of Biomass for Fuels and Chemicals: Explorations from Natural Utilization Systems, The Royal Society of Chemistry: 358-380.

Templeton, D. W., A. D. Sluiter, T. K. Hayward and B. R. Hames (2009). "Assessing corn stover composition and source of variability via NIRS." Cellulose 16(4): 621-639.

Teymouri, F., L. Laureano-Perez, H. Alizadeh and B. E. Dale (2005). "Optimization of the ammonia fiber explosion (AFEX) treatment parameters for enzymatic hydrolysis of corn stover." Bioresource Technology 96: 2014-2018.

Thrush, A. J. (2003). History, Organization and Strategies for Grain Producers and the Grain Industry in Michigan. MSc, Michigan State University.

Tumuluru, J. S., K. G. Cafferty and K. L. Kenney (2014). Techno-economic Analysis of Conventional, High Moisture Pelletization and Briquetting Process. ASABE and CSBE/SCGAB Annual International Meeting Montreal, Quebec, Canada

Vachal, K. and D. Tolliver (2001). Regional Elevator Survey: Grain Transport and Industry Trends For Great Plains Elevators. Fargo, ND, USA, Upper Great Plains Transportation Institute, North Dakota State University. http://www.ugpti.org/pubs/pdf/DP143.pdf Accessed May 12, 2014.

Webb, E., M. Hilliard, C. Brandt, S. Sokhansanj, L. Eaton and M. M. Gonzalez (2014). Spatial Analysis of Depots for Advanced Biomass Processing. Oak Ridge, TN, USA, Oak Ridge National Laboratory.

Weiss, N. D., J. D. Farmer and D. J. Schell (2010). "Impact of corn stover composition on hemicellulose conversion during dilute acid pretreatment and enzymatic cellulose digestibility of the preatrated solids." Bioresource Technology 101(2): 674-678. 


\section{Appendix A}

\section{A-1 Dry Matter Loss}

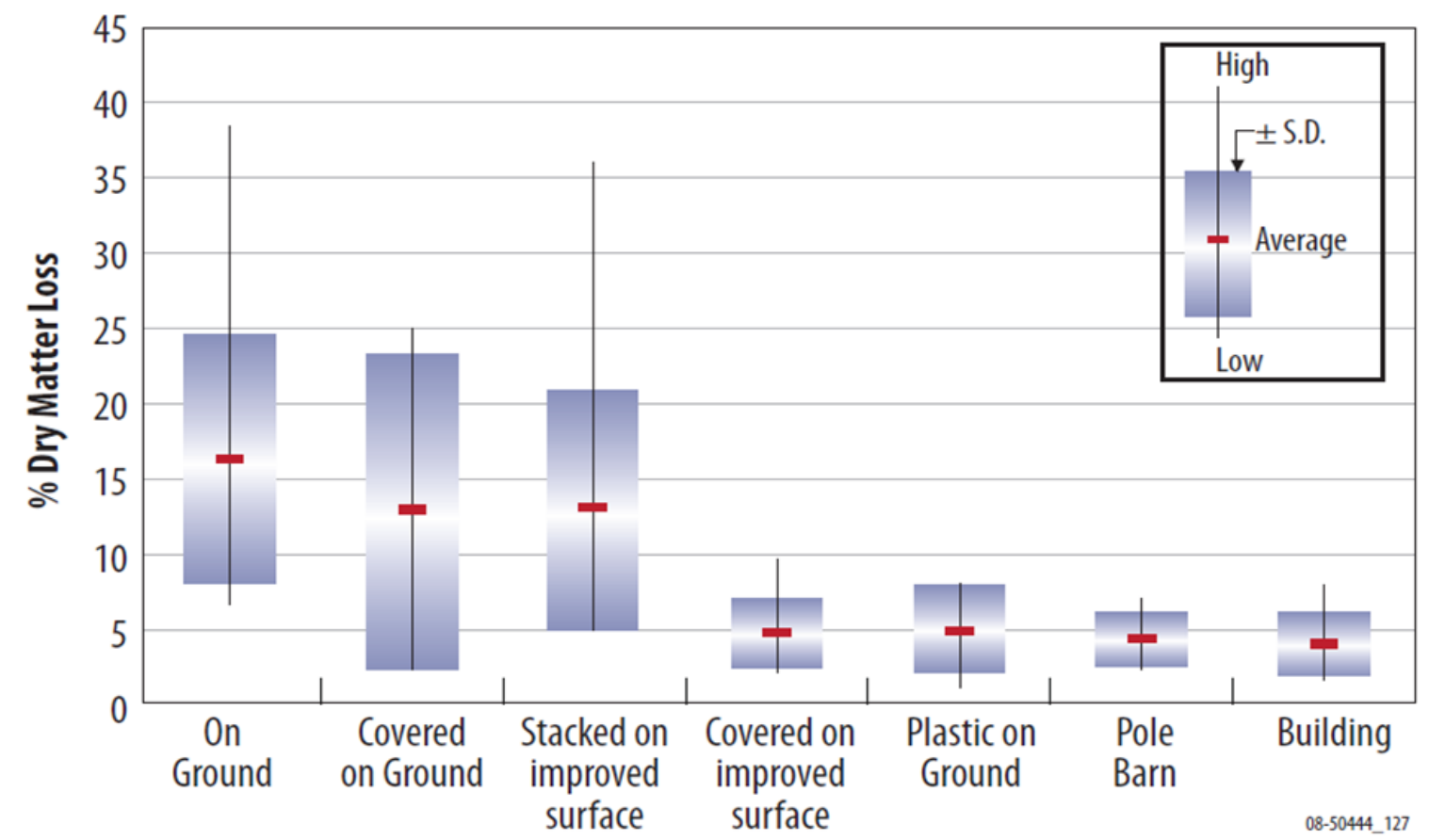

Figure A1:1. Average DML losses experienced under different storage configurations Hess et al. 2009.

\section{A-2 Blending}

Regional biomass production supply curves from the BT2 (DOE 2011) were used to identify "high impact" 30 " scenarios to develop and demonstrate the 2017 feedstock supply chain scenarios at the US\$80 per DT target. A scenario below focuses on a South-Eastern U.S. delivering a formulated feedstock for fast pyrolysis conversion pathway that produces a bio-oil. It is important to note that the baseline scenarios are regionally focused to establish feedstock costs and technical performance requirements of the supply chain; however, the supply chain technologies and designs are broadly applicable across the U.S.

Using a least cost formulation spatial tool developed at INL, a high impact formulation based on forest thinning, logging residues and plantation-grown loblolly pine creates an opportunity to meet the feedstock cost and quality targets for the bio-oil conversion pathway. Forest thinnings and logging residues are low cost resources to procure, but often have unfavorable quality specs, specifically high ash content. Money saved in procuring these biomass resources (instead of pulpwood for instance) can be applied to address quality issues, such as active ash management. The identified formulation uses $40 \%$ forest thinnings, $40 \%$ logging residues, and $20 \%$ purposegrown pine (Table A2:1). Both the forest thinnings and logging residues are reduced to $2.25 \%$ ash with a hot water extraction process. The purpose grown pine is debarked and chipped at the landing resulting in an ash content of $0.5 \%$. Forest thinnings and logging residues are delivered

\footnotetext{
${ }^{30}$ To be considered high impact, the feedstock must be domestically available and have the agronomically and ecologically sustainable ultimate availability potential to produce at least 1 billion gallons per year of an acceptable biofuel.
} 
through supply chains ${ }^{31}$ that include the ash reduction unit operation at costs below the US\$80 per DT target. However, the ash reduction technology has not yet been demonstrated to achieve levels below $2 \%$. The $20 \%$ fraction of clean pine chips does not meet the cost target, at nearly US\$100 per DT, but it does provide low ash material to support meeting that conversion specification. When blended, the complete formulation meets both the cost and feedstock quality targets.

Table A2:1. Costs and specifications for woody feedstocks and blends for thermochemical conversion.

\begin{tabular}{lccc}
\hline \multicolumn{1}{c}{ Feedstock } & $\begin{array}{c}\text { Reactor Throat } \\
\text { Feedstock Cost } \\
\text { (US\$/dry ton) }\end{array}$ & $\begin{array}{c}\text { Formulation } \\
\text { Fraction (\%) }\end{array}$ & $\begin{array}{c}\text { Reactor } \\
\text { Throat Ash }\end{array}$ \\
\hline Forest thinnings & 76.40 & 40 & 2.25 \\
\hline Logging residues $^{32}$ & 74.13 & 40 & 2.25 \\
\hline Purpose grown pine & 98.52 & 20 & 0.5 \\
\hline Delivered formulation totals & 79.92 & 100 & 1.9 \\
\hline
\end{tabular}

The cost estimates for the South-East blends the three feedstocks (thinnings, residues, and pulpwood) assume initial harvest, collection, and preprocessing (i.e., de-barking and size reduction) at the landing site while secondary preprocessing, storage, and handling occur within the biorefinery gates. At the landing all feedstocks are comminuted, but only pulpwood includes a debarking process. Pulpwood preprocessing involves grinding and drying. Thinnings and residues preprocessing includes a chip cleaning operation as well as a dryer and grinder. Note that many additional design elements could be incorporated to meet cost targets, including densification (including high-moisture densification), ash reduction, fractionation, thermal and hydrothermal treatments, and other developing technologies.

Table A2:2 shows the projected magnitude of the potential reduction in the feedstock logistics costs for a fast pyrolysis conversion process from 2009 through 2017. Preliminary results on feedstock supply chains delivering material to cellulosic sugar, bio-oil, and syngas conversion pathways suggest that with the ability to blend multiple feedstocks and include some preprocessing operations, it will be possible to acquire high biomass volumes, reduce feedstock variability to meet biorefinery in-feed specifications and meet the required US\$80 per DT cost of feedstock to the throat of the biorefinery.

More research is needed on both the performance of blended material and the blending strategies themselves, as well as other technologies incorporated into advanced designs. Also, additional analysis is required to understand the behavior that blended feedstocks will have on overall fuel conversion. Even though it may be possible to blend to specification as measured by composition and physical properties, an additional challenge of the blended feedstock approach is to have the blended feedstock actually perform as well as or better than a singular feedstock in the conversion process. Better understanding of the interactions of blendstocks in the conversion

\footnotetext{
${ }^{31}$ For more details on the specific design used to achieve this cost target, see Muth et al. 2013.

${ }^{32}$ For the purposes of this analysis, residues do not include costs for harvest and collection, as they are moved to the landing while attached to the merchantable portion of the tree (for example, timber or pulpwood).
} 
process will require additional research and development to better inform blended feedstock development.

Table A2:2. Feedstock logistics costs for feedstock for a pyrolysis conversion process. ${ }^{33}$

\begin{tabular}{lcccccc}
\hline \multirow{2}{*}{\multicolumn{1}{c}{2011 US\$ }} & $\mathbf{2 0 0 9}$ & $\mathbf{2 0 1 0}$ & $\mathbf{2 0 1 1}$ & $\mathbf{2 0 1 2}$ & $\mathbf{2 0 1 3}$ & $\mathbf{2 0 1 7}$ \\
\cline { 2 - 7 } & SOT & SOT & SOT & SOT & Projection & Projection \\
\hline Total feedstock logistics, US\$/dry ton & 106.80 & 102.84 & 90.45 & 79.59 & 114.15 & 79.92 \\
\hline Feedstock & Pine & Pine & Pine & Pine & $\begin{array}{c}\text { Woody } \\
\text { Blend }\end{array}$ & $\begin{array}{c}\text { Woody } \\
\text { Blend }\end{array}$ \\
\hline $\begin{array}{l}\text { Grower payment } \\
\text { US\$/dry ton }\end{array}$ & 15.90 & 15.90 & 15.90 & 15.90 & 43.18 & 9.45 \\
\hline $\begin{array}{l}\text { Total feedstock logistics (excluding } \\
\text { grower payment) US\$/dry ton }\end{array}$ & 90.90 & 86.94 & 74.55 & 63.69 & 70.97 & 70.47 \\
\hline $\begin{array}{l}\text { Harvest and collection } \\
\text { Landing and preprocessing }\end{array}$ & 24.89 & 23.77 & 23.15 & 22.24 & 20.83 & 13.88 \\
\hline
\end{tabular}

\section{A-3 Basic Assumptions}

The TEA calculations, as they only cover 'within-gate' costs, does not specifically locate the depots.

Table A3:1. Economic parameter assumptions.

\begin{tabular}{lc}
\hline Annual interest rate & $6 \%$ \\
\hline Taxes & $1 \%$ \\
\hline Housing & $.75 \%$ \\
\hline Insurance & $.25 \%$ \\
\hline Labor rate grinder (US\$) & 15.03 \\
\hline Labor rate pellet mill (US\$) & 15.71 \\
\hline Number of operator per machine & 0.5 \\
\hline Number of shifts per day & 3 \\
\hline Number of hours per week per worker & 40 \\
\hline Number of weeks per year & 50 \\
\hline
\end{tabular}

33 Through 2012, the feedstock is a debarked southern pine chip. For 2013 through 2017, the feedstock is a blend. Costs are based on research and analysis conducted at U.S. DOE National Labs. Note that the grower payment for 2013 and 2017 projection is the weighted average associated with a blend scenario. Grower payment includes harvest, collection and landing preprocessing costs, but these cost are also reflected in the feedstock logistics cost to demonstrate all logistics components. For 2013, the blend is $87 \%$ pulpwood, $3 \%$ thinnings, and $10 \%$ residues. For 2017 , the blend is $20 \%$ pulpwood, $40 \%$ thinnings, and $40 \%$ residues. These blends were chosen based on the ability to meet downstream specifications for conversion. For 2013, pulpwood must contribute most because of the inability to remove ash. In 2017, ash technology is assumed to improve therefore allowing for more residue and thinnings that have lower grower payments associated. 
Table A3:2. Average feedstock characteristics and process parameter assumptions.

\begin{tabular}{lc}
\hline Feedstock name & Corn Stover \\
\hline Moisture received at depot & $30 \%$ \\
\hline Moisture level after densification & $9 \%$ \\
\hline Screen size at stage-1 grinding & $2 "-6^{\prime \prime *}$ \\
\hline Screen size at stage-2 grinding & $3 / 16^{\prime \prime}$ \\
\hline Bulk density when received at depot & $12 \mathrm{lbs} / \mathrm{ft}^{3}$ \\
\hline Bulk density after densification & $35 \mathrm{lbs} / \mathrm{ft}^{3}$ \\
\hline \multicolumn{2}{c}{ * screen size changes due to fractional milling }
\end{tabular}

\section{A-4 Formulae applied}

Cost year indices: The cost-year of 2011 was chosen for this analysis to keep the consistency across all DOE-BETO platforms for which similar "design case target" reports are being established during 2013-2014 efforts. Capital costs provided in a year other than 2011US\$ were adjusted using the Plant Cost Index from Chemical Engineering Magazine (CEM 2011) to a common basis year of 2011.

The general formula for year-dollar back-casting is:

$$
2011 \text { Cost }=(\text { Base Cost })\left(\frac{2011 \text { Cost Index }}{\text { Base Year Index }}\right)
$$

Total capital investment: Section 4 describes the details of the conceptual process design and how the sequence of process operation is determined. The list of equipment can be determined by performing a detailed study of everything required to make the depot operational. A complete list of the equipment is provided in Appendix A-5, along with equipment purchased and installed costs. The equipment prices used in this analysis are obtained from local dealers. The Agricultural \& Applied Economics Association (AAEA) indicates that the difference between purchase price and list price may be up to 15\% (AAEA 2000). While this quoted price may be the list price, no adjustment of this price per AAEA guidance was applied.

Once the total fixed capital equipment cost has been determined in the year of interest, we add several additional equipment (e.g. electrical installation, instrumentation and control), other direct cost (e.g., yard improvements, land, building, etc.) and indirect costs(e.g., engineering and supervision, construction expenses, contractor's fee, contingency, etc.) to determine the total capital investment. These costs are estimated based on Peters et al. 1968, and are considered part of the fixed capital investment.

Ownership cost: Ownership cost consists of interests, depreciation cost, insurance, housing, and taxes.

Interest and depreciation (I\&D)

The ASABE lists two different methods for costing depreciation and interest: (1) calculate depreciation and interest separately, or (2) calculate depreciation and interest on the value to be 
depreciated and then calculate interest on the salvage value. The AAEA uses the second method, which can be expressed as the following equation:

where

$$
I \& D=(P-S)\left[\frac{(i)(1+i)^{n}}{\left\{(1+i)^{n}\right\}-1}\right]+S \times i
$$

$$
\begin{array}{ll}
\mathrm{I} \& \mathrm{D} & =\text { Interest and depreciation } \\
\mathrm{P} & =\text { purchase price of equipment } \\
\mathrm{i} & =\text { annual interest rate } \\
\mathrm{n} & =\text { life of the equipment in years } \\
\mathrm{k} & =\text { sum of rates for taxes, housing (shelter), insurance } \\
\mathrm{S} & =\text { salvage value (salvage value } \% \times \text { list price) }
\end{array}
$$

Salvage value (remaining value) must be known or estimated to determine interest and depreciation. The America Society of Agricultural and Biological Engineers (ASABE) method was used for determination of salvage value (ASABE 2006, D496.31, Section 6.2.2).

\section{Insurance, Housing, and Taxes (IH\&T)}

Insurance, housing (cost of shelter for equipment), and taxes (IH\&T) refer to the fixed costs related to the equipment, and these costs are estimated as percentages of the purchase price (Equation 2). If actual data are not available, the ASABE suggests using the following percentages: taxes $1.00 \%$, housing $0.75 \%$, and insurance $0.25 \%$, for a total of $2.00 \%$.

$$
I H \& T=\frac{\left(I_{\text {Percentage }}+H_{\text {Percentage }}+T_{\text {Percentage }}\right) \times \text { average }(\text { purchase price, salvage })}{\text { Work hours per year } \times \text { effciency factor }}=\frac{\$}{\mathrm{hr}}
$$

Operating cost: Operating cost consists of repair and maintenance (R\&M), as well as fuel and labor cost. Expenditures are necessary to keep a machine operable due to wear, part failure, accidents, and natural deterioration. The costs for repairing a machine are highly variable. Good management may keep costs low. In the present study, the following equation is used for calculating the R\&M costs.

$$
R \& M=\frac{\text { list price } \times \text { repairs and maintenance percentage }}{\text { life time }(\mathrm{hr})}=\frac{\$}{\mathrm{hr}}
$$

Repairs and maintenance percentage is estimated based on ASABE 2006. Fuel consumption cost is calculated based on actual $\mathrm{kW}$ data obtained either from machinery specifications or from actual estimates obtained from laboratory-scale and pilot-scale experimental data. Labor rates were obtained from the Idaho Bureau of Labor Statistics, and labor hours were based on assumed shift schedules. The total working hours include three shifts, 40 hours per week, and 50 weeks per year. The assumed labor rate for horizontal bale grinder, hammer mill, dryer, pallet mill and chemical pretreatment are US\$15.88, US\$19.88, US\$15.51, US\$15.51 and US\$19.88 respectively. Also, we have assumed that one person will be able to manage two machines. 


\section{A-5 Equipment lists}

All calculated depot design cases are set to an hourly capacity of 10 DT. The individual equipment sizes in below tables may show less than 10 DT per hour indicating that several types of the specific machinery were required to reach the 10 DT per hour capacity.

Table A5:1. Grinder.

\begin{tabular}{|c|c|c|c|c|}
\hline \multirow[t]{2}{*}{ Input } & \multicolumn{4}{|c|}{$\begin{array}{c}\text { Depot type depending on preprocessing } \\
\text { operations }\end{array}$} \\
\hline & $\begin{array}{c}\text { CPP } \\
\text { (herb.) }\end{array}$ & HMPP & HMPPFM & AFEX \\
\hline Effective capacity (DT/hour) & 2 & 5 & 8 & 9.2 \\
\hline Fuel type & electrical & electrical & electrical & electrical \\
\hline Fuel use (kWh) & 40 & 40 & 40 & 18 \\
\hline \multicolumn{5}{|l|}{ CAPEX } \\
\hline $\begin{array}{l}\text { Minimum equipment list prices (all } \\
\text { in } 2011 \$ \text { except AFEX. AFEX is in } \\
2013 \$ \text { ) }\end{array}$ & 180,000 & 180,000 & 180,000 & $\$ 174,000$ \\
\hline Useful life (hours) & 15,000 & 15,000 & 15,000 & 15,000 \\
\hline Salvage value (\% of list price) & 30 & 30 & 30 & 10 \\
\hline $\begin{array}{l}\text { Repair and maintenance cost } \\
\text { (measured as \% of list price or any } \\
\text { other unit) }\end{array}$ & 10 & 10 & 10 & 3 \\
\hline \multicolumn{5}{|l|}{ OPEX } \\
\hline $\begin{array}{l}\text { Manpower (number of operators } \\
\text { required) }\end{array}$ & 0.5 & 0.5 & 0.5 & 1 \\
\hline \multicolumn{5}{|l|}{ Feedstock Characteristics } \\
\hline Input feedstock moisture (\%wt) & 30 & 30 & 30 & 15 \\
\hline Output feedstock moisture (\%wt) & 30 & 30 & 30 & 14 \\
\hline Input feedstock density $\left(\mathrm{lb} / \mathrm{ft}^{3}\right)$ & 9 & 9 & 9 & 7.5 \\
\hline Output feedstock density $\left(\mathrm{lb} / \mathrm{ft}^{3}\right)$ & 9 & 9 & 9 & 2.5 \\
\hline
\end{tabular}


Table A5:2. Hammer Mill.

\begin{tabular}{|c|c|c|c|c|c|}
\hline \multirow[b]{2}{*}{ Input } & \multicolumn{5}{|c|}{ Depot type depending on preprocessing operations } \\
\hline & $\begin{array}{c}\text { CPP } \\
\text { (herb.) }\end{array}$ & $\begin{array}{c}\text { CPP } \\
\text { (woody) }\end{array}$ & HMPP & HMPPFM & AFEX \\
\hline Effective capacity (DT/hour) & 2 & 2 & 5 & 5 & 9.2 \\
\hline Fuel type & Electricity & Electricity & Electricity & Electricity & Electricity \\
\hline Fuel use (kWh) & 78 & 43 & 107 & 53.5 & 28.91 \\
\hline \multicolumn{6}{|l|}{ CAPEX } \\
\hline $\begin{array}{l}\text { Minimum equipment list prices } \\
\text { ( } \$ \text { in } 2009 \text {, except AFEX. AFEX } \\
\text { price is in } 2013 \$ \text { ) }\end{array}$ & 104,242 & 104,242 & 104,242 & 104,242 & $\$ 138,400$ \\
\hline Useful life (hours) & 40,000 & 40,000 & 40,000 & 40,000 & 15,000 \\
\hline Salvage value (\% of list price) & 30 & 30 & 30 & 30 & 0 \\
\hline $\begin{array}{l}\text { Repair and maintenance cost } \\
\text { (measured as \% of list price) }\end{array}$ & 10 & 10 & 10 & 10 & 3 \\
\hline \multicolumn{6}{|l|}{ OPEX } \\
\hline $\begin{array}{l}\text { Manpower (number of } \\
\text { operators required) }\end{array}$ & 0.5 & 0.5 & 0.5 & 0.5 & 0.1 \\
\hline \multicolumn{6}{|l|}{ Feedstock Characteristics } \\
\hline Input feedstock moisture (\%wt) & 30 & 30 & 30 & 30 & 12 \\
\hline $\begin{array}{l}\text { Output feedstock moisture } \\
\text { (\%wt) }\end{array}$ & 30 & 30 & 30 & 30 & 12 \\
\hline Input feedstock density $\left(\mathrm{lb} / \mathrm{ft}^{3}\right)$ & 9 & 15 & 9 & 9 & 2.5 \\
\hline Output feedstock density $\left(\mathrm{lb} / \mathrm{ft}^{3}\right)$ & 9 & 15 & 9 & 9 & 4 \\
\hline
\end{tabular}


Table A5:3. Dryer.

\begin{tabular}{|c|c|c|c|c|c|}
\hline \multirow[b]{2}{*}{ Input } & \multicolumn{5}{|c|}{ Depot type depending on preprocessing operations } \\
\hline & $\begin{array}{c}\text { CPP } \\
\text { (herb.) }\end{array}$ & $\begin{array}{c}\text { CPP } \\
\text { (woody) }\end{array}$ & HMPP & HMPPFM & AFEX \\
\hline Capacity (DT/hour) & 2 & 2 & 5 & 5 & 2 \\
\hline Fuel type & Electricity & Electricity & Electricity & Electricity & $\begin{array}{l}\text { Electricity } \\
\text { and natural } \\
\text { gas }\end{array}$ \\
\hline Fuel use (kWh/DT) & 300 & 400 & 50 & 50 & 300 \\
\hline \multicolumn{6}{|l|}{ CAPEX } \\
\hline Minimum equipment list prices & $\begin{array}{c}351,000 \\
(\$ \text { in } 2009)\end{array}$ & $\begin{array}{c}351,000 \\
(\$ \text { in 2009) }\end{array}$ & $\begin{array}{c}35,500 \\
(\$ \text { in } 2014)\end{array}$ & $\begin{array}{c}35,500 \\
(\$ \text { in } 2014)\end{array}$ & $\begin{array}{c}\$ 530,000 \\
(\$ \text { in } 2013)\end{array}$ \\
\hline Useful life (hours) & 168,000 & 168,000 & 168,000 & 168,000 & 168,000 \\
\hline Salvage value (\% of list price) & 30 & 30 & 30 & 30 & 10 \\
\hline $\begin{array}{l}\text { Repair and maintenance cost } \\
\text { (measured as \% of list price or any } \\
\text { other unit) }\end{array}$ & 10 & 10 & 10 & 10 & 20 \\
\hline \multicolumn{6}{|l|}{ OPEX } \\
\hline $\begin{array}{l}\text { Manpower } \\
\text { (number of operators required) }\end{array}$ & 0.5 & 0.5 & 0.5 & 0.5 & 0.5 \\
\hline \multicolumn{6}{|l|}{ Feedstock Characteristics } \\
\hline Input feedstock moisture (\%wt) & 30 & 30 & 30 & 30 & 45 \\
\hline Output feedstock moisture (\%wt) & 9 & 10 & 19 & 19 & 12 \\
\hline Input feedstock density $\left(\mathrm{lb} / \mathrm{ft}^{3}\right)$ & 9 & 15 & 9 & 9 & 2.5 \\
\hline Output feedstock density $\left(\mathrm{lb} / \mathrm{ft}^{3}\right)$ & 9 & 15 & 9 & 9 & 2.5 \\
\hline
\end{tabular}


Table A5:4. Densifier.

\begin{tabular}{|c|c|c|c|c|c|}
\hline \multirow[b]{2}{*}{ Input } & \multicolumn{5}{|c|}{ Depot type depending on preprocessing operations } \\
\hline & $\begin{array}{c}\text { CPP } \\
\text { (herb.) }\end{array}$ & $\begin{array}{c}\text { CPP } \\
\text { (woody) }\end{array}$ & HMPP & HMPPFM & AFEX \\
\hline Effective Capacity (DT/hour) & 5 & 5 & 5 & 5 & 9.2 \\
\hline Fuel type & Electricity & Electricity & Electricity & Electricity & Electricity \\
\hline Fuel use (kWh) & 75 & 49 & 50 & 50 & 60 \\
\hline \multicolumn{6}{|l|}{ CAPEX } \\
\hline $\begin{array}{l}\text { Minimum equipment list } \\
\text { prices ( } \$ \text { in } 2008 \text {, except AFEX. } \\
\text { AFEX price is in } 2013 \$ \text { ) }\end{array}$ & 300,000 & 300,000 & 300,000 & 300,000 & 640,000 \\
\hline Useful life (hours) & 100,000 & 100,000 & 100,000 & 100,000 & 100,000 \\
\hline Salvage value (\% of list price) & 30 & 30 & 30 & 30 & 10 \\
\hline $\begin{array}{l}\text { Repair and maintenance cost } \\
\text { (measured as \% of list price or } \\
\text { any other unit) }\end{array}$ & 10 & 10 & 10 & 10 & 10 \\
\hline \multicolumn{6}{|l|}{ OPEX } \\
\hline $\begin{array}{l}\text { Manpower (number of } \\
\text { operators required) }\end{array}$ & 0.5 & 0.5 & 0.5 & 0.5 & 0.5 \\
\hline \multicolumn{6}{|l|}{ Feedstock Characteristics } \\
\hline $\begin{array}{l}\text { Input feedstock moisture } \\
\text { (\%wt) }\end{array}$ & 9 & 10 & 19 & 19 & 12 \\
\hline $\begin{array}{l}\text { Output feedstock moisture } \\
\text { (\%wt) }\end{array}$ & 9 & 10 & 9 & 9 & 10 \\
\hline Input feedstock density (lb/ft $\left.{ }^{3}\right)$ & 9 & 15 & 9 & 9 & 2.5 \\
\hline $\begin{array}{l}\text { Output feedstock density } \\
\left(\mathrm{lb} / \mathrm{ft}^{3}\right)\end{array}$ & 32 & 40 & 32 & 32 & 36 \\
\hline
\end{tabular}


Table A5:5. AFEX: Chemical Pretreatment.

\begin{tabular}{|c|c|}
\hline Specification & Data \\
\hline Capacity (DT/hour) & 9.2 \\
\hline Horse power & 600 \\
\hline Fuel type & Electricity and natural gas \\
\hline Fuel use & $300 \mathrm{kWh}$ and $11 \mathrm{MMBTU} / \mathrm{hour}$ \\
\hline Dry matter loss (\%) & 0 \\
\hline \multicolumn{2}{|l|}{ CAPEX } \\
\hline $\begin{array}{l}\text { Minimum equipment list prices } \\
(\$ \text { in } 2013)\end{array}$ & $\$ 3,130,000$ \\
\hline Useful life (hours) & 262,800 \\
\hline Salvage value (\% of list price) & 15 \\
\hline $\begin{array}{l}\text { Repair and maintenance cost } \\
\text { (measured as \% of list price or any other unit) }\end{array}$ & 5 \\
\hline \multicolumn{2}{|l|}{ OPEX } \\
\hline Manpower (number of operators required) & 1 \\
\hline Ammonia consumption (kg/DT) & 20 \\
\hline \multicolumn{2}{|l|}{$\begin{array}{l}\text { Feedstock Characteristics } \\
\end{array}$} \\
\hline Input feedstock moisture (\%wt) & 20 \\
\hline Output feedstock moisture (\%wt) & 42 \\
\hline Input feedstock density $\left(\mathrm{lb} / \mathrm{ft}^{3}\right)$ & 6.24 \\
\hline Output feedstock density $\left(\mathrm{lb} / \mathrm{ft}^{3}\right)$ & 6.24 \\
\hline
\end{tabular}

